\title{
DIE GASTEROPODEN
}

\author{
DER \\ IIEERES-ABLAGERUNGEN \\ $\mathrm{DER}$ \\ ERSTEN UND ZWEITEN MIOCÄNEN MEDITERRAN-STUFE
}

IN DER OSTERREICHISCH-UNGARISCHEN NONARCHIE

R. HOERNES

5. Lienteruna

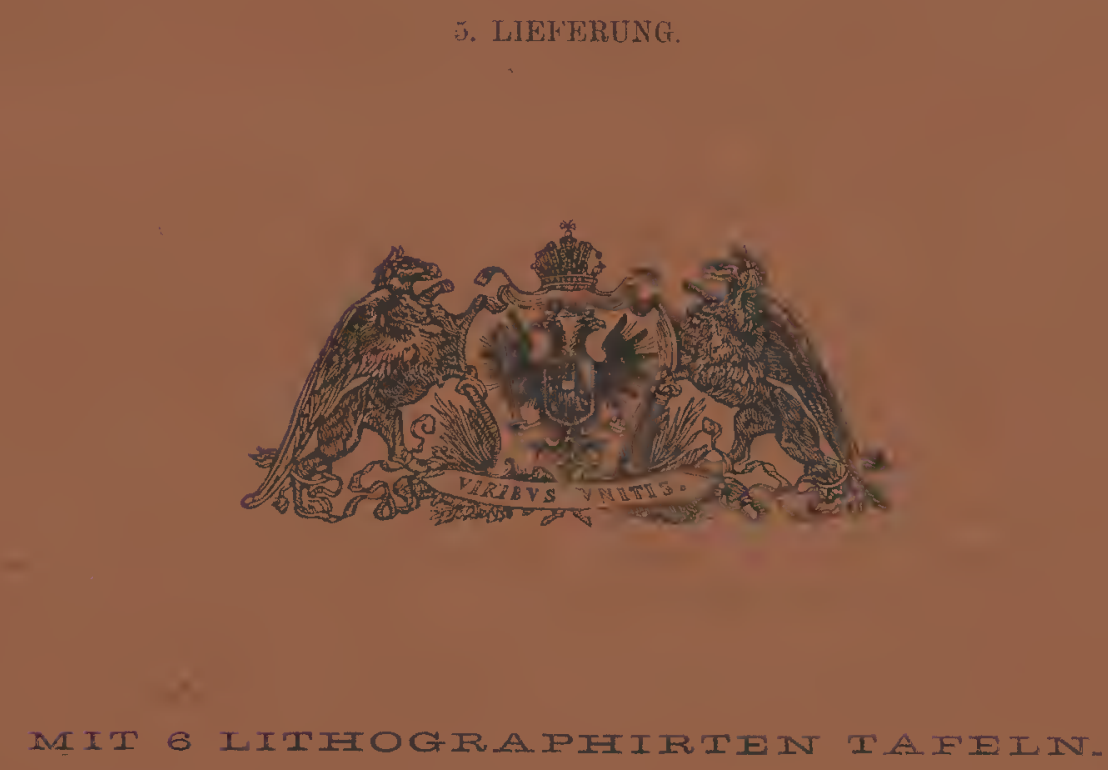

$=$

MUNGER.

WIEN, 1885.

ALFRED HÖLDER

K K. HOF-UND UNIVERSITÄTS-BUCHḦ̈DLER

ROTHEN'THURMSTRASSE 1 ij. 
Zur: gefälligen Beachlung für die Besitzer und Abonnenten

der

\section{„ABHANDLUNGEN DER K. K. GEOLOGISCHEN REICHSANSTATT \\ in Wien.}

Im unterzeichneten Verlage ist friiher erschienen und durch alle Buchhandlungen zu beziehen:

\section{DIE GASTEROPODEN}

der

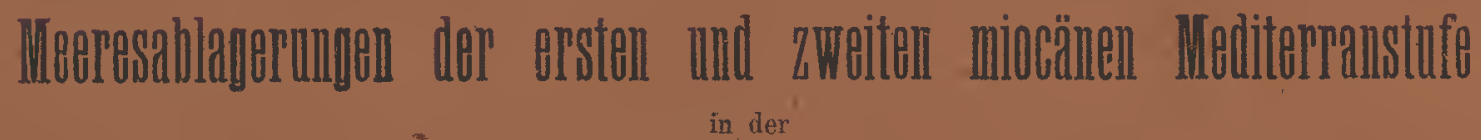

österreichisch-ungarisehen Monarchie

ron

R. HOERNES und M. AUINGER.

IV. Lieferung. Mit ${ }^{6}$ Jithographirten Tafeln. - Preis $8 \mathrm{fl} \div 16 \mathrm{M}$.

Die Fortsetzung dieses bedentenden paläontologischen Werkes, dessen erste drei Lieferungen im XII. Bande der "Abhandlungen der k. k. geologischen Reichsanstalt" in Wien veröffentlicht wurden, wird in Folge Uebereinkommens mit letzterer Anstalt von obiger Lieferung angefangen nicht mehr in deren „Abhandlungen“, sondern in meinem Verlage als selbstiondige Publication erscheinen.

Nachdem nun obige 3 Lieferungen aus dem XII. Bande der "Abhandlungen" ausgeschieden wurden, wird dieser" Band nochmals neu zur Ansgabe gelangen und an Stelle der "Gasteropoden“ andere in Vorbereitung befindliche Arbeiten enthalten.

Tch erlaube mir insbesondere alle jene Aliademien, wissenschaftichen Tnstitute, Gesellschaften und Bibliotheken auf diese Verändermgen aufmerksam zu machen. welche die ersten drei Lieferungen im Dedications- oder Tanschwege direct von der k. k. geologischen Reichsanstalt empfingen und dieses wichtige, jedlem Paläontologen unentbehrliche Werl: vollständig zu besitzen wuinschen.

W i e n, März 1885.

Die Verlagshandlung

\section{Alfred Hölder}

k. k. Hof- und Universitäts-Buchliändler I., Rothenthurmstrasse 15. 
von Murex. Wir werden demgemäss die von Bellardi vorgenommene Einreihung von Trophon als Subgenus der Gattung Murex in Anwendung bringen und haben ausserdem wohl noch ein anderes Subgenus zu acceptiren: Vitularia Swains., welches in den österreichisch-ungarischen Miocänbildungen ebenso wie in den französischen durch eine ausgezeichnete Form: Murex lingua-bovis Bast. vertreten ist. - Ausser Murex und seinen Untergattungen, sowie Typhis wollen wir in unmittelbarem Anschlusse an diese, den Muricinac zuzurechnenden Formen auch jene im österreichisch-ungarischen Miocän auftretenden Conchylien besprechen, welche den Gattungen Jania Bellardi und Pollia Gray angehören, und zwar aus dem Grunde, weil diese Formen früher ganz allgemein zu Murex gestellt wurden und auch von M. Hoe rnes zum grössten Theile bei dieser Gattung angeführt worden sind. Es würde den Gebrauch des vorliegenden Werkes bei der Nothwendigkeit des stetigen Vergleiches mit den "Fossilen Mollusken des Tertiärbeckens von Wien" wesentlich erschweren, wollten wir die alten Gruppen: Murex, Pyrula, Fusus in die zahlreichen Gattungen und Untergattungen der neueren Systematik auflösen und der Reihe nach besprechen. Wir verweisen behufs Anwendung der letzteren (abgesehen von den bei der Discussion jeder Gruppe oder Gattung im alten Sinne gegebenen Erörterung) auf die am Schlusse dieses Werkes zu gebenden Verzeichnisse, welche einen Ueberblick der geschilderten Formen, sowohl vom alten als vom neuen Standpunkt, ermöglichen werden.

Wir wenden uns nun zur kritischen Uebersicht der von M. Hoernes aus dem Wiener Becken angeführten 47 Murex-Arten. Es sind dies:

\begin{tabular}{|c|c|c|}
\hline 1. & & trunculus Linné, \\
\hline 2. & $n$ & Aquitanicus Grat., \\
\hline 3. & $\pi$ & Sedgwicki Michti., \\
\hline 4. & , & rudis Bors., \\
\hline อ. & & absonus Jan., \\
\hline 6. & & incisus Brod., \\
\hline 7. & n & porulosus Michti., \\
\hline 8. & $"$ & varicosissimus Bon., \\
\hline 9. & $n$ & capito Phil., \\
\hline 10. & & goniostomus Partsch, \\
\hline 11. & $n$ & Haidingeri M. Hoern., \\
\hline 12. & & vaginatus Jan., \\
\hline 13. & $"$ & lingua-bovis Bast., \\
\hline 14. & $\pi$ & ventricosus $M$. Hoern., \\
\hline 15. & & Genei Bell. et Michti., \\
\hline 16, & & Lassaignei Bast., \\
\hline 17. & " & Sandbergeri M. Hoern., \\
\hline 18. & & craticulatus Broce., \\
\hline 19. & $n$ & Schönni M. Hoern., \\
\hline 20. & " & striaeformis Michti., \\
\hline 21. & $n$ & sublavatus Bast., \\
\hline 22. & $n$ & angulosus Brocc., \\
\hline 23. & r & imbricatus Broce. var., \\
\hline 24. & " & scalaris Brocc., \\
\hline
\end{tabular}

\begin{tabular}{|c|c|c|}
\hline & & intercisus Michti., \\
\hline 26. & 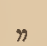 & flexicauda Bronn., \\
\hline 27. & $n$ & labrosus Michti., \\
\hline 8. & $"$ & cristatus Broce., \\
\hline & $"$ & plicatus Brocc., \\
\hline & $n$ & distinctus Jan., \\
\hline & $n$ & latilabris Bell. et Michti., \\
\hline & $"$ & Swainsoni Michti., \\
\hline & " & tortuosus Sow., \\
\hline & " & erinaceus Linnć, \\
\hline & $"$ & Vindobonensis M. Hoern., \\
\hline & $n$ & Borni M. Hoern., \\
\hline & $"$ & granuliferus Michti., \\
\hline & $"$ & graniferus Michti., \\
\hline & $n$ & heptagonatus Bronn., \\
\hline & $n$ & brandaris Linné var., \\
\hline & m & Partschi M. Hoern., \\
\hline & $n$ & spinicosta Bronn., \\
\hline & n & Delbosianus Grat., \\
\hline & $"$ & (Typhis) horridus Brocc., \\
\hline & " & " fistulosus Bronn., \\
\hline & 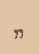 & tetrapterus Bronn., \\
\hline & $n$ & "Wenzelidesi Hoern. \\
\hline
\end{tabular}

Wir haben zu diesen Arten folgende Bemerkungen zu machen:

1. Murex trunculus. Die unter diesem Namen aus dem Wiener Becken geschilderten Gehäuse stimmen nicht überein mit der Linnéschen Art, welche heute im Mittelmeer lebt, sie müssen vielmehr, wie die italienischen Paläontologen gezeigt haben, zu Murex (Phyllonotus) subasperrimus d'Orb. gestellt werden.

2. Murex Aquitanicus Grat. Von dieser Form, welche der Untergattung Chicoreus zuzurechnen ist, liegen uns dermalen noch schlankere Gehäuse vor, als M. H o er n es (Foss. Moll. d. Tert.-Beck. v. Wien, Taf. XXII. Fig. 2) zur Darstellung brachte.

3. Murex Sedgwicki. Die unter diesem Namen von M. Ho ernes geschilderten Gehäuse sind gänzlich verschieden von den italienischen Formen, für welche Michelotti den Namen creirte, und müssen zu jener Art gerechnet werden, welche d'A ncona Murex Hoernesi genannt hat, und welche ihre. Stellung neben Murex subasperrimus im Subgenus Phyllonotus findet. 
4. Murex rudis Bors. Der Schilderung dieser durch M. Ho ernes richtig erkannten, dem Subgenus Phyllonotus angehörigen Form haben wir nichts beizufügen und müssen. uns auf die Anführung einiger neuer Fundorte beschränken.

5. Murex absomus Jan. Diese Form, welche dem Subgenus Muricidea angchört, liegt uns heute in mehreren Exemplaren vor, welche eine ziemliche Variabilität wahrnehmen lassen.

6. Murex incisus Brod. wurde von M. Hoernes richtig mit der im atlantischen Ocean lebenden Form identificirt. Die fossilen Vorkommnisse gehörcn im österreichisch-ungarischen wie im italienischen Tertiär zu den seltenen Funden.

7. Murex porulosus. Die unter diesem Namen von M. Hoernes angeführte Form stimmt, wie Bellardi mit Recht hervorhebt, nicht mit der als Murex porulosus von Michelotti beschriebenen Form. Sie muss daher den ursprünglich ihr von M. Hoernes zugedachten Namen Murex Cžjželí erhalten; - gleich den nahe verwandten Murex absonus und Murex incisus gehört sie dem Subgenus Muricidea an.

8. Murex varicosissimus Bon. Der Schilderung dieser Form, welche der Untergattung Trophon angehört, haben wir nichts Wcsentliches beizufügen.

9. Murex capito Phil. Von dieser interessanten, dem Subgenus Trophon angehörigen Form liegen uns leider auch heute nur die beiden durch M. Hoernes besprochenen, fragmentären Gehäuse vor, so dass wir auf eine weitere Discussion der Frage, ob sie wirklich dem Mrurex capito Phil. zuzurechnen seien, verzichten müssen.

10. Murex goniostomus Partsch. Diese Form, welche der Untergattung Trophon angehört, ist zwar nahe verwandt mit derjenigen, welche Bellardi als Murex citimus beschrieben hat, jedoch hinlänglich von demselben verschieden, um die Aufstellung der Bellardi'schen Art zu rechtfertigen.

11. Murex Haidingeri M. Hocrn. Diese Form wurde auf ein einziges Gehäuse gegründet, welches aus den Sandablagerungen von Grund stammt. Uns liegt ein zweites Exemplar aus denselben Schichten vor, welches zu constatiren gestattet, dass dieser interessante Trophon einen geschlossenen Canal besass.

12. Murex vaginatus Jan. Dieser zierliche, im Badener Tegel ziemlich häufige Trophon besitzt, zumal in der Entwicklung der Varices, ziemlich bedeutende Variabilität.

13. Murex lingua-bovis Bast. Diese ausgezeichnete, der Untergattung Vitularia angehörige Form ist bedeutenden Variationen hinsichtlich der Gesamnitgestalt und der Varices unterworfen, wie bereits M. Ho ernes hervorgehoben hat, und wie wir durch Abbildung mehrerer Gehäuse zur Anschauung bringen werden.

14. Murex ventricosus $M$. Hoern. ist eine höchst eigenthümliche Form, welche unter allen recenten und fossilen Vertretern der Gattung Murex keinen näheren Verwandten besitzt und nur unter Vorbehalt in die Untergattung Occenebra eingereiht werden darf, in welcher Murex bicaudatus Bors. und Murex patulus Bell. noch am meisten (wenn auch sehr geringe) Aehnlichkeit besitzen.

15. Murex Genei. Die unter diesem Namen von M. Hoernes geschilderten (der Untergattung Phyllonotus angehörigen) Gehäuse stimmen, wie Bellardi gezeigt hat, nicht ganz mit der italienischen Type überein. Wir halten die Unterschiede für genügend, um die Aufstellung einer eigenen Form für die österreichischen Vorkommnisse zu rechtfertigen, welche wir nunmehr unter dem Namen Murex austriacus anführen wollen.

16. Murex Lassaignei Bast. Diese, dem Subgenus Phyllonotus angehörige Form, welche im Wiener Becken zu den grössten Seltenheiten gehört, kommt zu Lapugy ziemlich häufig vor.

17. Murex Sandbergeri M. Hoern. ist eine eigenthümliche, seltene, dem Formenkreis des Murex (Occenebra) craticulatus Linn. angehörige Form.

18. Murex craticulatus. Unter diesem Namen hat M. H oernes zwei durch Uebergänge vollständig verbundene Formen zusammengefasst, von welchen eine dem echten Murex craticulatus entspricht, während die andere so weit von demselben abweicht, dass wir die Creirung einer eigenen Form (Murex Boeckhi) für räthlich hielten.

19. Murex Schönni M. Hoern. Diese, bisher nur an einem einzigen Fundort (Molt) bekannte, der Untergattung Occenebra angehörige Form ist zwar mit Murex crassilabiatus Hilb. und Murex nodosus Bell. nahe verwandt, von beiden jedoch durch mehrere Merkmale hinreichend verschieden.

20. Murex striaeformis Michti. Hinsichtlich dieser, dem Subgenus Phyllonotus angehörigen Form haben wir der Schilderung durch M. Hoernes nichts Wesentliches beizufügen. 
21. Nurex sublavatus Bast. Unter diesem Namen hat M. Hoernes mehrere nahe verwandte Formen begriffen, welche, obwohl sie durch Uebergänge verbunden sind, unterschieden werden dürfen, da die extrem entwickelten Gehäuse nur schwer unter einer Diagnose zusammengeworfen werden könnten. Wir glauben ausser dem typischen Murex sublavatus in diesem Formenkreise noch Murex caelatus Grat., sowie Murex Dertonensis May. und endlich eine neue, durch ungewöhnlich starke Sculptur ausgezeichnete Form, die wir als Murex Credneri schildern werden, unterscheiden zu sollen.

22. Murex angulosus. Die unter diesem Namen von M. Hoernes angeführte Form, welche dem von Bellardi errichteten Genus Jania angehört, stimmt, wie Bellardi gezeigt hat, nicht mit Jania (Murex) angulosa Brocc., sondern mit Jania maxillosa Bon. überein. Uebrigens kommt, wie wir bei Besprechung des Genus Jania zu zeigen haben werden, auch die echte Jania angulosa im österreichischen Miocän vor.

23. Murex imbricatus. M. Hoernes hat unter diesem Namen eine Occenebra beschrieben, welche von Murex (Occenebra) imbricatus Brocc. verschieden ist, wie Bellardi mit Recht hervorgehoben hat. Wir werden sie nunmehr als Murex imbricatoides bezeichnen; - es kommt übrigens auch dor echte Murex imbricatus im österreichisch-ungarischen Miocän vor.

24. Murex scalaris Brocc. Diese Form, bezüglich welcher wir der Schilderung durch M. Hoernes nichts beizufügen haben, gehört zu den seltenen Conchylien des österreichischen Miocäns; sie ist bis nun nur von drei Fundorten bekannt geworden und kommt an einem einzigen (Steinabrunn) etwas häufiger vor.

25. Murex intercisus Michti. Dies ist eine Pollia, welche übrigens nicht vollständig mit Pollia intercisa Michti. der italienischen Tertiärablagerungen übereinstimmt.

26. Murex flexicauda. Die unter diesem Namen von M. Hoernes beschriebene Form des Wiener Beckens ist eine Pollia, welche von Pollia turrita oder flexicauda verschieden ist, und daher, wie später bei Besprechung derjenigen Formen, welche der Gattung Pollia angehören, erörtert werden soll, einen neuen Namen erhalten muss.

27. Murex labrosus. M. Ho ernes machte bereits bei Schilderung der unter diesem Namen von ihn angeführten Form des Wiener Beckens auf die Unterschiede aufmerksam, welche sie von der italienischen Type Mich elot ti's trennen. Bellardi hat neuerdings mit Recht die Unmöglichkeit betont, die von M. Hoernes als Murex labrosus angeführte Form mit dem echten Murex labrosus Michti. zu identificiren - es muss daher für die Form des Wiener Beckens zu jenem Namen zurückgegriffen werden, welchel M. Hoernes 1848 in dem Verzeichniss der Fossilreste in $\mathrm{C} \check{z} \mathrm{j} \check{z} \theta \mathrm{k}$ 's Erläuterungen zur geognostischen Karte von Wien gegeben hat: Murex Reussi. Es ist dies jedoch kein Murex im eigentlichen, engeren Sinne, er muss vielmehr der Gattung Jania Bellardi zugewiesen werden.

28. Murex cristatus Brocc. Fast alle Gehäuse aus dem Wiener Becken gehören der Varietät mit wenig entwickelten und stumpfen Knoten an; - in Lapugy hingegen, wo Murex cristatus ziemlich häufig vorkommt, sind die Gehäuse nicht blos viel grösser und kräftiger, sondern auch durch stark entwickelte Dornen ausgezeichnet. Wir folgen Bellardi, indem wir Murex cristatus beim Subgenus Phyllonotus einreihen, obwohl diese Form ebensogut zu Muricidea gestellt werden könnte.

29. Murex plicatus. Die unter diesem Namen von M. Hoernes angeführte Form des Wiener Beckens werden wir als Pollia exsculpta Duj. zu besprechen haben.

30. Murex distinctus Jan. Dem Vorgange Bellardi's folgend, wenden wir für diese, der Untergattung Muricidea angehörige Form den von Blainville zuerst gegebenen Namen: Murex scalarioides an.

31. Murex latilabris Bell. et Michti. Der Schilderung, welche diese im österreichisch-ungarischen Tertiär überaus seltene, der Untergattung Pteronotus angehörige Form durch M. Hoernes gefunden hat, haben wir nichts Wesentliches beizufügen, übrigens hindert uns nur das spärliche Material, diese Form, welche von der italienischen Type wesentlich abweicht, von derselben zu trennen.

32. Murex Swainsoni Michti. Die Erörterung dieser Form durch M. Hoernes haben wir durch Anführung und Illustrirung der grossen Variabilität, welcher dieser Pteronotus unterliegt, zu ergänzen.

33. Murex tortuosus Sow. Der Discussion, welche diese, dem Subgenus Pteronotus angehörige Form durch M. Hoernes erfahren hat, haben wir nichts Wesentliches beizufügen.

34. Murcx erinaceus $L$. Unter dieser Bezeichnung hat M. Hoernes auch jene Formen begriffen, welche wir, dem Vorgange Bellardi's folgend, dem Murex (Pteronotus) Sowerbyi Michti. zurechnen. Aber auch die von zwei verschiedenen Fundorten (Enzesfeld und Molt) des Wiener Beckens stammenden Grehäuse, welche wir provisorisch noch dem Murex erinaceus anreihen, differiren unter sich sowie vom recenten Murex erinaceus ganz wesentlich, und nur das beschränkte Material, über welches wir verfügen, hindert uns, wenigstens die Molter Gehäuse als selbstständige Form abzutrennen. 
35. Murex Vindobonensis M. Hoern. Der Beschreibung, welche diese zum Subgenus Phyllonotus gehörige Form durch M. Hoernes gefunden hat, haben wir wenig beizufügen, es erübrigt uns nur, weitere Belege für die grosse Variabilität dieser Form anzuführen.

36. Murex Borni M. Hoern. Die Selbstständigkeit dieser, zu Chicoreus gehörigen Form ist eine geringe - man könnte sie füglich als blosse Varietät des Murex (Chicoreus) granuliferus Grat. betrachten. Die von M. Hoernes angeführten trennenden Unterschiede sind nur zum Theil stichhältig.

37. Murex granuliferus Grat. Die Schilderung dieser Form durch M. Hoernes ist im Grossen und Ganzen richtig, doch müssen wir ein als constant angeführtes und Murex granuliferus von Murex Borni unterscheiden sollendes Merkmal (die Ausdehnung des oberen Theiles des linken Mundrandes) als nicht durchgreifend, sondern im Gegentheil nur bei einigen Gehäusen zu beobachtend bezeichnen. M. Hoe rnes verfügte bei Aufstellung seiner Murex Borni nur über wenige Exemplare des Murex granuliferus. Wären ihm die heute in der Sammlung des Hof-Mineralien-Cabinetes befindlichen neunzehn Gehäuse des Murex granuliferus vom Fundorte Lapugy vorgelegen, so würde er die Mündungscharaktere nicht zur Abtrennung des Murex Borni benützt - oder (was uns noch wahrscheinlicher dünkt) die letztgenannte Form überhaupt nicht als selbstständig aufgestellt haben. Als trennendes Merkmal lässt sich nur die abgerundete Gestalt der Varices bei Murcx Borni anführen, doch sind auch in dieser Richtung Uebergänge angedeutet, die Trennung der beiden in Rede stehenden Formen daher willkürlich.

38. Murex graniferus Michti. In Betreff dieser, der Untergattung Pteronotus angehörigen, im österreichisch-ungarischen Miocän ebenso wie im italienischen Tertiär überaus seltenen Form haben wir der durch M. Hoernes gegebenen Schilderung nur wenig beizufügen.

39. Murex heptagonatus Bronn. Wir ergänzen die Schilderung dieser, der Untergattung Muricidea angehörigen Form durch Discussion des ziemlich reichen, in der Sammlung des Hof-Mineralien-Cabinetes aufbewahrten Materiales, unter welchem insbesondere zahlreiche und wohlerhaltene Exemplare vom Fundorte Lapugy bemerkenswerth sind. Dieses Material, von welchem wir einige charakteristische Formen zur Abbildung bringen, gestattete uns, die grosse Variabilität des Murex heptagonatus eingehend zu studiren.

40. Murex brandaris. Die unter diesem Namen von M. Hoernes geschilderte Form des Wiener Beckens entspricht weder dem recenten Murex brandaris L. noch auch dem Murex torularius Lamk, welchem die meisten tertiären Gehäuse zugerechnet werden müssen, welche in der Literatur als Murex brandaris angeführt werden. Wir sehen uns daher veranlasst, die in Rede stehende Form des österreichisch-ungarischen Tertiär als Murex (Rhynocantha) subtorularius nov. form. zu bezeichnen.

41. Murex Partschi M. Hoern. Der durch M. Hoernes gelieferten Beschreibung dieser interessanten Form haben wir nichts Wesentliches beizufügen. Wir rechnen sie zum Subgenus Haustellum, während Bellardi sie zu Murcx im engsten Sinne stellt.

42. Murex spinicosta Bronn. Der Schilderung, welche diese, der Gattung Murex im engsten Sinne angehörige Form durch M. Hoernes gefunden hat, haben wir nichts beizufügen.

43. Murex Delbosianus Grat. An dem durch M. Hoernes zur Abbildung gebrachten Gehäuse von Grund ist die Entwicklung der Stachel sehr zurückgeblieben, wir bringen daher mehrere Exemplare (von Korytnice in Russisch-Polen und von Kostej) zur Abbildung, um die typische Gestaltung dieser, der Gattung Murex im engsten Sinne angehörigen Form zu zeigen.

44. Murex (Typhis) horridus Brocc. Wie wir später, bei Discussion der Formen, welche der Gattung Typhis Montf. angehören, zu zeigen haben werden, ist die Beschreibung, welche diese Form hinsichtlich des Vorkommens in österreichisch-ungarischen Tertiärablagerungen durch M. Hoernes gefunden hat, lediglich durch Anführung neuer Fundorte zu ergänzen.

45. Murex (Typhis) fistulosus Bronn. Der Beschreibung dieser Form haben wir ebenfalls nur die Aufzählung einiger neuer Fundorte beizufügen.

46. Murex (Typhis) tetrapterus Bronn. M. Hoernes hat unter diesem Namen ein Gehäuse zur Abbildung gebracht, welches ziemlich verschieden ist von der italienischen Type. Es gehört dasselbe einer Varietät an, welche einen Uebergang zu Murex (Typhis) fistulosus darstellt. Neben derselben kommt jedoch im österreichisch-ungarischen Miocän auch der echte Murex tetrapterus vor.

47. Murex (Typhis) Wcnzelidesi M. Hoern. Von dieser überaus seltenen Form kannte M. Ho ernes bei ihrer Aufstellung nur ein einziges Gehäuse von Steinabrunn; - seither haben sich noch einige von demselben Fundorte, sowie eines von Forchtenau gefunden. 
Ueberblieken wir das Resultat unserer Betrachtungen, so bleiben von den angeführten 47 Formen nur 37 übrig, welche ihren Namen olne Veränderung behalten können, nämlich:
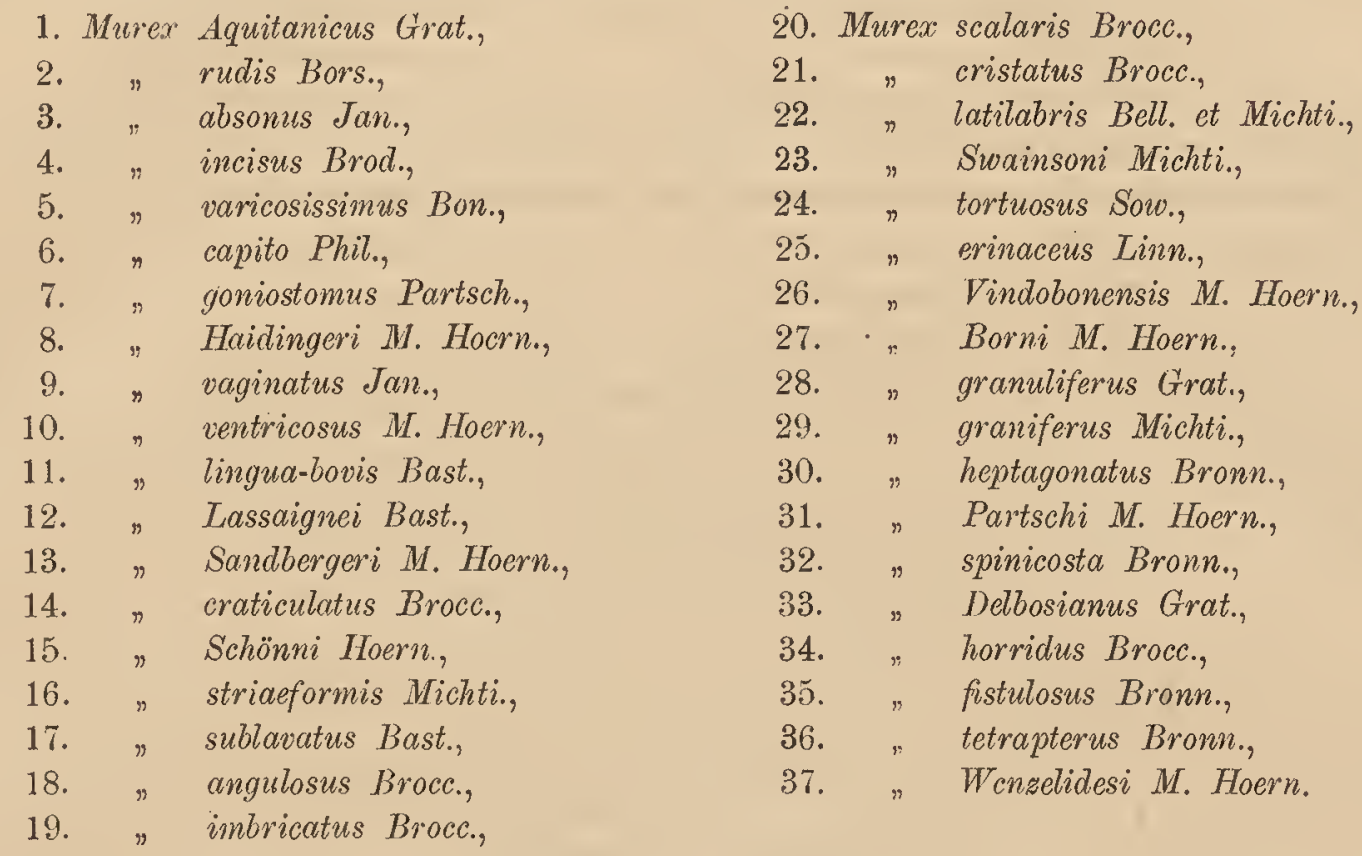

Naehdem die vier letztgenannten Formen der Gattung Typhis Montf., die sub 18 angeführte (Murex angulosus) aber der Gattung Jania Bell. angehört, erübrigen uns nur 34 der. Gattung Murex und ihren Untergattungen angehörige, bereits dureh $\mathrm{M}$. Hoernes angeführte Formen. Wir müssen jedoeh bemerken, dass auch unter diesen noch einige zweifelhafte sich befinden (Murex capito Phil., Murex latilabris Bell. et Michti, Murex Borni M. Hoern.) - dass wir mehrere Formen als unrichtig umgrenzt und mit nahe verwandten verweehselt oder zusammengezogen fanden (so Murex evinaceus L., Murex craticulatus Brocc., Murex sublavatus Bast., Murex imbricatus Brocc.) - von welchen sämmtlich wir Formen abtrennen mussten, welche theils von anderen Autoren bereits besehrieben waren, theils als neue Formen gesehildert werden müssen.

Die oben namhaft gemachten, durch M. Hoernes riehtig angeführten 34 Murices werden zunäehst vermehrt dureh eilf Formen, welehe früher unter unriehtigen Namen angeführt oder mit anderen Formen zusammengezogen waren. Es sind dies:

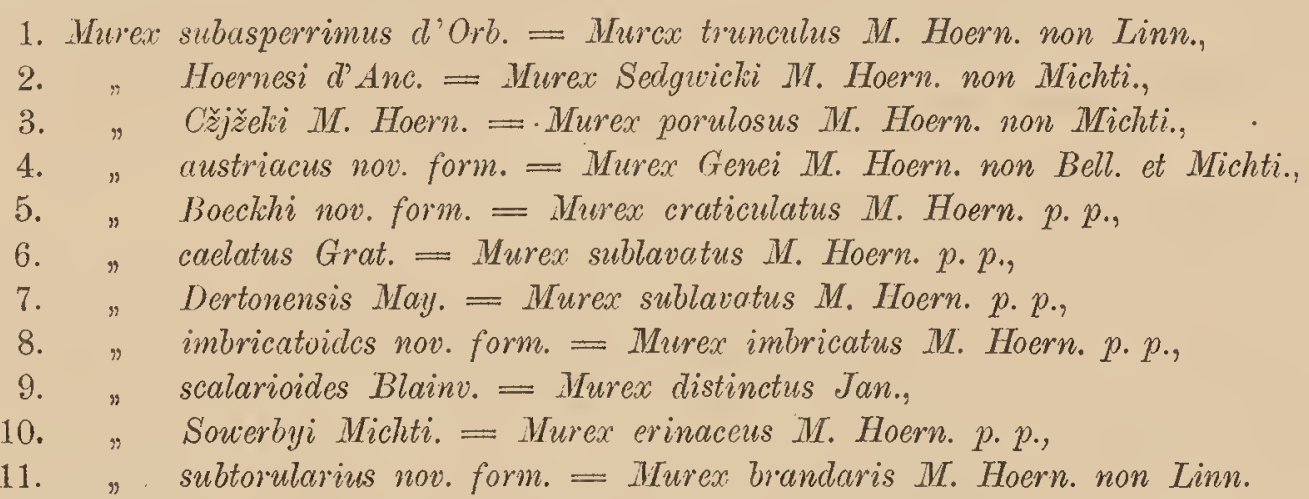

Hiezu kommen ferner zwei Formen, welche Dr. V. Hilber aus österreichischen Tertiärbildungen beschrieben hat, nämlieh: Murex crassilabiatus (V. Hilber: Neue Conchylien aus den mittelsteirischen Mediterranschichten, 79. Bd. d. Sitzbr. d. k. Akad. d. Wiss., I. Abth., 1879, pag. 17, Taf. III, Fig. 1, 2), eine Form, welche M. Hoernes dem Murex sublavatus Bast. zureehnete, die uns jedoeh mehr Verwandtschaft mit Murex Schönni M. Hoern. zu besitzen seheint; - ferner Murex Galicianus Hilb. (vgl. Hilber: Neue und wenig bekannte Conchylien aus dem ostgalizisehen Mioeän. Abhandl. d. geolog. Reichsanst., Bd. VII., Heft VI, pag. 5, Taf. I, Fig. 7, 8), eine Form, welche sich innig an Murex Borni M. Hoern. anzuschliessen scheint. Die dritte von Hilber beschriebene Murex-Art (Murcx Pauli - Neue und wenig kekannte Conchyl. etc., pag. 5, Taf. I, Fig. 6) ist eine Pollia, welehe der Pollia pusilla Bcll. sehr gleicht, aber doch von derselben verschieden ist, also hier nicht in Betracht kommt. 
Wir konnten ferner das Vorkommen vier italienischer, von Bellardi und von Michelotti bereits beschriebener Formen in den österreichisch-ungarischen Tertiärablagerungen constatiren; es sind dies:

$$
\begin{gathered}
\text { Murex (Pteronotus) trinodosus Bell. } \quad \text { Murex (Occenebra) alternatus Bell., } \\
" \quad \text { (Chicoreus) perlongus Bcll., }
\end{gathered}
$$

letztere Form allerdings in einer von der italienischen Type abweichenden Varietät.

Endlich haben wir fünf neue Formen zu schildern, welche bis nun weder aus österreichisch-ungarischen, noch aus fremdländischen Tertiärablagerungen bekannt geworden sind. Es sind dies:

$$
\begin{aligned}
& \begin{array}{cr}
\text { Murex (Muricidea) moravicus, } \\
\text { transsylvanicus, }
\end{array} \\
& \text { transsylvanicus, } \\
& \text { Murex (Occenebra) Hochstcttcri. }
\end{aligned}
$$

Wir erhalten so im Ganzen 54 Formen der Gattung Murex und ihrer Untergattungen. Wenden wir die neun von Bellardi acceptirten Sectionen oder Untergattungen an, und fügen wir, veranlasst durch das Auftreten des Murex lingua-bovis noch die zehnte: Vitularia hinzu, so vertheilen sich diese 54 MurexFormen des österreichisch-ungarischen Tertiärs auf dieselben in folgender Weise:

\section{Section: Murex sens. strict.}
1. Murcx (a) spinicosta Bronn.,
2. Murex (b) Delbosianus Grat.

\section{Section: Haustellum.}

3. Murex (Haustellum) Partschi M. Hoern.

\section{Section: Rhynocantha.}

4. Murex (Rhyrocantha) subtorularius nov. form.

\section{Section: Pteronotus.}

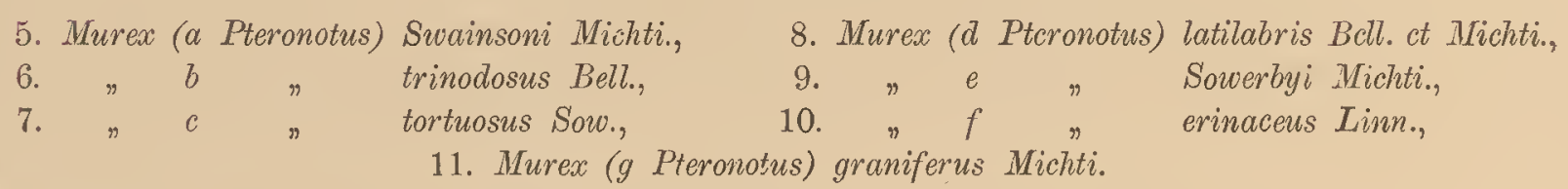

\section{Section: Muricidea,}

12. Murex (a Muricidea) heptagonatus Bronn., 13. " $b$ " absonus Jan., 14. " $"$ " CŽjžeki M. Hoern., 18. Murex (g Muricidea) transsylvanicus nov. form

15. Murex (d Muricidea) incisus Brod., 16. " $e$ "moravicus nov. form., 17. $" f$ " scalarioides Blainv.,

\section{Section: Chicoreus.}

19. Murex (a Chicoreus) perlongus Bell., 20. "b " Aquitanicus Grat. 21. Murex (c Chicoreus) granuliferus Grat, 23. Murex (e Chicorens) Galicianus Hilb.

\section{Section: Phyllonotus,}

24. Murex' (a Phyllonotus) cristatus Brocc.,

$\begin{array}{lllll}25 . & & b & & \text { subasperrimus d'Orb., } \\ 26 . & " & c & " & \text { Hoernesi d'Anc., } \\ 27 . & \quad & d & & \text { rudis Bors., }\end{array}$

28. Murex (e Phyllonotus) austriacus nov. form., 29. " $\quad "$ striaeformis Michti., 30. " $"$ " Lassaignei Bast., 31. $" h n$ Vindobonensis M. Hoern.

VIII. Section: Vitularia.

32. Murex (Vitularia) lingua-bovis Bast.

\section{Section: Trophon.}

33. Murex (a Trophon) ruditzensis nov. form., 34. " $b$ " Haidingeri M. Hoern., 36. Murex (d Trophon) varicosissimus Bon., 35. " $\quad$ c " goniostomus Partsch,

$\begin{array}{lllll}37 . & \quad & e & & \text { vaginatus Jan., } \\ 38 . & \cdots & f & \cdots & \text { capito Phit. }\end{array}$




\section{Section: Occenebra.}

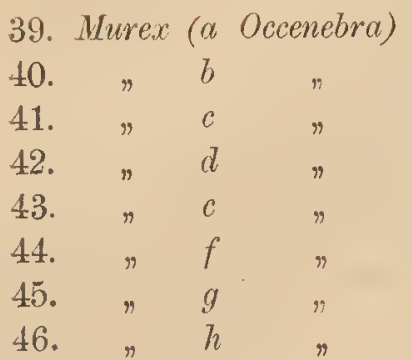

sublavatus Bast.,
caclatus Grat.,
Dertonensis May.,
Crcdneri nov. form.,
Schönni M. Hoern.,
crassitabiatus Hilb.,
craticulatus Limn.,
Bocckhi nov. form.,

47. Murex

48 .

49.

50.

51.

52.

53.

54 .

$\begin{array}{lll}r & 1 & " \\ " & k & n \\ " & l & n \\ n & m & " \\ n & n & " \\ " & 0 & " \\ " & p & n\end{array}$

\author{
Sandbergeri MT. Hoern., \\ scalaris Brocc., \\ imbricatus Brocc., \\ imbricatoides nov. form., \\ alternatus Bell. \\ Hochstetteri nov. for'm., \\ Renieri Michti., \\ ventricosus $M$. Hoern.
}

In dieser Ordnung sind die aufgezählten vierundfünfzig Formen auch in der nachstehenden eingehenderen Discussion aneinander gereiht.

\section{Section: Murex sens. strict.}

\section{Murex spinicosta Bronn.}

Murex spinicosta Bronn. M. Ho ernes: Foss. Moll. d. Tert.-Beck. v. Wien, I., pag. 259, Taf. XXIV, Fig. 6, 7, 8.

Murex spinicosta Bronn. C. d'Ancona: Malac. plioc. ital., pag. 18, Taf. II, Fig. 5.

Murex spinicosta Bronn. L. Bellardi: I Moll. d. terr. terz. d. Piem. e d. Ligur., I., pag. 44.

Murex spinicosta Bronn. F. Fontannes: Les moll. plioc. d. 1. vall. du Rhône et du Roussillon, I., pag. 1.

Der Schilderung dieser mit den italienischen Vorkommnissen im Allgemeinen gut übereinstimmenden Form durch M. Hoernes haben wir nichts Wesentliches beizufügen.

Auf die Eigenthümlichkeiten der österreichisch-ungarischen Vertreter des Murex spinicosta hat F. Fontannes treffend hingewiesen mit den Worten: "A en juger d'après le seul exemplaire qui me soit connu, le Murex spinicosta du Roussillon est identique avec les individus typiques du pliocène italien, et ne diffère pas d'ailleurs sensiblement de ceux du bassin de Vienne. Dans cette dernière région cependant, la spire est généralement un peu plus aiguë; les sutures sont plus profondes, les épines des carènes plus fines, plus longues, plus recourbées en arrière; le faciès général est, en somme, plus svelte, plus élégant, du moins pour la majorité des individus."

M. Hoernes nennt als Fundorte des Wiener Beckens: Baden, Vöslau, Möllersdorf, Gumpoldskirchen, Gainfahrn, Enzesfeld, Grund und Szobb bei Gran mit dem Beisatz "nicht selten“, und führt unter den auswärtigen Fundorten auch Lapugy an. Gegenwärtig sind in der Sammlung des Hof-Mineralien-Cabinetes auch die Orte Grussbach, Jerutek, Forchtenau und Kostej als Fundpunkte des Murex spinicosta, jedoch nur durch einzelne Exemplare vertreten.

\section{Murex Delbosianus Grat.}

Taf. XXIV, Fig. 9 von Kostej, Fig. 10, 11 von Korytnice.

Murex Delbosianus Grat. M. Hoernes: Foss. Moll. d. Tert.-Beck. v. Wien, I, pag. 675, Taf. LI, Fig. 7.

M. Hoernes führt nur einen einzigen Fundort dieser Art im Wiener Becken an: Grund (mit dem Beisatz "sehr selten“). Unter den auswärtigen Fundorten nennt M. Hoernes auch Korytnice. Von letzterem Fundorte, wo Murex Delbosianus ziemlich häufig vorzukommen scheint (es liegen uns von dort 37 Exemplare vor), bringen wir zwei Gehäuse zur Abbildung, hauptsächlich zu dem Zwecke, um die gewaltige Entwicklung. der Stacheln zu zeigen, die an dem durch M. Hoernes zur Abbildung gebrachten Gehäuse von Grund sehr zurücktreten. Das grössere der beiden Exemplare, welches in Fig. 11 dargestellt ist, misst 41 Mm. Höhe es dürfte (die Stacheln sind theilweise abgebrochen) über $30 \mathrm{Mm}$. breit gewesen sein. Das kleinere Gehäuse, welches Fig. 10 zur Anschauung bringt, ist. $35 \mathrm{Mm}$. hoch - es dürfte über $26 \mathrm{Mm}$. Breite erreicht haben. Das kleine Gehäuse von Kostej, welches in Fig. 9 zur Abbildung gebracht wurde, bleibt hinsichtlich der Stachelentwicklung nicht hinter den Exemplaren von Korytnice zurück. Gleiches gilt von den meisten Gehäusen, die uns von anderen Fundorten vorliegen. Das in Fig. 9 dargestellte Exemplar ist 28 Mm. hoch, $18 \mathrm{Mm}$. breit.

Ausser den zwei Gehäusen von Grund und den 37 von Korytnice liegen uns noch vier von Grussbach, eins von Niederleis, eins von Niederkreuzstätten, neun von Kostej und sechs von Lapugy vor. 


\section{Section: Haustellum.}

\section{Murex (Haustellum) Partschi M. Hoernes.}

Murex Partschi. M. Hoernes: Foss. Moll. d. Tert.-Beck. v. Wien, I., pag. 258, Taf. XXVI, Fig. 5. Murex Partschi M. Hoern. L. Bellardi: Foss. Moll. d. terr. terz. d. Piem. e d. Ligur., I., pag. 45.

B ellardi stellt diese Form a. a. O. zu Murex im engeren Sinn (I. Section) - wir rechnen sie zur Untergattung Haustellum (II. Section der Gattung Murex bei B ellardi), da wir an manchen der zahlreichen uns vorliegenden Exemplare vier und mehr Varices auf der Schlusswindung beobachten können, obwohl die Mehrzahl der Gehäuse allerdings, den Angaben von M. Hoernes entsprechend, nur drei Varices aufweist, die jedoch stets unregelmässig angeordnet sind.

M. Hoernes nennt als Fundorte des Murex Partschi im Wiener Becken: Grund, Baden, Vöslau, Gainfahrn, Forchtenau, Szobb bei Gran mit dem Beisatz "selten"; unter den auswärtigen Fundorten führt er auch Lapugy in Siebenbürgen und Nemesey (recte Nemesest) im Banat an. Heute liegen uns vor: 6 Exemplare von Baden, 1 von Gainfahrn, 1 von Porzteich, 3 von Lissitz, 6 von Grussbach, 4, von Grund, 10 von Niederleis, 17 von Forchtenau, 13 von Szobb, 1 von Nemesest, 10 von Kostej, 1 von Bujtur und 28 von Lapugy. Einzig an dem letzterwähnten Fundorte scheint Murex Partschi ziemlich häufig vorzukommen.

\section{Section: Rhynocantha.}

\section{Murex (Rhynocantha) subtorularius nov. form.}

Murex brandaris. M. Hoernes: Foss. Moll. d. Tert.-Beck. v. Wien, I., pag. 257, Taf. XXVI, Fig. 3, 4 (excl. Syn.) non Linné!

Diese Form kann weder auf Murex brandaris L., noch auf Murex torularius Lamk. bezogen werden. Der letzteren Gattung gehören die meisten, von M. H o ern es angeführten fossilen Vorkommnisse des Auslandes an, welche in der Literatur als Murex brandaris oder Murex cornutus L. besprochen erscheinen. Die Verschiedenheit der fossilen Form einer-, der recenten Typen andererseits hat schon d'Orbigny veranlasst, in seinem Prodrome, Vol. III, pag. 72, die fossilen Formen als Murcx subbrandaris zu bezeichnen, und C. d'A ncona hat neuerdings den Namen Murex pseudo-brandaris für dieselbe creirt (Malac. plioc. ital., pag. 19). B ellardi aber zeigte (Moll. d. terr. terz. d. Piem. e d. Ligur., I., pag. 59), dass der Name des MIurex torularius Lamk. auf dieselben angewendet werden müsse, da die von $\mathrm{L}$ a marck aufgestellte Bezeichnung (Anim. sans vert., Vol. VII., pag. 177) die unzweifelhafte Priorität habe. Wir verweisen auf die ausführliche Darlegung der Synonyme und Citate bei Bellardi, sowie auf dessen übersichtliche Erörterung der Unterschiede der drei so oft confundirten Arten Murex brandaris, Murex cornutus und Murex torularius. Als Hauptunterschied der letztgenannten fossilen Form von den unstreitig nahe verwandten, im genetischen Zusammenhang stehenden recenten Arten wird von Bellardi die deutliche und tiefe Naht hervorgehoben, welche an allen Gehäusen des Murex torularius zu beobachten ist. Alle übrigen Merkmale (die von Bellardi sehr übersichtlich in Tabellenform zusammengestellt wurden) sind weniger constant. Es sind sowohl hinsichtlich der allgemeinen Form wie hinsichtlich der Verzierung Uebergänge vorhanden, wie Bellardi selbst hervorhebt; die Sutur aber ist bei Murex torularius constant tief - bei Murex cornutus und Murex brandaris seicht. Nun ist aber bei der von M. Hoernes als Murex brandaris angeführten Form des Wiener Beckens die Sutur seicht, überdies aber die Sculptur ganz verschieden von jener der sämmtlichen in Frage kommenden Arten. Bellardi sagt hierüber bei Discussion des Murex torularius: „Ho riferito con dubbio alla presente specie le forme figurate dal Hoernes, perchè mi sembrano mancare di uno de' suoi principali caratteri, vale a dire la profondità delle suture, e perchè le spine vi sono brevissime, rappresentati da nodi." - Beide Merkmale: die seichte Naht und die schwache Entwicklung der Dornen, veranlassen uns, die Form des österreichisch-ungarischen Miocäns als Murex subtorularius abzutrennen. Wir müssen hervorbeben, dass uns ausser dem von M. Ho ernes, l. c. in Fig. 3, zur Anschauung gebrachten Gebäuse von Gainfahrn nur noch ein zweites von demselben Fundorte vorliegt, welches ebenfalls auf der Schlusswindung drei wenig vortretende Knotenreihen trägt, von welchen die oberste noch am stärksten entwickelt ist. Ein weiteres, sehr grosses Exemplar von Gainfahrn (selbes ist $62 \mathrm{Mm}$. breit und dürfte bei vollständiger Erhaltung - der Canal und die Spitze des Gehäuses ist weggebrochen - mindestens 95 M.m. Höhe besessen haben) weist die beiden unteren Knotenreihen nur ill sehr schwacher Entwicklung auf und bildet einen vollständigen 
Uebergang zu dem von M. Hoernes in Fig. 4 dargestellten Gehäuse von Grund, mit welchem alle übrigen uns vorliegenden Exemplare in Gestalt und Verzierung übereinstimmen.

M. Hoernes gibt als Fundorte der in Rede stehenden Form an: Gainfahrn, Grund und Szobb (mit dem Beisatze „sehr selten“) sowie Lapugy. Uns liegen derzeit vor: 4 Gehäuse von Gainfahrn, 3 von Grund, 1 von Grinzing, 1 von Kostej, 6 von Lapugy. Jedenfalls stellt Murex subtorularius eine der selteneren Erscheinungen im österreichisch-ungarischen Miocän vor. M. Hoernes bemerkt, dass eine mit der österreichischen Form übereinstimmende Varietät des Murcx brandaris sich auch zu Turin finde. Dies müssen wir in Abrede stellen. Murex rudis Michti. (vergl. Mi h elotti: Foss. mioc. inf., pag. 118, Tav. XII, Fig. 13) non Bors., welchen M. Ho er nes bei dieser Bemerkung im Auge gehabt haben dürfte, gehört in eine ganz andere Gruppe der Gattung Murex (Subgenus: Haustellum), weleher er von Bellardi unter dem Namen Murex Ighinae zugerechnet wird. Von unserem Murex subtorularius unterscheidet er sich schon durch die viel höhere Spira. Auch Murex trunculoides Pusch. (Polens Paläontologie, pag. 136, Taf. XI, Fig. 23), welcher von M. Ho ernes unter den Synonymen angeführt wird, besitzt ein viel höheres Gewinde und gehört nicht in die nähere Verwandtschaft des Murex subtorularius. Weinkauff sowohl als Kobelt folgten M. Hoernes, indem sie Murex brandaris als bäufige Form der miocänen Schichten anführen und auf Murex rudis Michelotti als Stammform zurückführen. So sagt Kobelt (Iconographie der schalentragenden europäischen Meeresconchylien, Heft 1, 1883): „Fossil reicht Murex brandaris zurück bis ins typische Miocän und findet sich überall in den Tertiärschichten der Mediterranländer, in Südfrankreich, dem Wiener Becken und bis nach Volhynien " ${ }^{1}$ ), und "für fossile Formen mit ganz verkümmerten oder selbst fehlenden Knoten sind Murex coronatus Risso und Murex rudis Michelotti errichtet worden. Nach W c ink a uff (Mittelmeer-Conchylien, Bd. II, pag. 84) sind diese ungestachelten Formen, welche lebend seltener und fast nur unter ungünstigen Verhältnissen vorkommen, die älteren und somit als die Stammeltern der Art anzusehen."

Bei dem Interesse, welches jeder Versuch, die Abstammung recenter Thierformen von jenen vergangener Perioden nachzuweisen, besitzt, können wir uns nicht versagen, jene Stelle des Weinkauff'schen Werkes wörtlich zu citiren, auf welche sich Kobelt bezieht. Sie lautet: „Die Art ändert sehr in Bezug auf Grösse und Zahl der Stacheln ab, für solche Formen möchte ich es jedoch nicht unternehmen, constante Varietäten festzuhalten ${ }^{2}$ ). Dagegen sind jene Formen, bei denen die Stacheln gänzlich oder theilweise zu blossen Knoten herabgesunken sind, hiezu besser geeignet, ja solche sind als besondere Arten (Murex coronatus Risso., Murex rudis Michti.) aufgestellt worden und finden sich in den älteren Tertiärbildungen vorzugsweise, ohne jedoch den neueren Bildungen und der Jetztzeit gänzlich zu fehlen. Sie sind indess mit den jungtertiären und lebend mehr verbreiteten stacheligen Formen der Art durch Uebergänge verbunden, dass von Festhaltung als besondere Arten längst abgesehen werden musste. Man kann die stachellosen Formen (Murex rudis Michti.) als die Stammform der Art ansehen und gelangt bei Betrachtung einer grossen Reihe fossiler und lebender Exemplare zu einer Vorstellung, bis zu welchem hohen Grade eine und dieselbe Art in einem langen Zeitraum auseinander laufen kann."

Zunächst müssen wir dem gegenüber betonen, dass von einer Ableitung der Rhinocantha brandaris von Haustellum Ighinae Bell. (Murex rudis Michti. non Bors.) nicht wohl die Rede sein kann. Was sodann die ungestachelten recenten Vorkommnisse des Murex brandaris anlangt, welche zur Vergleichung mit der angeblichen Vorfahren herangezogen werden, so sind sie, wie $\mathrm{Kobelt}$ hervorhebt, nicht nur selten, sondern auch an ungünstige äussere Verhältnisse gebunden. So stammt das von Kobelt in seiner Iconographie der europ. Meeresconchylien, Taf. I, Fig. 6, zur Abbildung gebrachte aus den Lagunen von Venedig, und Kobelt bemerkt ausdrücklich: ${ }_{n} \mathrm{Es}$ ist dies die Form, welche die Art unter ungünstigen Verhältnissen und besonders im Brackwasser annimmt; - eine ähnliche verkümmerte Form mit noch stärker reducirter oberer Knotenreihe lebt in den Lagunen am Faro di Messina, aber ich besitze von derselben kein zur Abbildung geeignetes Exemplar." Auch dies zeigt die Schwierigkeit, eine Entwicklungsreihe der mit Murex brandaris verwandten Formen im Sinne der oben citirten Ausführungen Weinkauff's anzunehmen. Die fossilen Verwandten des Mrurex brandaris erreichen bedeutendere Dimensionen, sie besitzen schwerere Gehäuse und zumal die pliocänen Repräsentanten (Murex torularius) übertreffen in der. Stachelentwicklung weitaus die lebende Form. Murex subtorularius der österreichisch-ungarischen Tertiärbildungen ist durch manche Eigenthümlichkeiten so sehr von Murex torularius geschieden, dass wir uns nicht getrauen, zumal bei dem relativ geringfügigen Material, welches

1) Da wir nicht annehmen können, dass Herrn Kobelt Bellardi's Monographie der tertiären Mollusken Piemonts und Liguriens unbekannt geblieben ist, finden wir es unbegreiflich, dass dessen Ausführungen über Murex torularius durch Kobelt weder acceptirt noch widerlegt wurden.

$\left.{ }^{2}\right)$. Eine solche, welche schon Chemnitz anführte, hat Frauenfeld unter dem Namen Rhinocantha trifariam spinosa als besondere Art aufgestellt.

Hoernes u. A u inger, Gasteropoden d. Meeres-Abl. d. 1. u. 2. Mediterranstufe, Heft 5. 
uns von dieser interessanten Form zugebote steht, die phylogenetische Bedeutung derselben zu erörtern. Es wäre möglich, dass sie derjenigen entspräche, welche Weinkauff für Murex Ighinae in Anspruch nimmt; ehe jedoch Bindeglieder vorliegen, welche den Uebergang zu der pliocänen Form herstellen, lässt sich kaum mehr als eine blosse Vermuthung äussern.

\section{Section: Pteronotus.}

\section{Murex (a Pteronotus) Swainsoni Michti.}

Taf. XXIX, Fig. 1, 2, 3 von Möllersdorf, Fig. 4 von Lapugy.

Murex Swainsoni Michti. M. Hoernes: Foss. Moll. d. Tert.-Beck. v. Wien, I., pag. 248. Taf. XXV, Fig. 13. Murex Swainsoni Michti. C. d'A ncona: Mal. plioc. ital, pag. 14, Tav. III, Fig. 5.

Murex Swainsoni Michti. L. Bellardi: I Moll. d. terr. terz. d. Piem. e d. Ligur., I., pag. 56, Tav. IV, Fig. 8.

Diese Form variirt nicht unbedeutend; wir konnten glücklicherweise ziemlich zahlreiches Material studiren, so dass wir der Versuchung, mehrere verschiedene Formen zu unterscheiden, entgehen konnten; zumal die durch Uebergänge vollständig verbundenen extremen Gehäuse nicht so weit von einander verschieden sind, dass sie unter allen Umständen verschiedene Namen zu erhalten verdienen würden. M. Hoe rnes bringt ein gedrungenes Gehäuse aus dem Badener Tegel zur Abbildung; wir fügen erstlich die Abbildungen mehrerer Gehäuse von Möllersdorf hinzu, um die nicht gerade sehr bedeutenden Differenzen der Grundform und die grosse Verschiedenheit in der Entwicklung der blättrigen Varices und des Canales zu zeigen. Es liegen uns vom selben Fundorte im Ganzen 18 Gehäuse vor, welche alle Uebergangsglieder von dem in Fig. 1 dargestellten schlanken Gehäuse bis zu der von M. Ho ernes bereits zur Anschauung gebrachten, gedrungenen Form darstellen. Unter acht Gehäusen von Lapugy, welche ebenfalls nicht unbedeutende Verschiedenheiten aufweisen, befindet sich das in Fig. 4 dargestellte, $60.5 \mathrm{Mm}$. hohe, 28 bis $30 \mathrm{Mm}$. breite Gehäuse, welches sehr an Murex longus Bell. (Bellardi: I Moll. d. terr. terz. d. Piem. e d. Ligur., I., pag. 55, Tav. IV, Fig. 6) erinnert. Es gleicht demselben in dem verlängertem Umriss, dem langen Canal, der Entwicklung der Varices und in dem Zurücktreten der Knoten zwischen den Varices der letzten Windungen. Wir halten es lediglich für ein abnormes, altes Exemplar des Murex Swainsoni und vermuthen, dass Bellardi's Murex longus in ähnlichem Verhältniss zu seinem Murex trinodosus stehe. Das Lapugyer Exemplar zeigt nämlich auf den oberen Windungen constant einen (wenn auch schwachen) Knoten zwischen den Várices, von Murex longus aber sagt Bellardi, dass bei ihm bisweilen drei schwache Längsknoten zwischen den Varices erscheinen. Dies deutet entschieden auf Verwandtschaft des Murex longus mit Murex trinodosus, bei welchem, wie unten zu erörtern sein wird, die Längsknoten zwischen den Varices sehr verschieden stark ausgeprägt sind.

M. Hoernes bemerkt von Murex Swainsoni: „Im Wiener Becken kommt diese Species (jedoch selten) nur im Tegel von Baden, Vöslau und Möllersdorf vor." Wir konnten ausser 40 Exemplaren, welche von den verschiedenen Fundorten des Badener Tegels stammen, noch 2 von Grinzing, 3 von Jaroměric und 8 von Lapugy untersuchen.

\section{Murex (b Pteronotus) trinodosus Bell.}

Taf. XXIX, Fig. 5 von Lissitz, Fig. 6, 7 von Jaroměric.

Murex trinodosus. Bellardi: I Moll. d. terr. terz. d. Piem. e d. Ligur., I., pag. 58, Tav. IV, Fig. 58.

Unter den zahlreichen Gehäusen des Murex Swainsoni Michti, welche in der Sammlung des k. k. HofMineralien-Cabinetes aufbewahrt werden, fanden sich von zwei Fundorten auch Exemplare, welche unzweifelhaft dem Murex trinodosus Bell. angehören. Diese Form stimmt in allen übrigen Merkmalen, was allgemeine Umrisse, Entwicklung der Varices, Mündung, Canal, undeutliche Querstreifung etc. anlangt, mit Murex Swainsoni überein, so dass eine eingehende Schilderung derselben überflüssig erscheint: zwischen je zwei Varices treten jedoch nicht ein rundlicher, sondern drei längliche Knoten auf. Diese Knoten sind bei den einzelnen uns vorliegenden Individuen verschieden stark entwickelt, nie erreichen sie jedoch die Stärke derjenigen, welche das Gehäuse der italienischen Type zieren. Auch die Querstreifung ist an dieser weitaus stärker ausgeprägt. $\mathrm{Da}$ jedoch, wie die von uns zur Abbildung gebrachten Gehäuse zeigen, die Längsknoten sowie die Quersculptur grosse Variabilität in ihrer Entwicklung wahrnehmen lassen, so glauben wìr die österreichisch-ungarischen Formen als Varietät dem Murex trinodosus anreihen zu dürfen. 
Von dieser interessanten Form liegen in der Sammlung des Hof-Mineralien-Cabinetes sieben Gehäuse von Jaromeřric und je eines von Steinabrunn und Lissitz. Wir bringen das letztere, sowie zwei der Gehäuse von Jaroměřic zur Abbildung. Fig. 7 stellt ein leider stark beschädigtes Gehäuse von Jaroměric vor, welches durch die kräftige Entwicklung der Sculptur unter allen uns vorliegenden Exemplaren noch am meisten an die italienische 'Type des Murex trinodosus gemahnt. Fig. 6 stellt ein $35 \mathrm{Mm}$. hohes, $17 \mathrm{Mm}$. breites Exemplar vom selben Fundorte dar, bei welchem die Sculptur sehr schwach ausgeprägt ist. Die drei charakteristischen Längsknoten können nur zwischen den Varices der obersten Windungen deutlich beobachtet werden, und die Querreifung ist kaum angedeutet, woran die Abreibung des nicht ganz frischen Gehäuses zum geringsten Theile Schuld trägt. Fig. 5 endlich stellt das ca. $32 \mathrm{Mm}$. hohe, ca. $15 \mathrm{Mm}$. breite (Canal und Varices sind stark beschädigt, genaue Massangaben daher kaum möglich) Gehäuse von Lissitz dar, welches in der Entwicklung der Sculptur zwischen den beiden von Jaroméřic zur Abbildung gebrachten Gehäusen steht. Mit diesem Gehäuse von Lissitz stimmen mehr oder minder die fünf übrigen Gehäuse von Jaroměřic überein. Die Variation, welcher die Sculptur der besprochenen Gehäuse unterworfen ist, veranlasst uns, sie als Varietät dem Murex trinodosus Bell. anzureihen, obwohl nicht geleugnet werden kann, dass bei diesem sowohl die Längs. knoten als die Querreifen stärker entwickelt sind.

\section{Murex (c Pteronotus) tortuosus Sow.}

Murex tortuosus Sow. M. Hoernes: Foss Moll. d. Tert.-Beck. v. Wien, I., pag. 249, Taf. XXV, Fig. 12:

Der Schilderung dieser Form durch M. Hoernes haben wir nichts Wesentliches beizufügen. Als Fundorte des Murex tortuosus Sow. im Wiener Becken werden von M. Hoernes Steinabrunn, Gainfahrn und Grinzing namhaft gemacht. Heute liegen uns in der Sammlung des k. k. Hof-Mineralien-Cabinetes 1 Gehäuse von Soos, 2 von Gainfahrn, 6 von Grinzing, 16 von Steinabrunn (darunter auch die grössten Exemplare), 4 von Marz und 1 von Tarnopol vor. Auch von Zalisze in Volhynien bewahrt die Sammlung 2 Exemplare, welche mit jenen aus dem Wiener Becken vollkommen übereinstimmen.

\section{Murex (d Pteronotus) latilabris Bell, et Michti.}

Mrurex latilabris Bell. et Michti. M. Hoernes: Foss. Moll. d Tert.-Beck. v. Wien, I., pag. 247, Taf. XXV, Fig. 11. Murex latilabris Bell. et Michti. L. Bellardi: I Moll. d. tert. terz. d. Piem. e d. Ligur., I., pag. 58, Taf. IV. Fig. 1.

M. Hoernes gibt als Fundorte dieser Art im Wiener Becken Forchtenau und Gainfahrn (mit dem Beisatz „sehr selten") an und nennt unter den auswärtigen Fundorten auch Lapugy. Wir vermögen dieser Aufzählung nur einen einzigen neuen Fundort: Niederleis, auf Grund eines einzigen, jugendlichen Gehäuses von $8 \mathrm{Mm}$. Höhe, hinzuzufügen. Von Grund und Gainfahrn liegen uns nur je eines, von Lapugy nur drei Gehäuse vor. Es ist die in Rede stehende Form unstreitig eine der seltensten unter den Conchylien des österreichisch-ungarischen Miocän. Wir beklagen dies um so lebhafter, als uns die Uebereinstimmung mit der italienischen Type keineswegs zweifellos erscheint. Die österreichischen Vorkommnisse weisen gröbere Quersculptur und schwächer entwickelte blättrige Varices auf. Wir vermuthen, dass die österreichische Form nicht sowohl eine Varietät des Murex latilabris als vielmehr eine eigene Art darstelle, können jedoch nicht die Aufstellung einer solchen wagen, da uns das spärliche Material, welches uns derzeit in der Sammlung des k. k. HofMineralien-Cabinetes vorliegt, nicht zu diesem Vorgange berechtigt.

\section{Murex (e Pteronotus) Sowerbyi Michti.}

Taf. XXIX, Fig. 8 von Lapugy.

Murex Sowerbyi. Michelotti: Monogr. Murex, pag. 8, Tav. I, Fig. 14, 15.

Murex erinaceus. M. Ho ernes: Foss. Moll. d. Tert.-Beck. v. Wien, I., pag. 250 (pro parte), Taf. XXV, Fig. 15 (cet. excl.).

Murex Sowerbyi Michti. C. d'A ncona: Malac. plioc. ital., pag. 12, Tav. III, Fig. 2.

Murex Sowerbyi Michti. L. Bellardi: I Moll. d. terr. terz. d. Piem. e d. Ligur., I., pag. 59.

Dies ist, wie Bellardi richtig bemerkt hat, eine Zwischenform zwischen Murex latilabris Bell. et Michti und Murex erinaceus Linn. Von letzterem trennt die in Rede stehende Form der spitzere Gewindewinkel, die geringere Zahl und die schwächere Ausprägung der Querrippen, sowie die bedeutend engere Mündung. Wir müssen daher Bellardi beipflichten, wenn er das von M. Hoernes, l. c. Fig. 15 der Taf. XXV, zur Anschauung gebrachte Gehäuse von Grund hieher bezieht. 
Es liegen uns heute in der Sammlung des k. k. Hof-Mineralien-Cabinetes 16 Gehäuse von Grund vor, welche sämmtlich mehr oder minder mit dem erwähnten, durch M. Hoernes zur Abbildung gebrachten Exemplare übereinstimmen; ferner 13 Gehäuse von Lapugy, von welchen wir eines, seiner schlanken Gestalt wegen, zum Gegenstand einer Abbildung gemacht haben. Es ist dasselbe $46 \mathrm{Mm}$. hoch, $23 \mathrm{Mm}$. breit. Wir heben hervor, dass uns vom selben Fundorte Gehäuse vorliegen, welche die vollständigen Uebergänge von dieser schlanken zu der gedrungenen und bauchigen Form darstellen, welche in Grund auftritt. Ferner fanden sich in der Sammlung des k. k. Hof-Mineralien-Cabinetes zwei Gehäuse von Ritzing, welche ziemlich genau mit den oben besprochenen von Grund übereinstimmen, sowie zwei sehr stark beschädigte von Niederkreuzstetten, welche eigentlich keine sichere Bestimmung zulassen. Sie gehören vielleicht sogar zu Murex latilabris Bell. et Michti, oder vielmehr zu der oben besprochenen Form des Wiener Beckens, welche dem Murex latilabris zwar nahe verwandt, wahrscheinlich aber doch von der italienischen Type verschieden ist.

\section{Murex (f Pteronotus) erinaceus Linn.}

Murex erinaceus timn. M. Ho ern es : Foss. Moll. d. Tert.-Beck. v. Wien, I, pag. 250 (pro parte), Taf. XXV, Fig. 14 u. 16 (15 excl.). Murex erinaceus Linn. C. d'Ancona: Malac. plioc. ital., pag. 11, Tav. III, Fig. 4.

Murex erinaceus Linn. L. Bellardi: I Moll. d. terr. terz. d. Piem. e d. Ligur., I., pag. 60.

Indem wir hinsichtlich der Synonyme und Citate, welche sich auf diese, sowie auf die vorhergehende Art beziehen, auf die Darstellung bei Bellardi verweisen, haben wir zu betonen, dass wir in der Auffassung des Murex erinaceus und des ihm so nahe verwandten Murex Sowerbyi dem genannten Autor vollständig beipflichten, wenigstens was die Abtrennung der oben erörterten auf Murex Sowerbyi bezogenen Gehäuse anlangt, welche M. Hoernes zu Murex erinaceus rechnete.

Was die österreichischen Vorkommnisse des echten Murex erinaceus L. anlangt, so beschränken sich dieselben nach Ausscheidung der dem Murex Sowerbyi zufallenden Fundorte auf zwei: Enzesfeld und Molt. Von ersterem Punkte liegen uns 7, von letzterem 24 Exemplare vor. Die ersteren stimmen sämmtlich mit dem von M. Hoernes, l. c., Fig. 14, zur Anschauung gebrachten Gehäuse überein, sind jedoch leider ohne Ausnahme nicht besonders gut erhalten, was der vereitelten Vergleichung mit den Molter Exemplaren wegen zu bedauern ist. Die 24 von Molt uns vorliegenden Gehäuse sind sämmtlich, wie dies auch schon das durch M. Hoernes von diesem Fundorte zur Abbildung gebrachte Exemplar erkennen lässt, durch stärkere Ausprägung der Quersculptur, kürzeren und unvollständig geschlossenen Canal ausgezeichnet. Die Frage, ob die im GesammtHabitus so verschiedenen Enzesfelder Exemplare nicht etwa von der Molter Form getrennt werden müssen, lässt sich kaum beantworten, da eben, wie bereits erwähnt, die schlechte Erhaltung der Enzesfelder Gehäuse einer genauen Vergleichung entgegensteht. Vorläufig führen wir daher die Gehäuse von beiden Fundorten als Varietäten des Murex erinaceus an, müssen jedoch die Möglichkeit zugeben, dass umfassenderes Material dereinst vielleicht eine Abtrennung der geologisch älteren Molter Form räthlich erscheinen lassen wird. - Wenn man jedoch die enorme Variabilität des recenten Murex erinaceus berücksichtigt (vergl. diesbezüglich Ko belt's Iconographie der schalentragenden europäischen Meeresconchylien, Taf. II, Fig. 5-8, Taf. III, Fig. 8, 9, Taf. IV, Fig. 2-9), wird man sich kaum zu einer weitgehenden Zersplitterung der fossilen Vertreter dieser Form veranlasst finden.

\section{Murex (g Pteronotus) graniferus Michti.}

Murex graniferus Michti. M. Hoernes: Foss. Moll. d. Tert.-Beck. v. Wien, I., pag. 254, Taf. XXVI, Fig. 1. Murex graniferus Michti. L. Bellardi: I Moll. d. terr. terz. d. Piem. e d. Ligur., I., pag. 65, Tav. V, Fig. 1

M. Hoernes nennt am angezeigten Orte Gainfahrn, Enzesfeld, Weinsteig und Nemesey (recte Nemesest) als Fundorte. Von jedem derselben liegt nur je ein Gehäuse in der Sammlung des k. k. HofMineralien-Cabinetes, desgleichen von den neu hinzugekommenen Fundorten Porstendorf und Kostej. Nur Lapugy hat zwei Gehäuse von dieser überaus seltenen Conchylie geliefert, welche den Angaben Bellardi's zufolge auch im italienischen Miocän sehr selten ist. Eines der beiden Lapugyer Exemplare, welches $57 \mathrm{Mm}$. hoch, 33 Mm. breit ist, zeichnet sich durch ungewöhnlich starke Entwicklung der Stachel auf den Varices aus. Diejenigen, welche den Kiel der Schlusswindung zieren, sind leider sämmtlich abgebrochen — ımsomehr fallen diejenigen auf, welche an der Rückseite des Canales hervortreten. 


\section{Section: Muricidea.}

\section{Murex (a Muricidea) heptagonatus Bronn.}

Taf. XXIV, Fig. 5 von Vöslau, Fig. 6 von Steinabrunn, Fig. 7, 8 von Lapugy.

Murex heptagonatus Bronn. M. Hoernes: Foss. Moll. d. Tert.-Beck. v. Wien, I., pag. 255, Taf. XXVI, Fig. 2. Murex heptagonatus Bronn. C. d'Ancona: Malac. plioc. ital., pag. 21, Tav. VII, Fig. 10.

Murex heptagonatus Bronn. L. Bellardi: I Moll. d. terr. terz. d. Piem. e d. Ligur., I., pag. 67.

Diese Form variirt sehr stark, zumal was die Zahl und Entwicklung der Varices anlangt; wir waren durch das ziemlich reiche, in der Sammlung des k. k. Hof-Mineralien-Cabinetes aufgespeicherte Material in der Lage, diese Verschiedenheiten recht gut studiren zu können.

M. Hoernes nennt als Fundorte des Murex heptagonotus im Wiener Becken: Enzesfeld, Steinabrunn, Forchtenau, Grund, mit dem Beisatz "selten", und gibt auch das Vorkommen zu Lapugy an. Es wurden von uns untersucht: 3 Gehäuse von Enzesfeld, 1 von Vöslau, 3 von Steinabrunn, 1 von Niederleis, 1 von Grund, 5 von Forchtenau und 22 von Lapugy. Namentlich Lapugy hat trefflich erhaltene Exemplare geliefert. Wir brachten zwei derselben zur Abbildung und machen zunächst auf das zierliche, schlanke Gehäuse aufmerksam, welches Fig. 7 zur Anschauung bringt. Dieses $34.5 \mathrm{Mm}$. lange, $22 \mathrm{Mm}$. breite Gehäuse zeichnet sich durch lange, wohlerhaltene Stachel und langen Canal aus. Das in Fig. 8 dargestellte Gehäuse vom selben Fundorte, welches etwa $50 \mathrm{Mm}$. lang, über $30 \mathrm{Mm}$. breit gewesen sein mag (der Canal ist beschädigt und die Stachel zum grössten Theile abgebrochen), ist gedrungener, der Umriss bauchiger, der Canal massiver und breiter. Das Gehäuse von Vöslau, welches die Fig. 5 darstellt, ist $34 \mathrm{Mm}$. lang und ca. $22 \mathrm{Mm}$. breit (auch hier sind die Stacheln beschädigt); es zeichnet sich gegenüber den Lapugyer Gehäusen durch zahlreichere Varices und schwächere Stachelentwicklung aus. Das in Fig. 6 dargestellte Exemplar von Steinabrunn endlich, welches etwa 36 Mm. lang, $22 \mathrm{Mm}$. breit gewesen sein mag (sowohl der Canal als die Varices sind ziemlich stark beschädigt), zeigt sehr zahlreiche Varices, welche viel schwächere Stacheln tragen, als die übrigen uns vorliegenden Gehäuse aufweisen. Es ist dies eine extreme Form, welche jedoch durch Bindeglieder mit den normalen Gehäusen verknüpft ist.

\section{Murex (b Muricidea) absonus Jan.}

Murex absonus Jan. MI. Hoernes: Foss. Moll. d. Tert.-Beck. v. Wien, I., pag. 222, Taf. XXIII, Fig. 6. Murex absonus Jan. L. Bellardi: I Moll. d. terr. terz. d. Piem. e d. Ligur., I., pag. 68.

Der Schilderung dieser Form durch M. Hoernes haben wir nichts Wesentliches beizufügen. Es liegt uns etwas reicheres Material vor; M. Ho ernes konnte nur drei Gehäuse von Steinabrunn untersuchen, während heute in der Sammlung des k. k. Hof-Mineralien-Cabinetes 7 von diesem Fundorte, 3 von Niederleis, 2 von Forchtenau und 1 von Luschitz aufbewahrt werden. Wir können in Folge dessen eine ziemliche Variabilität in der Gesammtgestalt wie in der Sculptur constatiren. Manche Exemplare sind schlanker und tragen weniger Varices - bei anderen ist auch die Spira kürzer, obwohl in dieser Hinsicht nie jene Verhältnisse erreicht werden, welche Bellardi's Varietät A (1. c., Tav. V, Fig. 3) aufweist. Das grösste der 7 Exemplare von Steinabrunn misst $21.5 \mathrm{Mm}$. in der Höhe, $15 \mathrm{Mm}$. in der Breite. Den Angaben Bellardi's zufolge werden die italienischen Vorkommnisse fast doppelt so gross.

\section{Murex (c Muricidea) Cžjž̀eki M. Hoern.}

Murex Cžjžeki. M. Ho ernes: Verz. in Č̌jǔek's Erläut. z. geogn. Karte v. Wien, pag. 18, Nr. 192

Murex porutosus. M. Ho ernes: Foss. Moll. d. Tert.-Beck. v. Wien, I., pag. 225, Taf. XXIII, Fig. 8 (non Michelotti!).

M. Ho ernes hatte dieser Art zuerst den Namen Murex Cžjžeki gegeben, glaubte aber später sie mit Murex porulosus Michti identificiren zu sollen, wozu wohl nur die schlechte Erhaltung der Michelotti'schen Original-Exemplare aus dem Turiner Grünsand verleiten konnte. Michelotti sagt bei Aufstellung des Murex porulosus (Descript. des Foss. mioc. de l'Italie sept., pag. 237) ausdrücklich: „Espèce voisine du Murex syphonostomus de Bonelli; elle est. allongée, à spire aiguë et formée de sept à huit tours de spire bien distincts, convexes, divisés par six varices dénuées d'épines et de points", während die österreichischen Vorkommnisse blättrige und stachelige Varices tragen. Bellardi bemerkt daher mit Recht (Moll. d. terr. terz. d. Piem. e d. Ligur., pag. 69): Il Murex porulosus Michelotti, figurato dal Hoernes non corrisponde alla forma così 
nominata dal Michelotti: si riferisce ad una forma distinta che manca nei nostri terreni." Murex porulosus Michelotti wird von Bellardi für ident nit Murcx absonus Jan. erklärt; ob mit Recht, vermögen wir nicht zu entscheiden - es möchte überhaupt schwer halten, die betreffenden schlecht erhaltenen Reste aus dem Grünsande von Turin sicher zu deuten. Jedenfalls aber ist Murex Cžjžeki auch von Murex absonus Jan. leicht zu unterscheiden, die trennenden Merkmale wurden bereits durch M. Hoernes so gut hervorgehoben, dass wir darauf verzichten können, auf sie zurückzukommen. M. Hoernes gibt als Fundorte der in Rede stehenden Art Steinabrunn, Nikolsburg (Muschelberg), Gainfahrn und Baden mit der Bemerkung "sehr selten" an. Heute liegen uns in der Sammlung des k. k. Hof-Mineralien-Cabinetes 80 Exemplare von Steinabrunn, 70 von Niederleis, 17 von Forchtenau, 11 von Baden, 5 von Lissitz, 3 von Kostej, 2 von Porzteich, 2 von Drnowitz, 1 von Kalladorf und 1 von Raussnitz vor, so dass Murex Cžjžeki im österreichisch-ungarischen Tertiär sowohl weit verbreitet als auch an einigen Fundpunkten geradezu häufig vorkommt. Nur den geringen Dimensionen des Murex Č̌jželki (das von M. Hoernes zur Abbildung gebrachte, $18 \mathrm{Mm}$. hohe, $10 \mathrm{Mm}$. breite Gehäuse ist das grösste unter allen oben aufgezählten) ist es zuzuschreiben, dass erst die späteren Aufsammlungen grösseres Material dieser interessanten Art ergeben haben. Wir müssen indess bemerken, dass uns drei Exemplare von Lapugy vorliegen, welche bedeutendere Dimensionen erreichen (das grösste derselben ist $21.5 \mathrm{Mm}$. hoch, 12.5 Mm. breit), doch weichen dieselben ein wenig von den typischen Gehäusen des Wiener Beckens ab, die Sculptur ist etwas stärker und die Gestalt gedrungen, so dass einige Aehnlichkeit mit Murex absonus eintritt, welche indess nicht so weit geht, um eine Abtrennung als besondere Art oder als Mittelform zwischen Murex Cžjžeki und Murex absonus zu rechtfertigen.

\section{Murex (d Muricidea) incisus Brod.}

M. Hoernes: Foss. Moll. d. Tert-Beck. v. Wien, I., pag 223, Taf. XXIII, Fig. 7.

Doderlein: Cenni geol. terr. mioc. sup. Ital. centr., pag 22.

C. d'Ancona: Malacologia pliocenica italiana, pag. 23, Tav. IV, Fig. 6.

L. Bellardi: I Moll. d. terr. terz. d. Piem. e d. Ligur., I, pag. 69.

M. Hoernes hat die fossile Form, welche Grateloup 1833 als Murex oblongus beschrieb, mit dem 1832 von Broderip geschilderten Murex incisus identificirt, welcher im Hafen von St. Helena und in West-Columbien lebt. Die italienischen Paläontologen haben sich diesem Vorgange angeschlossen. Nach Bellardi's Angaben ist Murex incisus im italienischen Miocän sehr selten, im Pliocän nicht häufig. Uns liegen 18 Exemplare von Steinabrunn, 1 von Porzteich und 3 von Lapugy vor. Die letzterwähnten zeichnen sich durch Grösse (bis $21 \mathrm{Mm}$. Höhe bei $14 \mathrm{Mm}$. Breite) und kräftige, mit dachziegelartiger Sculptur bedeckte Varices aus. - Die Form gehört sonach im österreichisch-ungarischen Tertiär wie im italienischen zu den Seltenheiten.

\section{Murex (e Muricidea) moravicus nov. form.}

\section{Taf. XXIV, Fig. 14, 15, 16 von Jaromĕřic.}

Diese Form ist am nächsten mit Murex alternicosta Michti. (M ichelotti: Monogr. Murex, pag. 19, Tav. V, Fig. 4, 5 und Descript. d. foss. d. terr. mioc. d. l'Italie sept., pag. 242, Tav. XI, Fig.6; vergl. auch die genaue Schilderung bei Bellardi: I Moll. d. terr. terz. d. Piem. e d. Ligur., I., pag. 71) verwandt, jedoch beträchtlich schlanker und mit stärkerer Sculptur ausgestattet, sowohl was die auf dem Kiel der Umgänge häufig stacheligen Varices als die Querreifen und die feine schuppige Verzierung der gesammten Oberfläche anlangt. Auch ist der Canal länger und stärker gedreht als bei der Michelotti'schen Form.

Murex moravicus besitzt ein schlankes, spindelförmiges Gehäuse, dessen Gewinde von fünf convexen Umgängen gebildet wird, welche einen mehr oder minder deutlichen Kiel tragen. Die stark ausgeprägten Varices, von welchen die Schlusswindung sieben aufweist, werden von erhabenen Querstreifen übersetzt, welche an der Kreuzungsstelle häufig in spitze Stacheln ausgezogen sind. Die ganze Schale ist mit einer feinen, schuppigen Sculptur bedeckt. Die Mündung ist oval, der rechte Mundrand mässig verdickt, im Innern mit 5 bis 6 stumpfen Zähnen besetzt, der Canal ziemlich kurz, offen; - an der Spindelseite befindet sich eine nabelartige Vertiefung.

Es liegen uns nur von einem einzigen Fundorte: Jaroměřic (südöstlich von Gewitsch in Mähren), 12 Gehäuse dieser Form vor. Das grösste, stark beschädigte Gehäuse ist ca. $22 \mathrm{Mm}$. hoch, $12 \mathrm{Mm}$. breit. 


\title{
17. Murex (f Muricidea) scalarioides Blainv.
}

Murex distinctus Jan. M. Hoernes: Foss. Moll. d. Tert.-Beck. v. Wien, I., pag. 246, Taf. XXV, Fig. 7. Murex scalarioides Blainv. L. Bellardi: I Moll. d. terr. terz. d. Piem. e d. Ligur, I., pag. 72.

Dem Vorgange Bellardi's folgend, wenden wir für diese Form den von Blainville gegebenen Namen an. M. Ho e rnes gibt als Fundort dieses Murex nur Steinabrunn an, mit der Bemerkung nsehr selten". Heute liegen uns 21 Gehäuse von Steinabrunn, 1 von Forchtenau, 2 von Kostej und 7 von Lapugy vor. Dem umfassenderen Material zufolge sind wir in der Lage, nicht unbedeutende Variationen dieser Form in den Gesammtumrissen zu constatiren. So misst ein schlankes Gehäuse von Steinabrunn $25 \mathrm{Mm}$. in der Höhe, $11 \mathrm{Mm}$. in der Breite. Ein merklich bauchigeres Exemplar von Lapugy ist $23 \mathrm{Mm}$. hoch, 13.5 Mm. breit, ein extrem gedrungenes Gehäuse von Steinabrunn nur 22.5 Mm. lang und $14 \mathrm{Mm}$. breit.

\section{Murex (g Muricidea) transsylvanicus nov. form.}

Taf. XXIV, Fig. 12 von Lapugy.

Das schlanke Gehäuse dieser zierlichen Art ist spindelförmig, das spitze Gewinde besteht aus 4 bis 5 convexen Umgängen, welche je 7 stark vorspringende Varices tragen. Ueber dieselben und die sonst glatten Zwischenräume setzten entferntstehende erhabene Querstreifen, so dass die Schale grobgegittert erscheint. Die Mündung ist oval, der rechte Mundrand stark verbreitert, innen mit 6 Zähnen besetzt; - der linke legt sich in Form einer sehr dünnen Lamelle an die Spindel. Der Canal ist mässig verlängert, offen.

Das grösste Gehäuse ist $12.5 \mathrm{Mm}$. lang, $7.5 \mathrm{Mm}$. breit.

Es liegen uns nur vier Gehäuse dieser interessanten Form vom Fundorte Lapugy vor. Sie gemahnen im allgemeinen Habitus and insbesondere in der durch die Varices und die erhabenen Querreifen verursachten Gittersculptür an Murex scalarioides Blainv, weisen jedoch geringere Dimensionen, weitaus schlankere Gestalt und zahlreiche, schärfer vorspringende Varices auf.

\section{Vl. Section: Chicoreus.}

\section{Murex (a Chicoreus) perlongus Bell.}

\author{
Taf. XXIV, Fig. 13 von Lapugy.
}

Murex perlongus. Bellardi: I Moll. foss. d. terr. terz. d. Piem. e d. Ligur., I., pag. 75, Taf. V, Fig. 8.

Das Gehäuse dieser merkwürdigen Form ist hoch gethürmt, spindelförmig, das Gewinde besteht aus sieben convexen Umgängen, welche drei mässig gedrehte Reihen scharf vorspringender Varices tragen. Zwischen diesen stark gefalteten scharfen Varices erheben sich stumpfe Längsknoten, über welche entferntstehende Querstreifen ziehen. Die letzteren sind so schwach entwickelt, dass die Oberfläche des Gehäuses nahezu als glatt bezeichnet werden darf. Die Mündung ist länglich oval, der rechte Mundrand im Innern mit sechs starken Zähnen besetzt, nach aussen blättrig erweitert, mit wellenförmig schoppiger Oberfläche. Der Canal ist ziemlich lang, stark nach rückwärts gebogen und nahezu geschlossen. Das grössere von den beiden, uns vom Fundorte Lapugy vorliegenden Exemplare (von einem anderen Punkte wurde uns Murex perlongus in den österreichischungarischen Tertiärablagerungen bisnun nicht bekannt) misst $75 \mathrm{Mm}$. in der Höhe, $33 \mathrm{Mm}$. in der Breite. Die Uebereinstimmung mit der italienischen Form, welche nach den Angaben Bellardi's gleichfalls sehr selten ist, scheint uns so zweifellos, dass wir auf eine nähere Begründung unserer Gleichstellung. verzichten zu dürfen glauben.

\section{Murex (b Chicoreus) Aquitanicus Grat.}

Taf. XXV, Fig. 3 von Gainfahrn.

Murex Aquitanicus Grat. M. Hoernes: Foss. Moll. d. Tert.-Beck. v. Wien, I., pag. 219, Taf. XXII, Fig. 1, $2,3$. Murex Aquitanicus Grat. L. Bellardi: I Moll. d. terr. terz d. Piem. e d. Ligur., I., pag. 78.

Diese Form variirt ausserordentlich, wie dies sowohl von M. Hoernes als L. B ellardi hervorgehoben wird. Ersterer bringt (1. c. Taf. XXII, Fig. 1) ein ungewöhnlich grosses Exemplar von Grund zur Abbildung, welches sich durch bauchige Gestalt und relatir kurze Spira auszeichnet. Das zweite durch M. Hoernes zur Ansicht gebrachte Gehäuse von Vöslau (ebendaselbst, Fig. 2) ist weitaus schlanker - es 
stellt, wie M. Hoernes bemerkt, jene Mittelform dar, an welche er sich bei der Beschreibung gehalten hat. Wir bringen in Fig. 3 der Tafel XXV eines der schlankesten Exemplare zur Abbildung, um die grosse Variabilität zu zeigen, weìcher die allgemeinen Umrisse des Murex Aquitanicus unterworfen sind. Der Schilderung, welche M. Hoernes gegeben hat, haben wir nichts Wesentliches beizufügen, als dass die Variabilität der Sculptur nicht minder gross ist als jene der allgemeinen Gestalt. Die Varices sind bald gerundet, bald blättrig, die Querrippen mehr minder zahlreich und stark, und es scheint als ob in dieser Hinsicht die österreichischen Vorkommnisse ebenso mit den italienischen übereinstimmen, als hinsichtlich des veränderlichen Umrisses der Gehäuse. Bellardi bemerkt vom Murex Aquitanicus: Questa forma presenta non poche modificazioni di cui le più frequentì sono: forma generale più o meno raccorciata, angolo spirale più o meno acuto, coste trasversali più o meno grosse e numerose, varici ora frondose ora nodose. - Sehr nahe verwandt mit Murex Aquitanicus ist Murex Michelottii Bell. (I Moll d. terr. terz. d. Piem. e d. Ligur., I., pag. 80, Tav. VI, Fig. 6), von welcher Form er sich unterscheidet: 1. per la maggior lunghezza proporzionale della spira; 2. per la maggior acutezża dell' angolo spirale; 3. per la maggiore profondità delle suture; 4. per la maggior grossezza e regolarità delle coste trasversali; 5. per la maggior profondità dei solchi interposti; 6. e per la maggior lunghezza e grossezza delle fronde. B ellardi führt jedoch auch eine Varietät „senza fronde“ an - so dass es fraglich erscheint, ob man in Murex Michelottii nicht etwa nur eine besonders schlanke und durch besonders starke Sculptur ausgezeichnete Varietät des Murex Aquitanicus zu erkennen hätte. Wir vermögen jedoch die Selbstständigkeit des Murex Michelottii Bell. schon aus dem Grunde nicht zu bestreiten, weil uns von österreichischen Fundorten weder Gehäuse vorliegen, welche wir dem Murex Michelottii zurechnen könnten, noch solche, die Mittelformen zwischen Murex Aquitanicus und Murex Michelottii darstellen würden.

Nur ein junges, $29 \mathrm{Mm}$. hohes, $17 \mathrm{Mm}$. breites Gehäuse von Kostej zeigt einige Aehnlichkeit mit Murex Michelottii, bleibt jedoch in der Entwicklung der Varices und insbesondere in der Stärke und Regelmässigkeit der Quersculptur so weit hinter der italienischen Type zurück, dass wir es ohne Zweifel dem Murex Aquitanicus zuzurechnen haben.

M. Hoernes nennt als Fundorte des Murex Aquitanicus Grund, Baden, Vöslau, Gainfahrn, Enzesfeld und Forchtenau, mit der Bemerkung, dass diese Art namentlich in Grund häufig vorkomme, an den anderen Orten hingegen selten sei. Auch Lapugy hat zahlreiche wohlerhaltene Gehäuse geliefert. Als weitere neue Fundorte sind zu nennen: Niederkreuzstetten, Niederleis, Lissitz, Jerutek, Porzteich, Jaroměřic, Poels bei Wildon, Ritzing, Kostej und Bujtur, doch liegen uns von diesen Orten nur einzelne Gehäuse (meist nur unerwachsene Exemplare und Fragmente) vor. - Murex Aquitanicus findet sich am häufigsten in den Sandablagerungen von Grund, etwas weniger häufig und meist durch schlankere Gestalt und schärfere Ausprägung der Sculptur ausgezeichnet zu Lapugy und an den Fundorten des Badener Tegels; - an allen anderen Fundstellen gehört Murex Aquitanicus zu den Seltenheiten.

\section{Murex (c Chicoreus) granuliferus Grat.}

Murex granuliferus Grat. M. Ho ernes: Foss. Moll. d. Tert.-Beck. v. Wien, I., pag. 254, Taf. XXV, Fig. 19. Murex granuliferus Grat. L. Bellardi: I Moll. foss. d. terr. terz. d. Piem. e d. Ligur., pag. 79 (excl. Var. A)

Der Schilderung dieser Form durch MI. Hoernes haben wir nichts beizufügen, als dass die Unterscheidung derselben von Murex Borni M. Hoern. sehr schwierig ist, ja geradezu willkürlich vorgenommen werden muss, da beide Formen durch Uebergänge mit einander verknüpft sind. M. Hoernes führt als Unterschiede an, erstlich dass die Varices bei Murex granuliferus nie abgerundet sind, sondern blättrig vortreten, sodann dass der linke Mundrand oben constant erweitert sei und daselbst die Spindel bedecke, was bei Murex Borni nie der Fall wäre. Wir müssen jedoch entweder den einen oder den anderen dieser angeblichen Unterschiede verwerfen, wenn wir überhaupt Murex Borni von Murex granuliferus, sei es als besondere Art oder (wofür wir uns fast lieber entscheiden möchten) als blosse Varietät, trennen wollen. Denn es liegen uns von Lapugy ziemlich viele (neunzehn!) wohlerhaltene Gehäuse vor, welche hinsichtlich der Gestaltung der Varices sich als dem echten Murex granuliferus angehörig documentiren, während der linke Mundrand nur bei einem kleinen Theil dieser Gehäuse der Schilderung entspricht, bei der Mehrzahl aber der linke Mundrand ebenso gestaltet ist wie bei Murex Borni, d. h, oben nicht erweitert und nicht über die Spindel a.usgedehnt. Bei einigen Gehäusen ist der linke Mundrand oben etwas erweitert, so dass sie gewissermassen Zwischenglieder darstellen. Wir glauben auf das zuletzt erörterte Merkmal gar kein Gewicht legen zu sollen und meinen nur wegen des gänzlich versehiedenen Habitus, welchen Murex Borni in Folge der abgerundeten Varices trägt, diese Form provisorisch von Murex granuliferus trennen zu sollen. 
M. Hoernes nennt als Fundorte des Murex granuliferus Forchtenau und Steinabrunn (sehr selten), sowie Lapugy. Heute liegen uns in der Sammlung des k. k. Hof-Mineralien-Cabinetes je ein Gehäuse von Vöslau, Baden, Lomnitzka und Forchtenau, 5 von Steinabrunn und 19 von Lapugy vor. - Bezüglich der letzteren haben wir bereits hervorgehoben, dass sie in Betreff der Gestaltung des linken Mundrandes von der Schilderung des Murex granuliferus durch M. Hoernes theilweise abweichen. Einige Gehäuse, welche wir noch zu Murex granuliferus rechnen, zeigen die Varices weniger blättrig und weniger vorragend als die übrigen, sie bilden den Uebergang zu Murex Borni, welche Form unserer Ueberzeugung nach nur willkürlich von Murex granuliferus getrennt werden kaun.

\section{Murex (d Chicoreus) Borni M. Hoern.}

Murex Borni. M. Hoernes: Foss. Moll. d. Tert.-Beck. v. Wien, I., pag. 253, Taf. XXV, Fig. 18.

Murex granuliferus var. A. L. Bellard i: I Moll. d terr. terz. d. Piem. e d. Ligur., I., pag. 79, Taf. VI, Fig. 4.

Diese Form wäre vielleicht besser nur als Varietät des Murex granuliferus Grat. zu betrachten jedenfalls ist ihre Trennung von diesem künstlich und willkürlich. Wir wollen nur provisorisch Murex Borni und Murex granuliferus auf Grund der blättrig vortretenden Varices des letzteren (während jene des Murex Borni abgerundet sind) aus einander halten, deun obwohl beide im österreichisch-ungarischen Miocän gleichzeitig vorkommen, wäre es möglich, dass Murex Borni dem Murex granuliferus gegenüber eine ähuliche Stellung einnähme, wie etwa Chenopus alatus Eichw. gegenüber dem Chenopus pespelecani Phil. Wir verfügen jedoch nicht über hinreichendes Material, um diese Frage zu discutiren.

Bereits bei Besprechung des Murex granuliferus wurde hervorgehoben, dass wir blos das erste von M. Hoernes angeführte trennende Merkmal der Gestaltung der Varices („blättrig vortretend" bei Murex granuliferus, gerundet bei Murex Borni) gelten lassen können, obwohl auch in dieser Hinsicht Uebergänge vorliegen. Das zweite unterscheidende Merkmal hingegen, welches M. Hoernes bei Discussion des Murex granuliferus anführt: „Der linke Mundrand ist oben constant erweitert und bedeckt daselbst die Spindel (dies ist ein sehr charakteristisches, der früheren Art [Murex Borni] (gänzlich fehlendes Kennzeichen)" - müssen wir, wie oben dargelegt, angesichts der Exemplare des Murex granuliferus von Lapugy fallen lassen, welche das Gegentheil lehren. - Es liegen uns von Lapugy im Ganzen 26 Gehäuse vor, von welchen 7 in jeder Hinsicht mit der durch M. Hoernes gegebenen Diagnose seines Murex Borni übereinstimmen, während die 19 übrigen mehr oder minder vollständig die Merkmale des Murex granuliferus tragen oder Uebergangsglieder zu Murex Borni darstellen.

Von Murex Borni konnten wir im Ganzen 34 Exemplare untersuchen, nämlich: 16 von Gainfahrn und.Enzesfeld (beide Fundorte sind in der Sammlung des k. k. Hof-Mineralien-Cabinetes zusammengeworfen), 3 von Niederleis, je 2 von Forchtenau und Soos, je 1 von Vöslau, Steinabrunn, Tarnopol und Kostej, und endlich die bereits erwähnten 7 Gehäuse von Lapugy.

\section{Murex (e Chicoreus) Galicianus Hilb.}

Taf. XXIX, Fig. 11 und 12 von Holubica.

Murex Galicianus Hilb.: Neue und wenig bekannte Conchylien aus dem ostgalizischen Miocän. Abhandl. d. k. k. geolog. Reichsanst., Band VII, Heft VI, pag. 5, Taf. I, Fig. 7, 8.

Von Murex Galicianus, deren Schilderung durch V. Hilber wir unten mit dessen eigenen Worten reproduciren, sagt derselbe: „Diese Form hat grosse Aehnlichkeit mit Murex Pauli, ist aber leicht durch die verschiedene Sculptur der Schlusswindung zu unterscheiden. Die Details der Sculptur waren nur an dem kleineren der abgebildeten Exemplare gut wahrnehmbar." Es zeigt indess gerade das grössere dieser Gehäuse, welche wir beide abermals zur Anschauung bringen müssen, da die von Hilber gegebenen Abbildungen auf Taf. I seiner Abhandlung so unzureichend sind, dass wir nicht zu begreifen vermögen, wie sie überhaupt zum Abdruck gelangen konnten ${ }^{1}$ ), dass die in Rede stehende Form ein echter Murex, dem Subgenus Chicoreus angehörig ist, während Murex Pauli der Gattung Pollia zugerechnet werden muss. Weder die Hilber'sche

1) Taf. I und II der Hilb e r'schen Abhandlung sind nach des Autors eigener Bemerkung ndie ersten Versuche, welche ein sonst trefflicher Künstler im Conchylienzeichnen unternahm". Jedenfalls war keine zwingende Nothwendigkeit vorhanden, diese "ersten Versuche" auch zum Abdruck zu bringen.

Hoernes u. Auinger, Gasteropoden d. Meeres-Abl. d. 1. u. 2. Mediterranstufe. Heft 5. 
Beschreibung noch die Ahbildung lässt vermuthen, dass Murex Galicicinus wohlentwickelte Varices hesitzt, welche mit kräfti; ;en Längsknoten alterniren. Hilbel's Beschreibung lautet einfach: „Die Gestalt ist ziemlich schlank. Mit Ausnahme der an meinen drei Exemplaren abgestossenen Emhryonalwindungen sind sechs Umgänge vorhanden. Jeder Umgang fällt in dem oheren Theil schwach concav dachförmig ab und trägt in diesem Theile drei his vier Querreifen, welche mit ebensovielen schwächeren alterniren. Durch einen Kiel geschieden ist der untere, nach abwärts fallende Theil der Windungen, welcher auf den Mittelwindungen zwei mit schwächeren abwechselnde Querreifen trägt. Die Schlusswindung hat drei verschieden starke Sorten von Querreifen: acht Hauptreifen, in der Mitte der Zwischenräume ist je ein schwächerer und in den durch diese letzteren entstehenden $Z$ wischenräumen wieder je ein noch schwächerer. Die Mündung ist länglich, innen mit fünf his siehen Zähnen, links mit einem wenig übergeschlagenen Callus versehen, der Canal ziemlich kurz und nach rückwärts gehogen. - Vorkommen: Holuhica, Podhorze (Sand, II. Med. st.)."

Demgegenüher hahen wir fürs erste unter Berücksichtigung der ganz richtigen Bemerkung Hilber's: „Die Details der Sculptur waren nur an dem kleineren der ahgehildeten Exemplare gut wahrzunehmen“; hervorzuhehen, dass es überhaupt nicht absolut sicher ist, dass dieses Jugend-Exemplar, welches $13 \mathrm{Mm}$. hoch, $7 \mathrm{Mm}$. breit ist, wirklich derselhen Art angehört wie das gleichfalls unerwachsene, von Hilher in Fig. 7, von nns in Fig. 12 zur Anschauung gehrachte, welches $19 \mathrm{Mm}$. hoch, $10 \mathrm{Mm}$. hreit ist. Ueher das erstere, in Fig. 8 hei Hilher, in Fig. 11 auf unserer Taf. XXIX dargestellte Jugend-Exemplar können wir uns kein Urtheil erlauben - es ist schlechterdings unmöglich, alle unausgehildeten Schalen zu bestimmen - das zweite Exemplar zeigt aher eine bedenkliche Aehnlichkeit mit Murex granuliferus Michti. und Murex Borni M. Hoern.; zumal mit der letzteren Form (die ja übrigens, wie ohen erörtert, vielleicht hesser als blosse Varietät des Murex granuliferus zu betrachten wäre). Wir wären in peinlicher Verlegenheit, sollten wir die Unterschiede suchen, welche Murex Galicianus von Murex Borni trennen. Von letzterem liegt uns ein schlankes Gehäuse von. Tarnopol vor, $26.5 \mathrm{Mm}$. hoch, $13 \mathrm{Mm}$. breit, zu welchem Murcx Galicianus recht gut als jugendliches Gehäuse passen würde.

Nur der Mangel weiteren Materiales hindert uns an der Einziehung der Hilher'schen Art, welche nur vorläufig beibehalten werden darf, wahrscheinlich aber ihre Selhstständigkeit verlieren wird, sobald zahlreichere und besser erhaltene Gehäuse vorliegen werden.

\title{
VII. Section: Phyllonotus.
}

\section{Murex (a Phyllonotus) cristatus Brocc.}

\author{
Taf. XXVI, Fig. 1, 2, 3 von Lapugy.
}

Murex cristatus Brocc. M. Hoernes: Foss. Moll. d. Tert.-Beck. v. Wien, I, pag. 243, Taf. XXV, Fig. 6. Murex cristatus Bracc. L. Bellaxdi: I Moll. d. terr. terz. d. Piem. e d. Ligur., I., pag. 85.

Wir folgen Bellardi, indem wir diese Form bei Phyllonotus und nicht hei Muricidea unterhringen (wo sie übrigens fast mit demselben Rechte stehen könnte).

M. Hoernes nennt als Fundorte des Murex cristatus im Wiener Becken: Gainfahrn, Enzesfeld, Pfaffstätten, Pötzleinsdorf, Grund, Steinahrunn, Nikolsburg mit dem Beisatze „selten“. Wir hahen denselhen noch Forchtenau und Kostej hinzuzufügen, von wo uns ehenfalls nur einzelne Gehäuse vorliegen, während Murex cristatus in Lapugy zu den häufigeren Conchylien zu gehören scheint. An allen ührigen Fundorten aher ist diese Form nicht gerade häufig. - Am meisten Gehäuse liegen uns noch von Steinabrunn vor (17), sie gehören, so wie fast alle Exemplare des Murex cristutus aus dem Wiener Becken, zu der Varietät mit wenig entwickelten und stumpfen Knoten. In Lapugy, wo Murex cristatus ziemlich häufig ist (wir konnten in der Sammlung des k. k. Hof-Mineralien-Cahinetes 37 Exemplare untersuchen), sind die Dornen meist stark entwickelt - wir hahen aus diesem Grunde 3 Exemplare von Lapugy zur Ahhildung gehracht. Die Gehäuse sind zugleich viel grösser und kräftiger als diejenigen, welche M. Hoernes aus dem Wiener Becken schilderte. So misst das in Fig. 2 unserer Taf, XXVI zur Anschauung gebrachte Exemplar $39 \mathrm{Mm}$. in der Höhe, $28 \mathrm{Mm}$. in der Breite. Die im Wiener Becken auftretende Varietät des Murex cristatus verhält sich solchen Gehäusen gegenüher wie eine verkümmerte Zwergform. Diese Lapugyer Exemplare übertreffen auch die recenten mittelmeerischen Vorkommnisse des Murex cristatus an Grösse, Stärke der Schale und Stärke der Sculptur, es bleihen selbst jene Formen, welche Kohelt in seiner Iconographie der europäischen Meeresconchylien von der Halbinsel Magnisi hei Syrakus als „Riesen-Exemplare“ zur Abhildung hringt (1. c. Taf. V, Fig. 7 und 8), merklich hinter ihnen zurück. 


\section{Murex (b Phyllonotus) subasperrimus d'Orb.}

Murex asperimus. Grateloup: Atl. Conch. foss. du bass. de l'Adour, Tab. XXXI, Fig. 15 (non Lamk.).

Murex subasperrimus. d'O rbigny: Prodrôme de Paléontologie, Vol. III, pag. 73, Nr. 1340 (excl Syn. Murex asperrimus Michti.).

Murex trunculus. Bronn: Lethaea geognostica, 3. Auflage, Bd. III, Tab. XLI, Fig. 25 (non Linné).

Murex trunculus. M. Ho ernes: Foss. Moll. d. Tert.-Beck. v. Wien, I., pag. 671, Taf. LI, Fig. 4 (non Linné).

Murex subasperrimus d'Orb. Bellardi: I Moll. d. terr. terz. d. Piem. e d. Ligur., I., pag. 88, Tav. VI, Fig. 12.

Wir folgen in der Auffassung dieser Form der Darstellung Bellardi's, welche uns vollständig richtig erscheint. D'Orbigny vereinigte in seinem Prodrôme zwei verschiedene Formen unter dem Namen Murex subasperrimus: Murex asperrimus Grat. und Murex asperrimus Michti., welche beide von Murex asperrimus Lamk., aber auch von einander verschieden sind. Murex asperrimus Michti. ist ident mit jener Form, welche M. Hoernes irrig mit Murcx Sedgwicki Michti. identificirte, und wurde von d'Ancona, wie unten zu erörtern sein wird, mit Recht als selbstständige Form betrachtet und unter dem Namen Murex Hoernesi beschrieben. Die italienischen Vorkommnisse des Murcx subasperrimus d'Orb. wurden von Bronn, die österreichischen von M. Hoernes dem Murex trunculus $L$. zugerechnet. M. Hoernes hielt sie ferner auch für ident mit Murex conglobatus Michti. und erörterte ausführlich die Gründe, aus welchen er die Trennung des Murcx trunculus und des Murex conglobatus verwerfen müsse. Allerdings variirt der recente Murex trunculus des Mittelmeeres ungemein (man vergleiche $\mathrm{Kobelt:} \mathrm{Iconographie} \mathrm{der} \mathrm{schalentragenden} \mathrm{europäischen} \mathrm{Meeres-}$ conchylien, Taf. II, Fig. 1-4; Taf. III, Fig. 1-3; 'Taf. IV, Fig. 1), allein dessenungeachtet dürfte es kaum gelingen, unter den Varietäten des echten Murex trunculus eine Form zu finden, welche vollständig mit einer fossilen übereinstimmen würde, welche man mit Murex trunculus identificiren zu können glaubte, und welche nun als Murex subasperrimus, Murex Hoernesi, Murex conglobatus, Murex truncatulus, Murex Tapparonii etc. von Bellardi mit vollem Rechte aus einander gehalten werden. Wir verweisen diesbezüglich auf Bella rdi's Darstellung bei Discussion des Murex conglobatus Michti. (1. c. pag. 90), welche auch die Unterschiede zwischen den unstreitig nahe verwandten Formen Murex Sedgwicki Michti., Murex subasperrimus d'Orb., Murex Hoernesi d'Anc. und Murex conglobatus Michti. trefflich hervorhebt. B ellardi sagt von den vier genannten Formen: „sono non solo intimamente collegate fra loro, ma lo souo eziandio strettamente col Murex trunculus Linn. dei mari attuali, la cui forma tipica non fu finora, che io mi sappia, trovata nei nostri terreni. Evidentemente sono le forme mioceniche e plioceniche dalle quale derivò la specie vivente: tuttuvia si possono da questa tener separate: 1. per la loro forma molto più raccorciata e rigonfia; 2. per la brevità della spira; 3. per la minor profondità delle suture; 4. per la mancanza di quella specie de carena degli aufratti che caratteriza la forme vivente, carena dietro alla quale la superficie è nel Murex trunculus più o meno depressa". Wir pflichten Bellardi in dieser Darstellung ebenso bei als in der Hervorhebung der Merkmale, welche Murex subasperrimus von seinen nächsten Verwandten trennen: „spira alquanto elevata; varici posteriormente spinose; coste trasversali più grosse, ombellico largo e profondo".

M. Hoernes führt als Fundort der in Rede stehenden Form nur Grund an, wo sich zwei Exemplare derselben fanden. Beide zeichnen sich durch aussergewöhnlich bedeutende Dimensionen und bauchige Gestalt aus. Es liegen uns jedoch heute von Grund noch zwei unerwachsene Gehäuse vor, von welchen das eine, $57 \mathrm{Mm}$. hohe und ca. $40 \mathrm{Mm}$. breite (der letzte Umgang ist stark beschädigt) in Umriss und Sculptur ganz mit dem von Bellardi, l. c. Tav. VI, Fig. 12, zur Abbildung gebrachten Exemplare übereinstimmt.

Mit den Gehäusen von Grund stimmen einige aus dem Badener Tegel (je zwei von Soos und von Vöslau) vortrefflich überein.

Endlich glauben wir einige Fragmente, welche uns von Niederkreuzstetten vorliegen, mit ziemlicher Sicherheit auf Murex subasperrimus beziehen zu dürfen.

\section{Murex (c Phyllonotus) Hoernesi d'Anc.}

Murex asperrimus. Michelotti : Monografia del genere Murex, pag. 27, Tav. III, Fig. 4, 5 (non Lamk.). Murex subasperrimus. d'O rbigny: Prodrôme de Paléontologie, Vol. III, pag. 73, Nr. 1340 (pro parte).

Murex Sedgwicki. M. Hoernes: Foss. Moll. d. Tert.-Beck. v. Wien, I., pag. 220, Taf. XXIII, Fig. 2, 3 (non Michti.).

Murex Hoernesi. C. d'Ancona: Malacologia pliocenica italiana, pag. 30, Tav. V, Fig. 2.

Murex Hoernesi d'Anc. L. Bellar d i : I Moll. d. terr. terz. d. Piem. e d. Ligur., I., pag. 88.

Murex Hoernesi d'Anc. F. Fontannes: Mollusques plioc. de la vallée du Rhône et du Roussillon, I., pag. 6.

Diese Form ist zwar mit dem echten Murcx Sedgwicli nahe verwandt, sie besitzt jedoch Dornen auf den Varices, welche dem Murex Sedgwicki fehlen, und einen bedeutend längeren und stärkeren Canal. Vergleicht man die neuere Abbildung, welche Bellardi von Murex Sedgwicki gibt (Moll. d. terr. terz. d. Piem. e d. Ligur., Tav. VI, Fig. 11), so erscheint jede Verwechslung ausgeschlossen. 
M. Hoernes führt als Fundorte dieser Art Gainfahrn, Enzesfeld, Baden, Vöslau, Steinabrunn, Nikolsburg, Grund, Niederkreuzstetten, Forchtenau, Ritring und Szobb mit der Bemerkung „nicht sehr häufig" an. Wir haben diesen Fundorten noch Rudelsdorf, Porzteich, Bujtur und Lapugy anzureihen. An letzterwähntem (schon von M. Hoernes unter den "auswärtigen Fundpunkten" aufgezählten) Orte scheint Murex Hoerncsi ebenso wie in Gainfahrn etwas häufiger vorzukommen, an allen anderen Orten ist er selten. Das grösste uns vorliegende Exemplar (von Enzesfeld) ist $95 \mathrm{Mm}$. hoch, $68 \mathrm{Mm}$. breit. Nur die Gehäuse von Gainfahrn, Steinabrunn und Lapugy erreichen ähnliche Dimensionen, alle übrigen bleiben weit dahinter zurück.

\section{Murex (d Phyllonotus) rudis Bors.}

M. Ho ernes: Foss. Moll. d. Tert.-Beck. v. Wien, I., pag. 674, Taf. LI, Fig. 6.

L. Bellardi: I Moll. d. terr. terz. d. Piem. e d. Ligur., I., pag. 91, Tav. VlI, Fig. 1.

Der Schilderung dieser Form durch M. Hoernes haben wir nichts beizufügen, als Fundort derselben wurde seinerzeit Grund mit der Bemerkung "sehr selten" angegeben. Heute liegen unter der Bezeichnung Murex rudis in der Sammlung des Hof-Mineralien-Cabinetes fünf Gehäuse von Grund, je eines von Steinabrumn, Niederkreuzstetten, Poels bei Wildon und Kostej, sowie drei von Lapugy. Nur für den letztgenannten Fundort kann das Vorkommen des Murex rudis mit voller Sicherheit behauptet werden, denn die Gehäuse von Steinabrunn und Poels rühren von unerwachsenen Exemplaren her, während jene von Niederkreuzstetten und Kostej so stark abgerieben sind, dass eine sichere Bestimmung schlechterdings ausgeschlossen scheint. Wir können daher das Vorkommen des Murex rudis an den genannten Fundorten nur mit einiger Wahrscheinlichkeit behaupten.

\section{Murex (e Phyllonotus) austriacus nov. form.}

Murex Genei. M. Hoernes: Foss. Moll. d. Tert.-Beck. v. Wien, I., pag. 231, Taf. XXIV, Fig. 6, 7 (non Bell. et Michti.).

Diese Form unterscheidet sich, wie Bellardi bei Besprechung des echten Murex Genei (Moll. d. terr. terz. d. Piem. e d. Ligur., I., pag. 94) hervorhebt, wesentlich von dieser durch B ell a rdi und Mich el ot ti 1840 aufgestellten Type. Er sagt: „Le figure citate dell' opera del Hoernes non corispondono alla forma tipica: i fossili ivi rappresentati hanno la carena trasversale quasi obliterata, le varici meno sporgenti ed ottuse, alcune delle quali vi sono trasformate in coste nodose. Bisognerebbe esaminare molti individui con questi caratteri per riconoscere se debbano riferirsi a questa specie come varietà o meglio forse costituire una specie distinta." Die angeführten trennenden Merkmale lassen sich nun an allen uns heute in der Sammlung des Hof-Mineralien-Cabinetes vorliegenden Exemplaren (11 von Grund, 2 von Niederleis) beobachten. Allerdings variiren dieselben einigermassen in ihrem Umriss, sowie in ihrer Sculptur, doch ist der Kiel nie deutlicher ausgesprochen als an dem durch M. Hoernes in Fig. 7 zur Ansicht gebrachten Exemplare, im Gegentheile zeigen einige Gehäuse ihn noch weniger als das in Fig. 6 dargestellte, so dass eigentlich bei ihnen von dem Vorhandensein eines Kieles gar nicht die Rede sein kann. - Die Sculptur aber ist nie stärker entwickelt; als es an den beiden abgebildeten Gehäusen der Fall ist, während die Varices bei der italienischen Type stark entwickelt sind. Wir sind daher gezwungen, den zweiten von Bellardi angedeuteten Ausweg einzuschlagen, und die österreichischen, von M. Hoernes als Murex Genei aufgefassten Vorkommnisse als eigene Form zu trennen. In Ermanglung einer anderen, etwa zur Vergleichung heranzuziehenden Form erübrigt uns nur die Erörterung der Frage, ob die in Rede stehenden Gehäuse nicht etwa auf Murex curvicosta Grat. (Conchyliologie fossile du bassin de l'Adour, pl. XXX, Fig. 34) zurückzuführen wären. So ungenügend nun auch die von Gratelou gegebene Abbildung ist, so glauben wir doch, dass sie noch eher auf ein Gehäuse des echten Murex Genei Bell. et Michti. zurückzuführen wäre, als auf die österreichische Form, für welche wir nunmehr den Namen Murex austriacus vorschlagen. Die Schilderung derselben durch M. Hoernes ist so vollständig, dass wir auf dieselbe verweisen können, ohne irgendwelche Zusätze für nöthig zu halten.

\section{Murex (f Phyllonotus) striaeformis Michti.}

Murex striaeformis Michti. M. Hoernes: Foss. Moll. d. Tert.-Beck. v. Wien, I., pag. 235, Taf. XXIV, Fig. 13. Murex striaeformis Michti. L. Bellardi: I Moll. d. terr. terz. d. Piem. e d. Ligur., I., pag. 95.

Diese Form, bezüglich welcher wir auf die durch M. Hoernes gegebene Schilderung verweisen, ist eine der seltensten Conchylien der österreichischen Tertiärbildungen. M. H oernes citirt als Fundorte: Grund und 
Porstendorf bei Mährisch-Trübau mit der Bemerkung "sehr selten". Uns liegen heute vom erstgenannten Fundorte dreizehn Gehäuse vor, deren grösstes $40 \mathrm{Mm}$. hoch, $24 \mathrm{Mm}$. breit ist. Ein weiterer Fundort ist uns nicht bekannt geworden. In den italienischen Miocänablagerungen der Colli torinesi, zu Termo-fourà, Villa Forzano, Rio della Batteria, Baldissero soll Murex striaeformis nach Bellardi nicht selten sein.

\section{Murex (g Phyllonotus) Lassaignei Bast.}

M. Hoernes: Foss. Moll. đ. Tert-Beck. v. Wien, I, pag. 232, Taf. XXIV, Fig. 8.

C. d'A ncona: Malacologia pliocenica italiana, pag. 16, Tav. IlI, Fig. 6.

L. Bellardi: Moll. d. terr. terz. d. Piem. e d. Ligur., I., pag. 97.

F. Fontannes: Mollusques plioc. de la vallée du Rhône et du Roussillon, I., pag. 6, pl. I, Fig. 6, 8.

M. Hoernes gibt als Fundorte dieser interessanten Form Vöslau und Enzesfeld mit der Bemerkung "sehr selten“ an. - Heute liegen uns in der Sammlung des k. k. Hof-Mineralien-Cabinetes ausser dem durch M. Hoernes zur Abbildung gebrachten Gehäuse von Vöslau drei von Enzesfeld, eines von Kostej und vierzehn von Lapugy vor. An letzterwähntem Fundert scheint Murex Lassaignei daher nicht gerade zu den Seltenheiten zu gehören - die Lapugyer Exemplare erreichen auch grössere Dimensionen (das grösste misst $40 \mathrm{Mm}$. Höhe bei $23 \mathrm{Mm}$. Breite) als jene aus dem Wiener Becken (das bei M. Hoernes abgebildete ist $31 \mathrm{Mm}$. hoch, $20 \mathrm{Mm}$. breit) und aus dem italienischen Tertiär (für letztere gibt Bellardi $27 \mathrm{Mm}$. Höhe, $17 \mathrm{Mm}$. Breite an).

\section{Murex (h Phyllonotus) Vindobonensis MI. Hoern.}

Taf. XXV, Fig. 2 (Varietät) von Lapugy.

Murex Vindobonensis. M. Ho ernes: Foss. Moll. d. Tert.-Beck. v. Wien, I., pag. 252, Taf. XXV, Fig. 17, 20.

Wie die von M. Hoernes gegebene Beschreibung mit Recht hervorhebt, ist dies eine recht vielgestaltige Forn, deren Varices meist in spitzige, blättrige Falten gespalten sind, welche theils frei, dornartig abstehen, theils durch Kalklamellen verbunden, continuirliche Mundwülste darstellen.

Murex Vindobonensis findet sich (wir verweisen auf die schon durch M. Ho ernes namhaft gemachten Fundorte) im Wiener Becken verbreitet und an manchen Punkten recht häufig. So liegen uns von Grund derzeit 40 Exemplare vor, welche fast sämmtlich mit dem von M. Hoernes in Fig. 17 der Taf. XXV seines Werkes zur Abbildung gebrachten Gehäuse vom gleichen Fundorte gut in der Gestaltung der Varices übereinstimmen. Manche davon weisen auch noch bedeutend stärkere frei vortretende Varices auf. Die meisten, von anderen Fundorten des Wiener Beckens in der Sammlung des Hof-Mineralien-Cabinetes aufbewahrten Gehäuse des Murex Vindobonensis gleichen mehr dem von M. Hoernes, 1. c. Fig. 20, zur Anschauung gebrachten Gehäuse von Gainfahrn. Als ein Extrem in dieser Richtung bringen wir in Fig. 2 unserer Taf. XXV ein Gebäuse von Lapugy zur Abbildung, bei welchem die Varices noch bedeutend weniger Neigung zur Stachelentwicklung zeigen als die uns aus dem Wiener Becken vorliegenden Exemplare. Dieses Gehäuse ist $31 \mathrm{Mm}$. hoch, $20 \mathrm{Mm}$. breit. Es liegt uns noch ein zweites ähnliches Gehäuse vom gleichen Fundorte vor. Wir zogen es vor, diese Form vorläufig als Varietät bei Murex Vindobonensis zu belassen, obwohI sie sich so weit von den typischen Exemplaren derselben entfernt, dass uns die Aufstellung einer eigenen Art fast berechtigt schien. Dann würde es aber auch nothwendig werden, die Grunder Form mit ihren dornigen Varices von Murex Vindobonensis (als dessen Type wir das von M. Hoernes zur Abbildung gebrachte Gainfahrner Gehäuse betrachten möchten) abzutrennen, wogegen das allerdings vereinzelte Vorkommen von Uebergangsgestalten und nicht mit dornigen Varices ausgestatteten Gehäusen in den Sanden von Grund spricht. Wir haben es für vortheilhafter erachtet, diese Formen ungetrennt zu lassen, als die Zahl der fossilen Murices durch zwei neue Namen zu bereichern.

\section{Section: Vitularia.}

\section{Murex (a Vitularia) lingua-bovis Bast.}

Taf. XXV, Fig. 4 von Porstendorf, Fig. 5 von Grund, Fig. 6, 7 von Gainfahrn.

Murex lingua-bovis Bast. M. Ho ernes: Foss. Moll. d. Tert.-Beck. v. Wien, I., pag. 230, Taf. XXIV, Fig. 1, 2, 3.

Wie schon M. Hoernes bei Schilderung dieser Form hervorgehoben hat, ist dieselbe starken Variationen ausgesetzt. Es variirt der Gesammtumriss, die Stärke der Knoten, und es treten bald blättrige Varices auf, bald fehlen sie, endlich zeigt auch die Mündung mannigfache Verschiedenheiten, da die Zähne 
des rechten Mundrandos sehr verschieden entwickelt sind, ja selbst ganz zurücktreten. Wir haben, um alle diese Variationen ersichtlich zu machen, eine Anzahl von Exemplaren zur Abbildung gebracht. Diese Gehäuse zeigen solche Verschiedenheiten in den oben aufgezählten Eigenschaften, dass man sie kaum einer und derselben Art zurechnen möchte, wäre nicht die ausgezeichnete feine, warzige Sculptur vorhanden, wodurch die Schalenoberfläche das Aussehen einer Rindszunge erhält, welches den durch Basterot bezeichnend gewählten Namen vollkommen gereshtfertigt erscheinen lässt.

Das in Fig. 4 zur Anschauung gebrachte, $21 \mathrm{Mm}$. hohe, $13.7 \mathrm{Mm}$. breite Jugend-Exemplar von. Porstendorf ist stark gekielt und es fällt der obere Theil der Umgänge nahezu in eine und dieselbe Fläche. Aehnlich gestaltet ist das extreme grosse in Fig. 5 dargestellte Gehäuse von Grund, welches ca. 85 Mm. hoch, $54 \mathrm{Mm}$. breit ist. Dieses Grehäuse ist birnförmig, mit wenig abgesetzten Umgängen, sehr kräftigen Knoten und sehr weiter Mündung - blättrig vorragende Varices fehlen ihm gänzlich. In schroffem Gegensatz zu diesem Grunder Gehäuse steht das in Fig. 6 zur Ansicht gebrachte Exemplar von Gainfahrn, welches, $49 \mathrm{Mm}$. hoch, $28 \mathrm{Mm}$. breit, durch gethürmte Gestalt, treppenförmig abgesetzte Windungen und blättrig vorragende, kräftige Varices ausgezeichnet ist. Man würde beim Anblick blos der in Fig. 5 und 6 dargestellten Gehäuse wohl kaum geneigt sein, beide einer und derselbẹn Form zuzurechnen; doch liegen uns von Gainfahrn 12 Gehäuse vor, welche alle Uebergänge einschliessen. Eines derselben bringt Fig. 7 zur Ansicht; - es ist $46 \mathrm{Mm}$. hoch, $33 \mathrm{Mm}$. breit und erinnert sehr an das grosse Gehäuse von Grund durch die gedrungenere Form und die kräftig entwickelten Knoten, doch ist ein Varix im letzten Drittel der Schlusswindung genau so wie bei dem in Fig. 6 dargestellten Exemplare entwickelt.

M. Hoernes nennt als Fundorte des Murex lingua-bovis: Grund, Gainfahrn, Vöslau und Steinabrunn mit der Bernerkung "selten". Heute liegen uns 6 Gehäuse von Grund, 12 von Gainfahrn, 1 von Steinabrunn, 1 von Vöslau, 2 von Soos, 1 von Forchtenau, 2 von Bujtur und 10 von Lapugy vor.

\title{
IX. Section: Trophon.
}

\section{Murex (a Trophon) ruditzensis nov. form.}

\author{
Taf. XXIV, Fig. 17 von Ruditz.
}

Von dieser interessanten Form liegen uns nur zwei nicht gerade zum besten erhaltene Gehäuse vor, von welchen wir das besser erhaltene zum Gegenstand einer Abbildung und Beschreibung machen, weil die unstreitig neue Form, der es angehört, in die Gruppe des Murex (Trophon) citimus Bell. und Murex (Trophan) carcarensis Bell. gehört (namentlich dem letzteren gleicht die in Rede stehende Form sehr), einer Gruppe, welche ein Bindeglied zwischen den eigentlichen Murices und Trophon darstellt und deshalb viel Interesse erregt.

Murex ruditzensis besitzt ein gedrungenes, bauchiges Gehäuse, von welchem uns nur drei convexe, durch eine tiefe Naht getrennte Umgänge erhalten sind. Auf dem unteren Theil der Mittelwindungen befindet sich ein mässig vortretender Kiel, über welchem eine schräge, mit Querstreifen bedeckte Fläche liegt, der schmale untere Theil des Umganges hingegen fällt fast senkrecht zur Naht ab. Die Umgänge tragen je sieben bis acht scharf vortretende Varices - ausserdem wird die Oberfläche von unregelmässigen Querstreifen bedeckt. Die Mündung ist weit, oval, nahezu kreisförmig, der rechte Mundrand an beiden Gehäusen abgebrochen, innen wahrscheinlich glatt. Der kurze Canal ist offen, an seiner linken Seite befindet sich ein weiter Nabel.

Das abgebildete Gehäuse dürfte etwa $20 \mathrm{Mm}$. hoch, $13.5 \mathrm{Mm}$. breit gewesen sein, ausser demselben liegt uns, wie bereits bemerkt, nur ein noch mehr beschädigtes vom selben Fundorte (Ruditz in Mähren) vor.

Murex ruditzensis hat unter allen uns bekannten Formen noch mit Murex carcarensis Bell. (Bell ar di: I Moll. d. terr. terz. d. Piem. e d. Ligur., I., pag. 102, Tav. VII, Fig. 10) die grösste Aehnlichkeit, ist jedoch bedeutend gedrungener und bauchiger, so dass an eine Identität mit der italienischen Type nicht wohl gedacht werden kann.

\section{Murex (b Trophon) Haidingeri M. Hoern.}

Taf. XXIX, Fig. 9 von Grund.

M. Hoernes: Foss. Moll. d. Tert.-Beck. v. Wien, I., pag. 228, Taf. XXIII, Fig. 12.

Von dieser ausgezeichneten und überaus seltenen Form kannte M. Hoern es bei Aufstellung derselbeu nur ein einziges Gehäuse aus den Sandablagerungen von Grund. Uns liegt heute ein zweites, etwas kleineres vor (dasselbe ist $36 \mathrm{Mm}$. hoch, $21 \mathrm{Mm}$. breit), welches vom selben Fundorte stammt und in allen wesentlichen 
Eigenthümlichkeiten mit dem durch M. Hoernes geschilderten übereinstimmt, nur dass die Basis besser erhalten ist und uns das Vorhandensein eines geschlossenen Canales zu constatiren gestattet. Bei genauerer Betrachtung des durch $\mathbf{M}$. Hoernes zur Abbildung gebrachten Gehäuses erkennt man, dass an demselben der Verschluss des Canales weggebrochen ist, so dass auch in dieser Hinsicht die beiden, bis nun einzigen Exemplare, welche von dieser Form bekannt wurden, übereinstimmen.

\section{MLurex (c Trophon) goniostomus Partsch.}

Murex goniostomus Partsch. M. Hoernes: Foss. Moll. d. Tert.-Beck. v. Wien, I., pag. 227, Taf. XXIII, Fig. 11.

Der Discussion, welche diese Form durch M. Ho e rnes gefunden hat, haben wir nichts Wesentliches beizufügen als dass Murex citimus Bellardi (I Moll. d. terr. terz. d. Piem. e d. Ligur., I., pag. 101, Tav. VII, Fig. 9) eine überaus nahe verwandte Type darstellt. Zur Hervorhebung der Unterschiede bedienen wir uns wohl am besten der eigenen Worte Bellardi's, der nach Beschreibung seiner Murcx citimus bemerkt: "I fossili qui descritti hanno una forma molto affine a quella del Murex goniostomus Partsch figurato dal Hoernes: sembrami per altro che ne debbano essere distinti: 1. per la loro forma più breve e più rigonfia; 2. per l'angolo spirale meno acuto; 3. per l'angolo posteriore degli anfratti più ottuse e più ravvicinnato alla sutura posteriore; 4. per le varici che all' incontro dell' angolo trasversale si protraggono in una specie di brevissima spina; 5 . per la coda molto più breve, più ripiegata verso il dorso e più obliquata a sinistra; 6. finalmente per l'ombellico che vi è bene distinto, abbenchè poco profondo." - Obwohl wir nun im Allgemeinen diese Unterschiede als richtig zugestehen müssen, haben wir doch hervorzuheben, dass die uns vorliegenden Gehäuse des Murex goniostomus eine nicht unbeträchtlicbe Variabilität aufweisen, sowohl was den Umriss als was die Verzierung der Gehäuse anlangt.

Manche Gehäuse sind noch beträchtlich schlanker als die durch M. Hoernes zur Abbildung gebrachten, so z. B. eines von Kalladorf, welches $33 \mathrm{Mm}$. Höhe, $16 \mathrm{Mm}$. Breite misst und sich durch einen abnorm langen Canal auszeichnet, andere hingegen sind gedrungen, bauchig, und weisen einen sehr kurzen Canal auf, wie ein Gehäuse von Lapugy, welches $26 \mathrm{Mm}$. hoch, $18 \mathrm{Mm}$. breit ist. Die Varices sind meist in Gestalt stark vorragender Blätter entwickelt und tragen einen starken Stachel an jener Stelle, wo sie den Kiel übersetzen, bald sind sie schwächer und der erwähnte Stachel bleibt rudimentär. Endlich ist der falsche Nabel zuweilen viel deutlicher und tiefer als an den durch M. Hoernes zur Abbildung gebrachten Exemplaren, zuweilen aber auch noch weniger entwickelt. - Es muss jedoch hervorgehoben werden, dass unter allen uns vorliegenden Exemplaren (45 von den verschiedenen Fundorten des Badener Tegels, 3 von Steinabrunn, 2 von Niederleis, 1 von Porzteich, 1 von Kalladorf, 1 von Kostej und 8 von Lapugy) kein einziges die gedrungene Gestalt und die Schwäche der Verzierung erreicht, welche Murex citimus Bell. auszeichnen. Auch der Nabel ist bei keinem Exemplare des Murex goniostomus so tief als bei der durch Bellardi beschriebenen Form.

M. Hoernes bemerkt, dass es nicht unmöglich wäre, dass die durch Grateloup als Murex calcitrapoides abgebildete Form (Atlas conch. foss., Taf. XXXI, Fig. 16, 20) zu Murex goniostomus gehöre. Bellardi glaubt Fig. 16 Grateloup's auf seinen Murex citimus beziehen zu sollen. - Bei der Ungenauigkeit der betreffenden Abbildung ist die Frage schlechterdings undiscutirbar.

\section{Murex (d Trophon) varicosissimus Bonelli.}

Murex varicosissimus Bon. M. Hoernes: Foss. Moll. d. Tert.-Beck. v. Wien, I., pag. 225, Taf. XXIII, Fig. 9. Murex varicosissimus Bon. L. Bellar di: I Moll. d. terr. terz. d. Piem. e d. Ligur., I., pag. 104.

Diese Form, bezüglich welcher wir der Schilderung durch M. Hoernes nichts Wesentliches beizufügen haben, kommt sowohl im italienischen als auch im österreichisch-ungarischen Miocän ziemlich selten vor. M. Ho ernes nennt als Fundorte: Baden, Enzesfeld, Steinabrunn mit dem Beisatz "sehr selten“. Heute liegen uns in der Sammlung des Hof-Mineralien-Cabinetes 4 Exemplare von Baden, 1 von Vöslau, 8 von Soos, 3 von Steinabrunn, 1 von Ruditz, 1 von Holubica und 2 von Kostej vor. Gesammtgestalt und Ornamentik zeigen die bei Trophon gewöhnlichen Variationen. Die blättrigen Mundwülste sind auf dem Kiele nicht selten in stärkere, faltige Zacken ausgezogen, als es die durch M. Hoernes gegebene Abbildung andeutet. 


\section{Murex (e Trophon) vaginatus Jan.}

Taf. XXV, Fig. 1 von Steinabrunn.

Murcx vaginatus Jan. M. Hoernes: Foss. Moll. d. Tert.-Beck. v. Wien, I, pag. 229, Taf. XXIII, Fig. 13. Murea vaginatus Jan. C. d'An cona: Malac. plioc. italian., pag. 46, Tav. III, Fig. 8. Murex vaginatus Jan. Bellar di: I Moll. d. terr. terz. d. Piem. e d. Ligur., p. 105.

Diese zierliche Form ist nicht unbedeutenden Variationen unterworfen, zumal was die Zahl und die Gestaltung der Varices anlangt. Wir bringen ein extrem entwickeltes Exemplar von Steinabrunn in Fig. 1 der Taf. XXV zur Ansicht, um die durch M. Hoernes gegebene Abbildung zu ergänzen. Dieses Gehäuse ist $27.5 \mathrm{Mm}$. hoch, $10 \mathrm{Mm}$. breit.

Als Fundorte nennt M. Hoernes: Baden, Vöslau, Möllersdorf, Steinabrunn und bemerkt: ${ }_{n}$ Im Wiener Becken ist diese Species nicht selten und kommt namentlich im Tegel von Baden ziemlich häufig vor. An den übrigen Localitäten ist dieselbe mehr oder weniger eine Seltenheit, so z. B. ist bis jetzt nur ein einziges Exemplar aus den Ablagerungen bei Steinabrunn bekannt, welches sich in der Sammlung des Herrn Poppelack in Feldsberg befindet." Uns liegen heute 87 Exemplare aus dem Badener Tegel, 9 von Steinabrunn, 19 von Porzteich, 2 von Ruditz, 2 von Grussbach und 1 von Forchtenau vor. Wenn darunter auch manche das durch M. Hoernes zur Abbildung gebrachte $21 \mathrm{Mm}$. hohe, $11 \mathrm{Mm}$. breite Gehäuse überragen, so bleiben sie doch merklich hinter den italienischen zurück, welche nach Bellardi $35 \mathrm{Mm}$. Höhe und $15 \mathrm{Mm}$. Breite erreichen.

\section{Murex (f Trophon) capito Phil.}

M. Hoernes: Foss. Moll. d. Tert.-Beck. v. Wien, I., pag. 226, Taf. XXIII, Fig. 10.

Der Discussion dieser Form durch M. Hoernes haben wir schon aus dem Grunde nichts beizufügen, weil das Materiale seither keine Vermehrung erfahren hat, und uns auch heute nur die beiden fragmentären Exemplare (eines von Gauderndorf und eines von Loibersdorf) vorliegen, welche M. Hoernes auf Murex capito Phil. zurückgeführt hat. Wir heben hervor, dass die Fig. 10 der Taf. XXIII der „Fossilen Mollusken" hinsichtlich der Basis eine Ergänzung nach dem zweiten Exemplare darstellt, welches jedoch auch hier so weit beschädigt ist, dass die Abbildung keineswegs Anspruch auf unbedingte Richtigkeit machen darf. - Es wäre zu wünschen, dass besseres Materiale die Frage, ob in Gauderndorf und Loibersdorf der echte Murex capito Phil. vorkommt, von neuem zu erörtern gestatten würde.

\section{Section: Occenebra.}

\section{Murex (a Occenebra) sublavatus Bast.}

Taf. XXVI, Fig. 4 Type, Fig. 5 Uebergang zur Varietät Grundensis, Fig. 6 Varietas Grundensis - sämmtlich von Grund.

Murex sublavatus. Basterot: Mém. géol. sur les environs de Bordeaux, pag. 59, Tab. III, Fig. 23.

Murex sublavatus Bast. Grateloup: Conch. foss. du bassin de l'Adour, Taf. XXX. Fig. 11.

Fusus polygonus. Grateloup: Conch. foss. du bassin de l'Adour, Taf. XXIV, Fig. 31.

Murex sublavatus. Hoernes: Foss. Moll. d. Tert.-Beck. v. Wien, I, pag. 236 (pro parte), Taf. XXIV, Fig. 14 (cet. excl.).

Diese Form fassen wir wesentlich enger als M. Hoernes, indem wir zunächst Murex caelatus Grat. abtrennen, obwohl dieser, wie noch zu erörtern sein wird, durch Uebergänge mit Murex sublavatus innig verbunden ist. Das von M. Hoernes l. c. Fig. 15 zur Abbildung gebrachte Gehäuse z. B. glauben wir besser dem Murex cuelatus zurechnen zu sollen. - Ferner unterscheiden wir Murex crassilabiatus Hilb., welchem das von M. Hoernes in Fig. 16 zur Anschauung gebrachte Gehäuse zuzurechnen sein wird, acceptiren weiters auch noch Mayer's Murex Dertonensis, obwohl er ebenfalls durch Uebergänge mit Murex caelatus verknüpft ist, und trennen schliesslich noch eine besonders kräftige und stark sculptirte Form unter dem Namen Murex Credneri ab. Dieser Vorgang ist ein ganz willkürlicher, denn nach der älteren Auffassung könnte man mit vollem Rechte alle angeführten, durch Uebergänge verknüpften Formen unter einem einzigen Namen belassen - andererseits aber auch, wenn man blos auf die Verschiedenheit der Gestait Rücksicht nimnit, die als Murex sublavatus var. Grundensis und die als Murex caelatus var. Badensis angeführten Formen mit eben demselben Recht als selbstständige Arten betrachten wie Murex Dertonensis und Murex crassilabiatus. - Uns 
scheint es zu genügen, wenn wir bei Murex eaelatus und Murex sublavatus je eine Varietät aufstellen, welche den Uebergang zu Murex Dertonensis einer-, zu Murex crassilabiatus andererseits vermittelt.

Auf MUrex sublavatus Bast. beziehen wir kräftige, ziemlich bauchige Gehäuse mit mehr oder minder deutlich hervortretendem Kiel, kräftiger Längsrippung, über welche deutliche, alternirend stärker und schwächer ausgeprägte Querreifen zichen. Die Längsrippen sind auf dem oberen, durch den Kiel geschiedenen Theile der Windungen nicht entwickelt, desto stärker markiren sie sich auf dem Kiele selbst. Die Mündung. ist weit, der rechte Mundrand scharf, innen nit verdickten Streifen geziert, die selten Anlage zur Zahnbildung verrathen. - Der kurze Canal ist gekrümmt, offen, an der Spindelseite befindet sich die schwache Andeutung eines Nabels. - Diese Form ist in den sarmatischen Schichten selur verbreitet - sie weist daselbst auch mehrere Variationen auf, deren Erörterung das Ziel, welches dem vorliegenden Werke gesteckt ist, überschreiten würde. Auch in den marinen Schichten ist sie verbreitet - es liegen uns 18 Exemplare von Niederkreuzstetten, 14 von Grund, 23 von Kienberg, 10 von Raussnit», 14 von Grussbach, 6 von Enzesfeld, 4 von Rudols. dorf, 4 ron Weinsteig, 4 von Lapugy, 2 von Vöslau und 1 Exemplar von Pöls vor.

Das in Fig. 4 dargestellte Gehäuse misst $29 \% \mathrm{Mm}$. in der Höhe, $11 \mathrm{Mm}$. in der Breite. Neben derartigen typischen Gehäusen kommen in den Sandablagerungen von Grund auch solche vor, welche einen Uebergang zur var. Grundensis bilden; dies gilt z. B. von dem in Fig. 5 abgebildeten Gehäuse, welches 21 Mm. hoch, $12 \mathrm{Mm}$. breit ist.

Als Varietas Grundensis betrachten wir jene Formen, welche durch dicke Schale, bauchige Gestalt, Zurücktreten des Kieles und schwächere Entwicklung der Längsrippen an Murex crassilabiatus Hilb. gemahnen, ohne dessen bezeichnende Eigenschaften vollständig zu erreichen. Der rechte Mundrand ist bei dieser Varietät ziemlich verdickt, er zeigt auf der Innenseite in Zähne übergehende Streifen, kurz in jeder Hinsicht stellt diese Varietät den Uebergang zu Murex erassilabiatus her. Ausser dem in Fig. 6 dargestellten, $31 \mathrm{Mm}$. hohen, $19 \mathrm{Mm}$. breiten Gehäuse bewahrt die Sammlung des k. k. Hof-Mineralien-Cabinetes noch 12 vollständig übereinstimmende Exemplare aus den Sandablagerungen von Grund.

\section{Murex (b Occenebra) caelatus Grat.}

Taf. XXVI, Fig. 7 bis 12 von Steinabrunn, Fnzesfeld und Gainfahrn, Fig. 9, 11, 12 stellen Bindeglieder zu Murex sublavatus var. Grundensis dar.

- Fusus lavatus. Basterot: Mém. géol. sur les environs de Bordeaux, pag. 62, Taf. III, Fig. 21 (non Brand).

Fusus excisus var. Grateloup: Conch. foss. du bassin de l'Adour, Taf. XXIV, Fig. 25.

Fusus caelatus var, Grateloup: Conch. foss. du bassin de l'Adour, Taf. XXIV, Fig. 26.

Fusus lavatus Bast. Gratelou p: Conch. foss. du bassin de l'Adour, Taf. XXIV, Fig. 27.

Murex sublavatus. Hoernes: Foss. Moll. d. Tert.-Beck. v. Wien, I., pag. 236 (pro parte), Taf. XXIV, Fig. 15 (cet. excl.)

Murex caelatus Grat. L. Bellardi: I Moll. d. terr. terz. d. Piem. e d. Ligur., I., pag. 114, Tav. VII, Fig. 16 bis 17.

In der Auffassung diescr Form folgen wir Bellardi und werden hiebei unterstützt durch die Resultate einer Vergleichung der Wiener Exemplare, welche wir dem Murex eaelatus zurechnen, und jener Gehäuse, welche unter der Bezeichnung "Murex lavatus" von französischen Fundorten (St. Jean de Marsac, St. Avit und Leognan) in der Sammlung des k. k. Hof-Mineralien-Cabinetes liegen.

M. Ho ernes hatte diese Formen dem Murex sublavatus Bast. zugerechnet, mit welchem sie auch, wie nicht geleugnet werden kann, durch Uebergänge innig verknüpft sind. Es unterscheiden sich jedoch die dem Murex ealatus zuzurechnenden Gehäuse von jenen des Murex sublavatus durch geringere Dimensionen, spitzeren Gewindewinkel, gewölbtere Umgänge, wenig oder gar nicht vortretenden Kiel, längeren und in der Regel geschlossenen, nach rückwärts gedrehten Canal.

Bezüglich der von uns zur Abbildung gebrachten Gehäuse des Murex caelatus sei zunächst bemerkt, dass eine nähere Fundortsangabe derselben nicht möglich ist, da leider die von den drei Fundorten: Steinabrunn, Enzesfeld und Gainfahrn herrührenden Gehäuse in der Sammlung des k. k. Hof-Mineralien-Cabinetes vereinigt aufbewahrt werden. Die in Fig. 9, 11 und 12 dargestellten Gehäuse können als Uebergänge zu Varietas Grundensis des Murex sublavatus aufgefasst werden, keines derselben erreicht freilich die Dimensionen und die kräftige Schalenbildung des Murex sublavatus. Am nächsten kommt der Grunder Varietät des Murex sul. lavatus noch das in Fig. 12 dargestellte Gehäuse, welches nur $23 \mathrm{Mm}$. hoch, $13.5 \mathrm{Mm}$. breit ist. - Die in Fig. 7 und 10 dargestelltelı Gehäuse hingegen ähneln der. unten z1l schildernden Varietas Badensis des Murex eaelatus. Dies gilt insbesondere von dem schlanken, in Fig. 7 zur Ansicht gebrachten Exemplare, welches $21 \mathrm{Mm}$. hoch, $10 \mathrm{Mm}$. breit ist und sich nur durch den kürzeren Canal von jenen unterscheidet, welche wir der Varietas Badensis zurechnen (vergl. insbesondere das in Fig. 13 dargestellte Exemplar). 
Murex caelatus kommt in Gainfahrn, Steinabrunn, Enzesfeld, Nikolsburg und Raussnitz ziemlieh häufig vor, die Fundorte Pötzleinsdorf, Grund, Niederleis, Grussbaeh, Bujtur und Lapugy sind hingegen nur dureh einzelne Gehäuse in der Sammlung des k. k. Hof-Mineralien-Cabinetes repräsentirt.

Als var. Badensis betraehten wir jene Gehäuse, welehe durch sehlankere Gestalt, verlängerte Mündung und längeren Canal ausgezeiehnet sind. Wir reehnen hieher jenes Gehäuse von Vöslau, welehes M. Ho e rne s in F'ig. 15 der Taf. XXIV zur Ansieht gebraeht hat, wenn dasselbe aueh die Merkmale der Varietät nieht so ausgeprägt zeigt als die von uns in Fig. 13 und 14 zur Abbildung gebraehten Exemplare. Das in Fig. 13 dargestellte Gehäuse ist $21 \mathrm{Mm}$. hoeh, $10 \mathrm{Mm}$. breit; - es wurde bereits oben bemerkt, dass Uebergänge von den typisehen Exemplaren des Murex caelatus zu dieser Varietät vorliegen. Die in Fig. 7 und 13 abgebildeten Exemplare gleiehen sieh im Umriss und in der Seulptur ungemein, nur besitzt das letztere eine etwas längere Mündung und längeren Canal.

Die Varietas Badensis des Murex caelatus bildet gewissermassen einen Uebergang zu Murex Dertonensis Mayer, - oder deutet vielmehr denselben an, denn weitere Bindeglieder zwisehen den in Fig. 13 und 14 dargestellten Gehäusen von Soos und Murex Dertonensis (welehem wir das in Fig. 15 dargestellte Gehäuse von Lapugy zureehnen zu dürfen glauben) sind uns bis jetzt nieht bekannt geworden.

Wir untersuehten 2 Gehäuse von Soos, 12 von Vöslau und 1 von Kostej, welehe wir der var. Badensis des Murex caelatus zureehnen wollen. Dieselbe kommt aueh in den italienisehen Tertiärbildungen vor, wenigstens gehört die von Bellardi a. o. eit. Orte, Tav. VII, Fig. 16, 17 abgebildete Form entsehieden hieher.

\title{
41. Murex (c Occenebra) Dertonensis May.
}

\author{
Taf. XXVI, Fig. 15 von Lapugy.
}

Murex Dertonensis May. L. Bellardi: I Moll. d. terr. terz. d. Piem. e d. Ligur., I., pag. 107, Tav. VII, Fig. 12.

Diese Form, welehe viel Aehnliehkeit mit der oben erörterten Varietät: Badensis des Murex caelatus aufweist, besitzt ein sehlankes, spindelförmiges Gehäuse, dessen spitzes Gewinde von 5 bis 6 Umgängen gebildet wird. Die Mittelwindungen tragen auf der unteren Hälfte einen deutliehen Kiel - der über demselben gelegene breitere Theil des Umganges ist sehwaeh eoneav, der sehmälere untere Theil eonvex. Das ganze Gehäuse ist mit kräftigen Längsrippen und alternirend stärkeren und sehwäeheren Querstreifen geziert. Die Mündung ist lang-oval, der reehte Mundrand seharf, innen gestreift. Der Canal ist lang, bei allen uns -vorliegenden Gehäusen mit Ausnahme zweier, aus den Sandablagerungen von Grund stammenden, offen. Auf der linken Seite des Canales befindet sieh ein mehr oder minder tiefer, in die Länge gezogener Nabel. Die Höhe sehwankt zwisehen 20 bis $27 \mathrm{Mm}$., die Breite zwisehen 11 und $13 \mathrm{Mm}$. (Das in Fig. 15 dargestellte Gehäuse von Lapugy ist $27 \mathrm{Mm}$. lang, $13 \mathrm{Mm}$. breit.)

Murex Dertonensis ist in den österreiehiseh-ungarisehen Mioeänablagerungen ziemlieh verbreitet, jedoch nirgends häufig. In der Sammlung des k. k. Hof-Mineralien-Cabinetes liegen uns je 1 Gehäuse von den Fundorten Grinzing, Lissitz und Pöls, 2 von Niederleis, 3 von Hölles, 4 von Nikolsburg, je 7 von Grund und Ruekersdorf, je 8 von Pötzleinsdorf und Kienberg, 9 von Hidas, 10 von Steinabrunn, und je 11 von Porstendorf und Lapugy vor.

Von auswärtigen Fundorten besitzt das Hof-Mineralien-Cabinet ein Gehäuse von Messina, welehes mit den österreiehisehen Exemplaren ebensogut übereinstimmt als die eitirte dureh B ellard i gegebene Abbildung.

Murex Dertonensis besitzt, wie bereits erwähnt, viel Aehnliehkeit mit der var. Badensis des Murex caelatus; ist jedoeh schlanker als dieser und unterseheidet sieh ausserdem dureh längeren, in der Regel offenen Canal, kräftigere Seulptur und gekielte Windungen.

\section{Murex (d Occenebra) Credneri nov. form.}

$$
\text { Taf. XXVI, Fig. 16, } 17 \text { von Lapugy. }
$$

Diese interessante Form, die kräftigste und stärkst seulptirte in der ganzen Formengruppe des Murex sublavatus, besitzt ein ei-spindelförmiges Gehäuse, dessen spitzes Gewinde (abgesehen von den an allen uns vorliegenden Exemplaren abgebroehenen Embryonalwindungen) aus 5 bis 6 eonvexen Umgängen besteht.

Die Mittelwindungen tragen auf der unteren Hälfte einen deutliehen Kiel - ihr oberer, breiterer Theil ist etwas coneav. Kräftige Längsrippen bedeeken das Gehäuse; sie werden von starken, mit feineren Linien alternirenden Querstreifen übersetzt und nehmen hiedurch knotigen Habitus an. Insbesondere auf dem 
Kiel treten starke stumpfe Knoten auf. Die Schlusswindung ist ziemlich stark aufgeblasen, die Mündung oval, der rechte Mundrand scharf, aussen verdickt, innen gestreift. Der kurze Canal ist geschlossen, an seiner linken Seite befindet sich ein weiter und tiefer Nabel. Die Höhe schwankt zwischen 26 und 35 Mm., die Breite zwischen 14 und $19 \mathrm{Mm}$. (das in Fig. 16 abgebildete Grchäuse ist $33 \mathrm{Mm}$. hoch, $18.5 \mathrm{Mm}$. breit - jenes in Fig. 17 dargestellte $27 \mathrm{Mm}$. hoch, 17.5 Mm. breit).

Murex Credneri ist von allen Formen, welche der Gruppe des Murex sublavatus angehören, durch kräftigen Bau und starke Sculptur so verschieden, dass wir uns veranlasst sahen, die besprochene Form mit einem eigenen Namen auszuzeichnen, obwohl uns nur ein beschränktes Materiale von derselben vorlag (8 Exemplare vom Fundorte Lapugy).

Der Vorgang, welchen wir bei der Trennung des Murex sublavatus (im Sinne von M. Hoernes) in Murex sublavatus, Murex eaclatus; Murex Dertonensis und Murex Credneri eingeschlagen haben, mag hier mit einigen Worten gerechtfertigt werden. Da zwischen den meisten genannten Formen vollständige Uebergänge vorkommen, so wäre man im Sinne der früheren Systematik berechtigt, alle diese Formen zusammenzuwerfen und höchstens Varietäten zu unterscheiden. Wir halten dies nicht für vortheilhaft, weil der genetische Werth der oben besprochenen Formen noch ziemlich unbekannt ist. Wir sind zugleich in der Lage, die hervorstechendsten Formen mit Bezeichnungen zu versehen, welche bereits in der Literatur Geltung besitzen; - zwei Variationen haben wir den nächst verwandten, schon von anderen Autoren beschriebenen angereiht (Murex sublavatus var. Grundensis, Murex eaelatus var. Badensis). Wer an diesem Vorgange Anstoss nimmt, mag entweder, wenn er zur weiteren Trennung Lust hat, diese Varietäten als eigene Formen auffassen - oder die ganze Gruppe unter einem Namen (als welcher dann Murex sublavatus gewählt werden müsste) vereinigen. Letzteres wäre gewiss noch willkürlicher als die Trennung.

Dass die neue Form z. B., welche wir Murex Credneri genannt haben, unmöglich mit Murex eaelatus zusammengeworfen werden kann, bedarf wohl nicht eingehend begründet zu werden. Dennoch sind alle angeführten Formen durch Bindeglieder vereinigt. Wir haben hier wieder ein Beispiel von der (wenigstens provisorischen) Zweckmässigkeit der Trennung durch Zwischenformen verbundener Typen, wie ein solches Strombus coronatus und Strombus Bonelli - Chenopus alatus und Chenopus pespelecani, sowie Murex granuliferus und Murex Borni in ganz ähnlicher Weise darbieten.

\section{Murex (e Occenebra) Schönni M. Hoern.}

M. Hoernes: Foss. Moll. d. Tert.-Beck. v. Wien, I., pag. 235, Taf. XXIV, Fig. 12.

Diese Form, bezüglich welcher wir der Schilderung des Autors nichts Wesentliches beizufügen haben, besitzt viel Aehnlichkeit mit zwei seither beschriebenen Formen: Murex crassilabiatus IIilb. und Murex nodosus Bell. Die von Hilber creirte Art besitzt cine weitaus schwächere Sculptur, zumal was die Querreifen anlangt, ihre Umgänge sind noch wenigẹ abgesetzt und fallen nahezu in eine Ebene, die Mündung endlich besitzt zahlreichere Zähne auf dem rechten Mundrand. Bellardi's Murex nodosus hingegen ist gedrungener, bauchiger, mit einer sehr weiten Mündung ausgestattet.

Von Murex Schönni bewahrt die Sammlung des k. k. Hof-Mineralien-Cabinetes gegenwärtig 9 Exemplare von Dreieichen bei Molt.

\section{Murex (f Occenebra) crassilabiatus Hilb.}

Taf. XXVI, Fig. 18 von Gamlitz (Copie nach Hilber), Fig. 19 von Niederkreuzstetten, Fig. 20 von Dreieichen.

Murex sublavatus. M. Ho erne s: Foss. Moll. d. Tert.-Beck. v. Wien, I., pag. 236 (pro parte), Taf. XXIV, Fig. 14 (cet. excl.). Murex crassilabiatus. Hilber: Neue Conchylien aus den mittelsteierischen Mediterranschichten (LXXIX. Bd. d. Sitzungsber. d. k. Akad. d. Wiss, I. Abth. 1879, pag. 17, Taf. III, Fig. 1, 2).

Wir reproduciren zunächst die. Beschreibung Hilber's:

„Länge 39, Breite 24, Höhe des letzten Umganges $30 \mathrm{Mm}$.

"Schale dick, verlängert eiförmig, fünf durch eine seichte Naht getrennte Umgänge. Breite, von Querreifen durchsetzte Längsrippen. An den abgebildeten, etwas corrodirten Exemplaren sind wellige Zuwachsstreifen zu bemerken. Einige Rippen sind als besonders starke Mundwülste ausgebildet. Mündung gestreckt, 
oval; der rechte, sehr stark verdickte Mundrand mit 7 bis 8 Zähncn versehen, der linke glatt, an die Spindel gelegt. Canal eng und ticf, ziemlich lang und nach rückwärts gebogen."

"Vorkommen: Gamlitz, St. Florian in Steiermark, Molt, Dreieichen, Grund, Ebersdorf, Weinsteig, Porstendorf im Wiener Becken, Rudelsdorf in Mähren.

"Original (Gamlitz): Grazer Universitäts-Sammlung.

"Die Form wurde bisher als Murex sublavatus Bast. angeführt; der Mangel eines Kieles, die dicke Mundwulst, der lange enge Canal unterscheiden sie von derselben.

„Unter den angegebenen Fundorten erreichen nur die Gamlitzer Exemplare die Grösse des abgebildeten. Doch stimmen an den Exemplaren der übrigen Localitäten die Charaktere so gut überein, dass einc weitere Trennung kaum gerechtfertigt wäre."

Wir bringen zunächst je ein Gehäuse von Niederkreuzstetten und Dreieichen bei Molt neben dem Gamlitzer Originale Hilber's zur Abbildung, um den Schlusssatz seiner Beschreibung zu illustriren. Beide Gehäuse sind beträchtlich kleiner als Hilber's Original von Gamlitz (Fig. 18 der Taf. XXVI); so misst das in Fig. 19 dargestellte Gehäuse von Niederkreuzstetten, dessen Spitze abgebrochen ist, etwa $29 \mathrm{Mm}$. in der Höhe, $19 \mathrm{Mm}$. in der Breitc, während das noch kleinere Exemplar von Dreieichen, welches Fig. 20 zur Ansicht bringt, $21.5 \mathrm{Mm}$. hoch, $13.5 \mathrm{Mm}$. breit ist. - Man bemerkt, dass, abgesehen von der Grösse, auch sonst in der Gestaltung des Canales, sowie in der Entwicklung des charakteristischen rechten Mundrandes manche Verschiedenheiten vorhanden sind, welche jedoch nicht so weit gehen, dass eine Trennung der einzelnen Formen räthlich erscheinen würde, weshalb wir uns mit Hilber's Auffassung und Abgrenzung seines Murex crassilabiatus für vollständig einverstanden erklären.

Das in Fig. 19 dargestellte Gehäuse erinnert in manchen Eigenthümlichkeiten an die oben erörterte var. Grundcnsis des Murex sublavatus (vergl. Fig. 6 derselben Tafel). Allein die Charaktere der Mündung dieser Form sind andere, die Aussenlippe ist nur wenig verdickt, die Mündung weiter, - das Gewinde ist, wenn auch seine Umgängc nahezu in einer Ebene liegen, doch treppenartig abgesetzt, die Längsrippen und überhaupt die ganze Sculptur viel schwächcr ausgeprägt. Zudem fehlen weitere Bindeglieder, welche einen Uebergang von Murex sublavatus var. Grundensis zu Murex crassilabiatus darstellen würden, und wir dürfen die durch Hilber vollzogene Abtrennung der letzteren von Murex sublavatus (zu welchem M. Hoernes die in Rede stehende Form gerechnet hatte) für gorechtfertigt erklären.

Noch näher als mit Murex sublavatus scheint uns Murex crassilabiatus indess mit Murex Schönni M. Hoern. verwandt zu sein, worauf wir bereits bei Besprechung der letztgenannten Form hinwiesen, nicht ohne die trennenden Unterschiede hervorzuheben, welche die Hilber'sche Art auch von Murex Schönni unterscheiden.

Wir ergänzen schliesslich Hilber's Angaben über die Fundorte des Murex crassilabiatus durch Anführung der Zahl jener Exemplare, welche im k. k. Hof-Mineralien-Cabinet aufbewahrt werden und von uns untersucht wuiden: Molt 6, Weinsteig 6, Ebersdorf 8, Niederkreuzstetten 16, Grund 3, Grussbach 5, Porstendorf 1, Rudelsdorf 4, Helsens bei Ernstbrunn 1, Bujtur 1; endlich von den vereinigten Fundorten Enzesfeld, Gainfahrn und Steinabrunn 12 Exemplare.

\section{Murex (g Occenebra) craticulatus Linn.}

Taf. XXVII, Fig. I von Enzesfeld, Fig. 2 von Grinzing.

Murex craticulatus Linn. M. Hoernes: Foss. Moll. d. Tert.-Beck. v. Wien, I., pag. 234, Taf. XXIV, Fig. 10 (9 und 11 excl.). Murex craticulatus Limn. L. Bellardi: I Moll. d. terr. terz. d. Piem. e d. Ligur., I., pag. 108.

Murex craticulatus Linn. C. d'Ancona: Malac. plioc. italian., pag. 42, Tav. VI, Fig. 4, 5; Tav. VII, Fig. 3.

Murex craticulatus Limn. F. Fontannes: Mollusques plioc de la vallée du Rhône et du Roussillon, I., pag. 8, Tav. II, Fig. 1.

Wie Bellardi l. c. bemerkt, stimmen die durch M. Hoernes unter dem Namen Murex craticulatus zur Abbildung gebrachten Gehäusc nicht mit den echten craticulatus überein (vergl. hierüber die Discussion des Murex Boeckhi nov. form.); es gilt dies indessen von den drei Original-Exemplaren in ungleichem Grade, denn wenn wir auch hinsichtlich der Fig. 9 und 11 der Taf. XXIV zugeben müssen, dass sie eine Form darstellen, welche nicht wohl mit Murex craticulatus vereinigt bleiben kann, so gilt dies von dem in Fig. 10 dargestellten Gehäuse von Gainfahrn keineswegs. Wir glauben dies vielmelir immer noch bei Murcx craticulatus belassen zu sollen, umsomehr als uns auch andere Exemplare aus den österreichisch-ungarischen Miocänbildungen vorliegen, welche so vollkommen mit Murex craticulatus stimmen (vergl, die neuen Abbildungen!), dass wir 
mit Beruhigung das Auftreten dieser Art im österreichisch-ungarischen Miocän behaupten können. Das in Fig. 1 dargestellte schlanke Gehäuse von Enzesfeld misst $38 \mathrm{Mm}$. in der Höhe, $20 \mathrm{Mm}$. in der Breite, das kräftigere, in Fig. 2 zur Ansicht gebrachte von Grinzing ist $45 \mathrm{Mm}$. hoch, $26 \mathrm{Mm}$. breit.

Mit dem echten Murex craticulatus vollständig übereinstimmende Gehäuse sind allerdings im österreichisch-ungarischen Miocän überaus selten; - es liegen uns ausser den 2 bereits besprochenen nur 1 weiteres Gehäuse von Grinzing, 2 von Hidas, 3 von Bujtur vor, sämmtlich mit offenem Canal, welche Eigenthümlichkeit theils der schlechten Erhaltung (auch bei einem weiteren erwaclısenen, $42 \mathrm{Mm}$. hohen, $22 \mathrm{Mm}$. breiten Gehäuse von Grinzing ist derselbe beschädigt), theils der unvollständigen Ausbildung (bei den übrigen, ausnahmslos unerwachsenen Exemplaren) zuzuschreiben ist.

Viel häufiger sind Uebergangsformen zu Murex Boeckhi nov. form., welche sich durch kürzere Spira, bauchigere Form und tiefer liegenden Kiel auszeichnen. Schon das oben erwähnte durch M. Hoernes in Fig. 10 zur Abbildung gebrachte Gehäuse von Gainfahrn weicht in dieser Richtung von der Type des Murex craticulatus ab, jedoch keineswegs so stark, dass die von Bellardi vorgeschlagene Trennung schon hier gerechtfertigt wäre. Es liegen uns jedoch zahlreiche Exemplare von verschiedenen Fundorten (10 von Gainfahrn und Enzesfeld, 18 von Ritzing, 7 von Kienberg, je 1 von Klein-Ebersdorf und Steinabrunn) vor, welche sämmtlich Bindeglieder zwischen Murex craticulatus und Murcx Boeckhi darstellen. Dessenungeachtet glaubten wir unter dem letzteren Namen jene Form von Murcx craticulatus trennen zu sollen, welche M. Hoernes l. c. Fig. 9 und 11 zur Anschauung bringt, zumal wir 56 Gehäuse von Grund untersuchen konnten, welche alle mehr oder minder in den von Bellardi hervorgehobenen, trennenden Merkmalen übereinstimmen. Wer mit diesem Vorgange nicht einverstanden ist, mag Murex Bocckhi als blosse Varietät des Murex craticulatus betrachten. Dieser Auffassung steht jedoch der Umstand entgegen, dass Murex Boeckhi und Murex craticulatus nicht absolut gleichzeitig gelebt haben, dass vielmehr der erstere als Stammform, der letztere als Nachkömmling bezeichnet werden muss, der erst später seine volle Ausbildung erreichte.

Murex craticulatus Linn. kommt, obschon selten, im Mittelmeere lebend vor, die recenten Formen schliessen sich iunig an die pliocänen an, werden aber meistens (z. B. Brusina: Contr. pella Fauna dei moll. dalmati, pag. 63, Weinkauff: Conchylien des Mittelmeeres, II., pag. 100) als Fusus angeführt. Der innige Zusammenhang der miocänen Vorläufer des Murex craticulatus mit einer so unzweifelhaft der Gattung Murex angehörigen Form, wie sie Murex Boeclihi nobis darstellt, lässt es unbedingt als nothwendig erscheinen: Murex craticulatus bei Murex zu belassen. Ob dann freilich der Name Murex craticulatus beibehalten werden kann, ist eine andere Frage, da es keineswegs sicher ist, ob Linné unter seinem Murex craticulatus dieselbe Form verstand wie Brocchi. Weink a ff nennt daher die in Rede stehende Form einfach Fusus craticulatus Brocchi, bemerkt aber ausdrücklich (l. c. pag. 101): „Da Linnés Murex craticulatus unermittelt geblieben ist, so kann man für unsere Art den Brocchi'schen Namen bestehen lassen, natürlich nur in dem Falle, dass man die Art zu Fusus stellt, was bekanntlich noch eine Streitfrage ist." Wir glauben aber, den Namen Murex craticulatus auch in dem Falle anwenden zu sollen, als die Form der Gattung Murex zugerechnet wird, da kaum ein Irrthum hieraus erwachsen könnte, während der Versuch, Murex craticulatus Brocchi und Murex craticulatus Linné aus einander zu halten, sofort vor die schwierig zu lösende Frage führt, ob die erstere Form den Namen Murex scaber Lamk. zu erhalten hätte. Da Kiener, Deshayes und Weinkauff über Murex scaber Lamk. sehr verschiedener Ansicht sind (Weinka u ff selbst führte zuerst [im Journ. de Conchyl., XIV., pag. 244], der Ansicht K i en er's folgend, den Murex craticulatus als Murex scaber an, während er später es vorzieht, Murex scaber als unermittelt zu bezeichnen), dürfte es vorzuziehen sein, der Erörterung dieser Frage, deren Lösung so namhaften Conchyliologen nicht gelungen ist, aus dem Wege zu gehen.

\section{Murex (h Occenebra) Boeckhi nov. form.}

Taf. XXVII, Fig. 3 (Varietät) von Niederleis.

Murex craticulatus. M. Ho ernes: Foss. Moll. d. Tert.-Beck. v. Wien, I., pag. 234 (pro parte!), Taf. XXIV, Fig. 9,11 (10 excl.).

L. Bellardi bemerkt bei Discussion des Murcx craticulatus Linn. (I Moll. d. terr. terz. d. Piem. e d. Ligur., I., pag. 110): „Non mi pare che i fossili riferiti dal H oernes a questa specie (Tav. 24, Fig. 9, 10, 11), vi apportengano 1. per avere il canale aperto; 2. per la spira molto più breve; 3. per le suture nolto meno profonde; 4. perchè la carena degli anfratti vi è molto ravvicinata alla sutura anteriore, mentre nel MLurex craticulatus Linn. occupa la regione mediana degli anfratti." Demgegenüber haben wir zunächst zu bemerken, dass diese Bemerkungen sich nicht in gleicher Weise gegenüber den in Fig. 9 und 11, und dem in Fig. 10 
dargestellten Gehäuse gerechtfertigt erweisen. Wir glauben (vergl. diesbezüglich unsere Discussion des Murex craticulatus) das in Fig. 10 von M. Hoernes zur Ansicht gebrachte Gehäuse von Gainfahrn auch heute noch zu Murex craticulatus stellen zu müssen. Anders verhält sich die Sache mit den in Fig. 9 und 11 abgebildeten Exemplaren von Grund, bezüglich welcher wir mit Bellardi darin übereinstimmen, dass sie von Murex craticulatus zu trennen sind. Wir bezeichnen sie nunmehr mit dem Namen Murex Boeckhi, können aber nur die von Bellardi unter 1 bis 4 angebrachten Trennungsgründe als richtig anerkennen. Denn der Canal ist bei einem guten Theil der zahlreichen, uns aus den Sandablagerungen von Grund vorliegenden Exemplare (56) vollständig geschlossen, wie denn auch die Fig. 11 bei M. Hoernes ein Gehäuse mit geschlossenem Canal darstellt und M. Hoernes ausdrücklich angibt: „Der Canal ist nicht sehr lang, gedreht, etwas nach rückwärts gebogen, bald offen, bald geschlossen, je nach der Abnützung der Schale." - Wir zählen unter den 56 Gehäusen von Grund 30 mit mehr oder minder vollständig geschlossenem und 26 mit offenem Canal. Es ist ferner bekannt, dass der Schluss des Canales bei den meisten Murices erst im Alter eintritt, zuweilen aber auch bei ganz erwachsenen Gehäusen aus irgend einem Grunde unterbleibt. Ein derartiges Merkmal lässt sich wohl kaum zur Charakterisirung einzelner Formen verwenden. - Die übrigen von Bellardi angeführten Merkmale können mit Erfolg zur Abtrennung des Murex Boeckhi geltend gemacht werden, jedoch unter der Beschränkung, dass sie nur relative Beständigkeit besitzen. Auf das Vorhandensein von Zwischenformen zwischen Murex craticulatus und Murex Boeckhi wurde bereits bei Schilderung der erstgenannten Form hingewiesen; - es kommen solche zu Gainfahrn, Ritzing, Kienberg nicht selten vor, während die zahlreichen Gehäuse des Murex Boeckhi von Grund sämmtlich die oben mit Bellardi's Worten aufgezählten trennenden Nerkmale erkennen lassen. Typische Exemplare des Murex Boeckhi liegen uns ferner noch vor von Grussbach (2), Enzesfeld, Gainfahrn (14) und Poels bei Wildon (1).

Das von uns in Fig. 3 der Taf. XXVII zur Ansicht gebrachte Gehäuse von Niederleis, welches $38 \mathrm{Mm}$. hoch, $22 \mathrm{Mm}$. breit ist, stellt ein abnorm kräftiges Exemplar des Murex Boeckhi dar, welches seh. starke Sculptur, kräftige Rippen und Querstreifen aufweist.- Der Mundwulst im letzten Drittel der Schlusswindung könnte vielleicht verleiten, diese Form von Murex Bocckhi als selbstständig abzutrennen; indess liegen uns auch unter den zahlreichen Gehäusen von Grund Exemplare vor, welche Andeutungen solcher Wülste aufweisen.

\section{Murex (i Occenebra) Sandbergeri M. Hoern.}

M. Ho ernes: Foss. Moll. d. Tert.-Beck. v. Wien, I., pag. 674, Taf. LI, Fig. 5.

Diese Form, bezüglich deren Schilderung wir den Ausführungen des Autors nichts beizufügen haben, gehört offenbar in den Formenkreis des Murex craticulatus Linn. und stellt eine aussergewöhnlich · kräftige und stark sculptirte Type desselben dar. Dies gilt insbesondere von dem durch M. Hoernes am angezeigten Orte geschilderten und zur Abbildung gebrachten Gehäuse von Gainfahrn, hinter welchem die übrigen uns vorliegenden Exemplare (2 von Forchtenau, 1 von Niederleis, 2 von Steinabruın, 9 von Lapugy) merklich an Grösse zurückbleiben, während sie theilweise stachelige Varices besitzen, die an jene des Murex funiculosus Brocc. gemahnen. Endlich sind fast alle übrigen Gehäuse merklich schlanker als das abgebildete OriginalExemplar, und keines besitzt einen so breiten falschen Nabel als dieses.

\section{Murex (j Occenebra) scalaris Brocc.}

Murex scalaris Brocc. M. Hoernes: Foss. Moll. d. Tert.-Beck. v. Wien, I., pag. 240, Taf. XXV, Fig. 5 .

Murex scalaris Broce. C. d'An c ona: Malacologia pliocenica italiana, pag. 39, Tav. VII, Fig. $5,6$.

Murex scalaris Broce. L. Bellardi: I Moll. d. terr. terz. d. Piem. e d. Ligur., I., pag. 113, Tav. VII, Fig. 15.

Murex scalaris Brocc. F. Fontannes: Mollusques plioc. de la vallée du Rhône et du Roussillon, I., pag. 12 , Taf. II, Fig. 7.

Diese Form, in Betreff deren wir der Schilderung durch M. Hoe rnes nichts beizufügen haben, ist eine der seltensten Conchylien der Tertiärbildungen des Wiener Beckens. M. Hoe rnes citirt, nur Nikolsburg und Kienberg als Fundorte; heute liegen im k. k. Hof-Mineralien-Cabinete 4 Gehäuse von ersterem, 6 von letzterem Fundorte, sowie 23 wohlerhaltene Exemplare von Steinabrunn.

Murex scalaris Brocc. wird sowohl von Brocchi selbst als später von Brusina (Contribuzione pella Fauna dei molluschi dalmati, pag. 63) und Weink a uff (Conchylien des Mittelmeeres, II., pag. 98) als im Mittelmeer lebend angeführt. Kobelt (Iconographie der europäischen Meeresconchylien, pag. 40) trennt die recente Form als Coralliophila Meyendorffii Calcara ab. Wir können dem Vorgange Kobel t's nur beistimmen, die von ihm 
angeführten Unterschiede ( ${ }_{n}$ Murcx scalaris hat immer einen halb geschlossenen Canal, viel feinere, nicht schräg gerichtete Rippenfalten und ist erheblich schlanker") gelten auch von der im österreichisch-ungarischen Miocän vorkommenden Varietät des Murex scalaris, welche sich von den typischen italienischen Exemplaren nicht unwesentlich unterscheidet.

Wir konnten uns nicht entschliessen, diese Form, obwohl sie unstreitig mit der recenten Coralliophila Meyendorffii verwandt ist, der Gattung Coralliophila H. a. A. Adams zuzurechnen, weil sich eben an fossilen Formen die Hauptmerkmale dieser Gattung: fehlende Zungenbewaffnung, in Folge parasitischer Lebensweise auf Korallen, schlechterdings nicht constatiren lassen. Da Coralliophila überdies aller Wahrscheinlichkeit (wenigstens was den grössten Theil der hiehergehörigen Formen anlangt) von Murex abstammt, so scheint es uns kein Fehler, diejenigen miocänen Formen, welche sich an Murex anschliessen, bei dieser Gattung zu belassen. Andere Coralliophila-Formen mögen auf demselben Wege (Anpassung an parasitäre Lebensbedingungen und daraus resultirender Verlust der Zungenbewaffnung, sowie Veränderung und unregelmässige Ausbildung der Gehäuse) aus anderen Zweigen der rachiglossen Proboscidiferen hervorgegangen sein, und dürfte allerdings die Familie der Purpuridae auch an der polyphyletischen Gattung Coralliophila bedeutenden Antheil haben. Es dürfte schwer, wenn nicht unmöglich sein, für die einzelnen Fälle die specielle Provenienz festzustellen. Die Trennung der coralliophilen Formen in die Gray'sche Gattung Latiaxis und die Adams'sche Coralliophila (welche auch Weinkauff acceptirte) ist jedenfalls künstlich; XL nterosato fasst sie daher als Pseudomurex zusammen, während Ko belt alle Arten bei Coralliophila H. a. A. Adams vereinigt.

Wir belassen vorläufig alle möglicherweise zu Coralliophila gehörigen miocänen Formen, insoweit sie sich an Murex anschliessen, bei dieser Gattung (speciell der Untergattung Occenebra), weil hiedurch erstens der unzweifelhafte genetische Zusammenhang zum Ausdruck gebracht wird, und zweitens der Zweifel, ob diese Formen (Murex scalaris Brocc., Murcx imbricatus Brocc., Murex Renieri Michti., Murex alternatus Bell. etc.) physiologisch bereits echte Coralliophilen waren, ausgesprochen erscheint.

\section{Murex (k Occenebra) imbricatus Brocc.}

Taf. XXVII, Fig. 4 von Lapugy.

Murex imbricatus. Brocchi: Conch. foss. subap., pag. 408, Tav. VII, Fig. 13.

Murex imbricatus Brocc. C. d'Ancona: Malacologia pliocenica italiaua, pag. 40, Tav. VI, Fig. $1 a, b$.

Murex imbricatus Brocc. L. Bellar di: I Moll. foss. d. terr. terz. d. Piem. e d. Ligur., I., pag. 115.

Murex imbricatus Broce. F. Fontannes: Mollusques plioc. de la vallée du Rhône et du Roussillon, I., pag. 10, pl. II, Fig. 3 bis 6.

Bellardi bemerkt am angezeigten Orte: „La forma figurata dal Hoernes (1. c. Tav. 25, Fig. 4) come varietà della presente specie manca nei nostri terreni: mi pare distinta da questa in particolar modo per la maggiore lunghezza ed acutezza della spira." In Erwägung der vollkommenen Richtigkeit dieser Bemerkung können wir nicht umhin, die von M. Hoernes als Varietät des Murex imbricatus geschilderte Form als selbstständig abzutrennen. Wir werden sie unten als Murex imbricatoides anführen.

Es kommt jedoch auch der echte Murex imbricatus Brocc. in österreichisch-ungarischen Tertiärablagerungen vor, wenngleich selten. Es liegen uns von 6 verschiedenen Fundorten im Ganzen 11 Gehäuse vor, welche sämmtlich im Umriss, in der Gestaltung des Gewindes, im Auftreten der Längsrippen u. s. w. mannigfache Variationen zeigen, ihre Zusammengehörigkeit jedoch insbesondere durch die charakteristische schuppige Sculptur der Querreifen erkennen lassen, welche für Murex imbricatus so bezeichnend ist.

Murex imbricatus besitzt ein gedrungenes, spitz eiförmiges Gehäuse, welches von 5 bis 6 mehr oder minder convexen Umgängen gebildet wird. Die Schlusswindung ist stark aufgeblasen, die Längsrippen sind auf derselben schwächer entwickelt und treten fast ganz zurück, während sie auf den Mittelwindungen lkäftiger ausgebildet sind. Die ganze Schale ist von alternirend stärkeren und schwächeren, feinen mit dachziegelartiger Sculptur gezierten Querstreifen bedeckt. Die Mündung ist sehr weit, der Canal ziemlich breit, kurz, stark nach links und rückwärts gedreht, der Nabel weit und tief.

Das abgebildete Gehäuse (vom Fundorte Lapugy) ist $40 \mathrm{Mm}$. hoch, $26 \mathrm{Mm}$. breit. Untersucht wurden je 1 Gehäuse von Niederleis, Ruditz und Drnowitz, je 2 von Baden und Lapugy, und endlich 4 von Jaroměřic.

F. Fontannes bemerkt bei Discussion des Murex imbricatus: „C'est à tort, paraît-il, que d'Orbigny a cité cette espèce de la colline de Turin, et que Hoernes lui a rapporté une forme du bassin de Vienne qui doit en être spécifiquement distinguée. Le Murex imbricatus est done, jusqu'ici, exclusirement pliocène 
dans toute la région méditerranéenne." Wenn auch der erste Theil dieses Satzes vollkommen richtig ist und wir genöthigt sind, die von M. Ho ernes als Murex imbricatus bezeichnete Form als Murex imbricatoides abzutrennen, so glauben wir nunmehr doch auch das Vorkommen des echten Murex imbricatus im österreichischungarischen Miocän behaupten zu dürfen.

Murex imbricatus Brocc. wird von Morelet als an den Azoren lebend angeführt $-\mathrm{Kobelt}$ (Iconographie der europ. Meeresconchylien, pag. 12) spricht die Ansicht aus, dass Mo relet damit Coralliophila (Fusus - Murex) lamellosa Jan. meine, welche wohl auch an den Canaren und Cap verden nicht fehlen dürfte. Murex imbricatus ist unzweifelhaft mit Coralliophila lamellosa nahe verwandt; doch finden wir keine Veranlassung, ihn der Gattung Coralliophila zuzuweisen, da bei einer fossilen Form das Hauptmerkmal der fehlenden Zungenbewaffnung (welche in Folge der schmarotzenden Lebensweise auf Korallen vcrloren ging) sich nicht nachweisen lässt. Auch die oben angeführten, sämmtlich auf Tegelablagerungen sich beziehenden Fundorte des Murex imbricatus Brocc. im österreichisch-ungarischen Miocän sprechen gegen die Zurechnung der Gattung Coralliophila, welche an seichteres Wasser und an Korallen- und Lithothamnienriffe gebunden ist.

\section{Murex (1 Occenebra) imbricatoides nov. form.}

Murex imbricatus. M. Hoernes; Foss. Moll. d. Tert.-Beck. v. Wien, I., pag. 239, Taf. XXV, Fig. 4.

Diese Form unterscheidet sich, wie Bellardi ganz richtig bemerkt hat, so wesentlich von Murex imbricatus (vergl. oben bei Murex imbricatus), dass wir uns veranlasst sehen, sie mit einem neuen Namen zu bezeichnen.

Der bereits durch M. Hoeṛnes gegebenen Schilderung haben wir hinzuzufügen, dass Murex imbricatoides sich von Murex imbricatus im Wesentlichen durch geringere Dimensionen, schlankere Gestalt und schärfere Spira unterscheidet. Die schwächere Sculptur wurde bereits durch M. Hoernes hervorgehoben.

M. Hoernes nennt als Fundorte der in Rede stehenden Form nur Vöslau und Pötzleinsdorf, mit dem Beisatze "sehr selten"; - es lag ihm von beiden Fundorten nur je ein Exemplar vor. Wir konnten in der Sammlung des Hof-Mineralien-Cabinetes derzeit 26 Gehäuse des Murex imbricatoides von österreichischungarischen Fundorten untersuchen, und zwar je ein Exemplar von Soos, Forchtenau, Ruditz, Grussbach und Jerutek, je zwei von Vöslau, Niederleis und Kostej, und endlich 15 von Lapugy. Murex imbricatoides ist demnach ziemlich verbreitet, aber überall selten, und kommt nur zu Lapugy etwas häufiger vor.

\section{Murex (m Occenebra) alternatus Bell.}

Taf. XXVII, Fig. 6, 7, 8 von Lapugy.

Murex alternatus. L. Bellardi: I Moll. d. terr. terz d. Piem. e d. Ligur., I., pag. 121, Tav. VIII, Fig. 8.

Diese interessante Form liegt uns nur vom Fundorte Lapugy in mehreren Exemplaren vor, welche mit der durch Bellardi l. c. gegebenen Beschreibung und Abbildung seines Murex alternatus so genau übereinstimmen, dass wir an der Identität nicht zweifeln können.

Die Schale ist ei-spindelförmig, bauchig; die Schlusswindung sehr aufgeblasen. Das spitze Gewinde besteht aus fünf bis sechs gewölbten Umgängen, welche auf dem unteren Theile einen deutlichen Kiel tragen. Die breitere Partie der Windungen, welche über diesem Kiel liegt, ist mässig convex, fast eben, die schmälere, unter dem Kiel gelegene, fällt schräge zur Naht ab. Die Schale ist mit mehr oder minder kräftigen, abgerundeten Längsrippen geziert, über welche zahlreiche engstehende, bald gleichmässige, bald alternirend stärkere und schwächere schuppige Querstreifen setzen. Die Mündung ist oval, stark erweitert; der rechte Mundrand scharf, innen glatt; der kurze Canal offen und kaum gedreht, zu seiner Linken befindet sich eine schwache, nabelartige Vertiefung.

Die Höhe schwankt zwischen 10 und $23 \mathrm{Mm}$., die Breite zwischen 7 und $13 \mathrm{Mm}$. Wie die Figuren 6 bis 8 unserer Taf. XXVII zeigen, schwanken die Umrisse der Gehäuse, welche wir dem. Murex alternatus Bell. zurechnen, nicht unwesentlich in den Verhältnissen der Höhe zur Breite. Fig. 8 stellt ein extrem schlankes, Fig. 7 ein ausnahmsweise gedrungenes Exemplar, Fig. 6 die verbindende Mittelform dar.

Murex alternatus Bell. hat sich bis nun nur an einem einzigen Punkte der österreichisch-ungarischen Monarchie - zu Lapugy in Siebenbürgen - gefunden. Es liegen von dort 13 Gehäuse in der Sammlung des k. k. Hof-Mineralien-Cabinetes. 


\title{
52. Murex (n Occenebra) Hochstetteri nov. form.
}

\author{
Taf. XXVII, Fig. 9, 10 von Lapugy.
}

Diese Form theilt mit Murex alternatus Bell., mit welchem sie nahe verwandt ist, das Vorkommen zu Lapugy; von einem anderen Fundpunkte ist sie uns nicht bekannt. Es kann nicht geleugnet werden, dass Murex Hochstetteri sich sehr innig an Murex alternatus anschliesst, dennoch glaubten wir beide Formen, wenig. stens vorläufig, aus einander halten zu sollen, müssen jedoch die Möglichkeit zugeben, dass man durch das Vorkommen von verbindenden Mittelformen gezwungen werden dürfte, beide wieder zu vereinigen.

Murex Hochstetteri besitzt eine ei-spindelförmige, bauchige Schale mit stark aufgeblasener Schlusswindung, deren Gewinde aus fünf bis sechs convexen, durch eine tiefe Naht deutlich getrennten Umgängen besteht. Stark vortretende, gerundete Längsrippen zieren das Gehäuse, sie werden auf den Mittelwindungen durch kräftige, ziemlich gleichmässig erhabene Querstreifen übersetzt. Auf der Schlusswindung treten vier bis fünf Querreifen bedeutend stärker hervor, zwischen welchen schwächere in ungleicher Zahl liegen. Die Mündung ist oval, weit, der rechte Mundrand scharf, innen glatt. Der kurze Canal ist offen, an seiner linken Seite befindet sich eine nabelartige Vertiefung, welche bald weit und tief, bald enger und seicht erscheint.

Die Höhe schwankt zwischen 12 und $20 \mathrm{Mm}$., die Breite zwischen 7 und $14 \mathrm{Mm}$. (das in Fig. 10 dargestellte Gehäuse ist das grösste unter den acht Exemplaren, welche im k. k. Hof-Mineralien-Cabinete vom Fundorte Lapugy aufbewahrt werden).

Wie bereits bemerkt, steht Murex Hochstetteri dem Murex alternatus Bell. sehr nahe, unterscheidet sich jedoch durch gedrungenere Form, gewölbtere, eines deutlichen Kieles entbehrende Umgänge, kräftigere Längsrippen und insbesondere durch die vier bis fünf stärkeren Querreifen auf der Schlusswindung. Wir müssen jedoch an dieser Stelle darauf aufmerksam machen, dass bei reichlicherem Materiale wahrscheinlich vollständige Uebergänge zwischen beiden Formen werden nachgewiesen werden können. Darauf deutet wenigstens das gedrungene Gehäuse hin, welches wir, als dem Murex alternatus angehörig, in Fig. 7 der Taf. XXVII abbilden liessen, und welches gewiss manche Eigenthümlichkeiten aufweist, die an Murex Hochstetteri erinnern, als: bauchigere Form, undeutlicheren Kiel, ungleiche Entwicklung der Querreifen.

Weiters müssen wir noch hervorheben, dass Murex Hochstetteri grosse Aehnlichkeit mit Murex electus Bell. (Bellardi: I Moll. d. terr. terz. d. Piem. e d. Ligur., I., pag. 127, Tav. VIII, Fig. 19) besitzt. Doch ist Murex electus bedeutend grösser, die Schale viel kräftiger und mit derberer Sculptur bedeckt, als dies bei Murex Hochstetteri der Fall ist. Die letztere Form steht in jeder Hinsicht zwischen Murex alternatus Bell. und Murex electus Bell. in der Mitte, ist jedoch von beiden soweit verschieden, dass sie wohl unter einern besonderen Namen ausgezeichnet zu werden verdient.

Uebrigens wird sich bei reichlicherem Materiale unzweifelhaft eine grosse Variabilität dieser Formen herausstellen, welche unstreitig mit den recenten Coralliophila-Arten verwandt sind. Berücksichtigt man die grosse Variabilität, welchen die Schalen der letzteren unterworfen sind (vergl. z. B. die Abbildungen der Coralliophila Meyendorffi Calcara in Kobelt's Iconographie der europäischen Meeresconchylien, Taf. VIII, Fig. 12, 13, 14, 16 und 17), so wird man auch geneigt sein, ähnliche Verhältnisse bei den fossilen Verwandten vorauszusetzen. Dann würde eventuell Murex imbricatoides wieder mit Murex imbricatus vereinigt werden, während Murex alternatus, Murex Hochstetteri und Murex electus ebenfalls zusammengezogen werden könnten. Doch fehlt es heute noch an den Uebergangsformen und lässt sich die Frage überhaupt nur bei dem Vorhandensein sehr reichlichen Materiales discutiren.

\section{Murex (o Occenebra) Renieri Michti.}

Taf. XXVII, Fig. 5 von Forchtenau.

Fusus Renieri. Michelotti in E. Sismonda: Synops. meth. anim. invert. Pedem. foss. I. ed., pag. 36.

Fusus Renieri. Michelotti: Descr. d. Foss. d. terr. mioc. de l'Italie sept., pag. 283, Tav. IX, Fig. 19.

Fusus Renieri Michti. E. Sis monda: Synops. meth. anim. invert. Pedem. foss. II ed., pag. 38.

Fusus Renieri Michti. d'Orbigny: Prodrôme de Paléontologie stratigraphique, Vol. III, pag. 68.

Murex Renieri Michti. Bellardi: I Moll. d terr. terz. d. Piem. e d. Ligur., I., pag. 126, Taf. VIII, Fig. 17.

Von dieser interessanten Form liegen uns nur einige wenige Exemplare von zwei Fundorten aus den miocänen Ablagerungen Oesterreich-Ungarns vor. Die Gehäuse stimmen nicht ganz mit der Schilderung und Abbildung, welche Bellardi von der italienischen Type liefert, sie sind gedrungener, ihre Mündung Hoernes u. Auinger, Gasteropoden d. Meeres-Abl. ã. 1. u. 2. Mediterranstufe. Heft 5. 
merklich kürzer; dessenungeachtet glauben wir, sie der italienischen Form wenigstens unter dem Titel einer, wenn auch ziemlich abweichenden Varietät anreihen zu dürfen.

Die Schale dieser Varietät ist ei-kegelförmig, ziemlich gedrungen, das Gewinde besteht aus fünf bis sechs mässig gewölbten Umgängen, welche durch eine seichte Naht unvollkommen getrennt werden. Mehr oder minder kräftige, rundliche Längsrippen bedecken die Schale und werden von engstehenden, gleichförmigen Querstreifen übersetzt, welche eine schuppig-körnelige Oberfläche besitzen. Die Mündung ist relativ eng, oval; der rechte Mundrand scharf, innen gestreift, der linke in Gestalt einer Lamelle über die Spindel gelegt. Der Canal ist sehr kurz, offen, zu seiner Linken befindet sich eine schwache, enge, nabelartige Vertiefung.

Die Höhe schwankt zwischen 18 und $25 \mathrm{Mm}$., die Breite zwischen 6.5 und $9.5 \mathrm{Mm}$. Das in Fig. 5 zur Abbildung gebrachte Gehäuse erreicht die als obere Grenze angegebenen Dimensionen.

Von dieser Form liegen uns nur ein Gehäuse vom Fundorte Pötzleinsdorf und vier von Forchtenau vor. Sie wurden früher in der Sammlung des k. k. Hof-Mineralien-Cabinetes unter der Bezeichnung „Murex imbricatus Brocc. var." aufbewahrt. Von dem echten Murex imbricatus ist die in Rede stehende Form so leicht zu unterscheiden, dass es uns überflüssig erscheint, die einzelnen trennenden Merkmale zu erörtern. Es mag genügen, auf die Abbildungen Fig. 4 und 5 unserer Taf. XXVII hinzuweisen, von welchen die erstere das überaus bauchige, weitmündige und weitgenabelte Gehäuse des Murex imbricatus, die zweite das kleinere, schlankere, engmündige und mit wenig entwickeltem Nabel ausgestattete Gehäuse der österreichischen Varietät des Murex Renieri darstellt. Näher steht der letzteren Form Murex imbricatoides (vergl. M. Ho e r n e s: Foss. Moll., I., Taf. XXV, Fig. 4); doch ist Murex imbricatoides bedeutend schlanker, seine Umgänge viel gewölbter und durch tiefere Nähte scharf getrennt; der Canal endlich beträchtlich länger, als dies bei Murex Renieri der Fall ist. - Auch ist die Sculptur sowohl bei Murex imbricatus als bei Murex imbricatoides beträchtlich kräftiger entwickelt, als dies bei Murex Renieri der Fall ist.

\section{Murex (p Occenebra) ventricosus M. Hoern.}

M. Hoernes: Foss. Moll. d. Tert-Beck. v. Wien, I., pag. 231, Taf. XXIV, Fig. 4 und 5.

Diese höchst eigenthümliche Form, welche, wie M. Hoernes mit Recht hervorhebt, weder unter den lebenden noch unter den bis nun bekannten fossilen Murices ein Analogon besitzt, fällt auch durch ihr, auf den Fundort Grund beschränktes isolirtes Auftreten auf. Auch in den Sandablagerungen von Grund gehört sie zu den grössten Seltenheiten, und besitzt das Hof-Mineralien-Cabinet aus denselben nur vier Exemplare. Wir sind deshalb nicht in der Lage, die Mittheilungen, welche M. Hoernes über diese interessante Form gemacht bat, zu erweitern oder zu ergänzell.

\section{Genus: Typhis Montfort.}

Wir machen uns eigentlich einer nicht unbedenklichen Inconsequenz schuldig, wenn wir, dem Beispiele Bellardi's folgend, Typhis von Murex abtrennen, Trophon aber als Untergattung bei Murex anführen. Trophon verdient mindestens mit demselben Rechte von Murex abgetrennt zu werden als Typhis. Aeussere Schwierigkeiten, welche in dem Vorhandensein fossiler Formen gelegen sind, die zwischen Murex und Trophon Bindeglieder bilden, liessen uns auf eine scharfe Trennung, welche für die recenten Trophon-Arten ganz am Platze sein mag, verzichten. Diese Mittelformen (von welchen wir z. B. eine unter dem Namen Murex (Trophon) Ruditzensis vorzuführen hatten) waren es, welche uns Veranlassung gaben, dem Beispiele Bellardi's folgend, Trophon in die Reihe der Untergattungen von Murex aufzunehmen. Uebrigens haben wir auch in der weiten Fassung der Untergattung Occenebra Bellardi's Ansichten adoptirt und unter Occenebra manche Formen aufgenommen, welche zumeist gänzlich von Murex getrennt werden. So die ganze Gruppe des Murex imbricatus Brocc. (Murex imbricatus, Murex imbricatoides, Murex alternatus Bell., Murex Hochstetteri, Murex Renieri Michti.), welche unstreitig mit recenten Angehörigen der Gattung Coralliophila sehr nahe verwandt sind und zu Coralliophila H. a. A. Adams gestellt werden müssten, wenn es überhaupt zulässig wäre, für fossile Formen, die nur in ihrer Schale, nicht aber in ihrer Zungenbewaffnung und in ihrer Lebensweise bekannt sind, eine derartige Eintheilung vorzunehmen.

Auch Murex craticulatus haben wir, dem Vorgange Bellardi's folgend, bei Occenebra eingereiht, obwohl die Conchyliologen (vergl. z. B. We in ka u ff, Conchylien dès Mittelmeeres, pag. 100) diese Form zumeist bei Fusus einreihen, oder wohl gar einen eigenen Gattungsnamen in Anwendung bringen (Hadriana Bucq. v. Dautz). 
Wenn wir alle diese verschiedenartigen Formen unter die Untergattungen von Murex reihen, andererseits aber Typhis abtrennen, so geschieht dies, weil die Trennung der letzteren Gattung keinerlei Schwierigkeiten unterliegt, da, wie bereits von M. Ho ern es hervorgehoben wurde (vergl. Foss. Moll. d. Tert.-Beck. v. Wien, I., pag. 217), die röhrenförmigen Fortsätze, welche das Gewinde der hiehergehörigen Formen zieren, ein ausgezeichnetes Merkmal darbieten. Allerdings bietet der für Typhis charakteristische hohle Dorn, welcher durch eine Ausstülpung des Mantelrandes eingenommen wird, während des Wachsthums grosse Aehnlichkeit mit dem oberen Canal der Ranellen oder mit ähnlich gestellten Dornen echter Murices dar. M. Hoernes meint deshalb: "Es stellt sich ein unmerklicher Uebergang zwischen dem eigentlichen Murex und zwischen Typhis heraus, und wenn man damit die Aehnlichkeit der Deckel verbindet, so kann man nicht umbin, der Ansicht D eshay es' beizupflichten, welcher diese Schalen nicht als ein selbstständiges Geschlecht, sondern als eine Gruppe im Geschlechte Murex betrachtet wissen will." - Indessen führt M. Ho ernes doch die vier zu Typhis gehörigen Arten aus dem Wiener Becken am Schlusse der Besprechung der Gattung Murex, und zwar als Murex (Typhis) horridus Brocc., fistulosus Brocc., tetrapterus Bronn., Wenzelidesi M. Hoern. an, gibt demnach schon durch diese Bezeichnung die theilweise Berechtigung der Abtrennung von Murex zu.

Wir bemerken gleich hier, dass die genannten vier Formen der Gattung Typhis, welche im österreichisch-ungarischen Miocän vorkommen, durch M. Ho e rn es vollkommen richtig angeführt wurden. Lediglich die als Typhis tetrapterus Bronn. geschilderte Form entspricht nicht genau den typischen italienischen Exemplaren, was Bellardi zu einer berichtigenden Bemerkung veranlasst hat. Es kommt indess auch die typische Form von Typhis tetrapterus im österreichisch-ungarischen Miocän vor; M. Hoernes hatte nur ein ziemlich abweichendes Gehäuse zum Gegenstand der Abbildung gewählt, doch stellt dasselbe keineswegs, wie Bellardi will, eine Zwischenform zwischen dem echten Typhis tetrapterus Bronn. und Typhis fistulosus Broce. dar, sondern ist mit der ersteren Form, der es überhaupt viel mehr gleicht, derart durch Uebergänge verbunden, dass wir es vorziehen, dieses und ähnliche Gehäuse, welche uns von mehreren Fundorten (Lapugy, Bujtur, Kostej) in geringer Zahl vorliegen, einer. Varietät des Typhis tetrapterus Bronn. zuzurechnen, als für dieselben einen neuen Namen zu creiren.

Eine weitere, der Gattung Typhis zuzurechnende Form ist uns aus österreichisch-ungarischen Miocänablagerungen nicht bekannt geworden, wir haben uns daher auf die Discussion der vier, schon von M. Ho ern es angeführten und geschilderten Arten:
1. Typhis horridus Brocc.,
3. $\gg$ tetrapterus Bronn.,
2. Typhis fistulosus Broce,
4. "Wenzelidesi M. Hoern.

zu beschränken. Mit Ausnahme der oben bereits erwähnten Variationen des Typhis tetrapterus, welche nähere Erörterung erheischen, werden wir die Schilderungen, welche M. Hoernes von diesen Formen gegeben hat, nur durch Anführung neuer Fundorte zu ergänzen haben.

\section{Typhis horridus Brocc.}

Typhis horridus Brocc. M. Hoernes: Foss. Moll. d. Tert.-Beck. v. Wien, I., pag. 260, Taf. XXVI, Fig. 9. Typhis horridus Brocc. L. Bellardi: I Moll. d. terr. terz. d. Piem. e d. Ligur., I., pag. 39.

Die Besprechung, welche M. Hoernes dieser Form widmete, haben wir nur hinsichtlich der Aufzählung der Fundorte zu ergänzen. M. Hoernes nennt als solche Baden, Vöslau, Möllersdorf, Grinzing, Gainfahrn und Steinabrunn mit dem Beisatze "selten“. Heute liegen uns in der Sammlung des k. k. Hof-. Mineralien-Cabinetes je 10 Gehäuse von Baden, Vöslau und Möllersdorf, je 2 von Soos, Gainfahrn, Niederleis und Forchtenau, 1 von Lissitz, 3 von Steinabrunn und endlich 4 von Lapugy vor. Es sei bemerkt, dass die Gehäuse von Steinabrunn die grössten Dimensionen erreichen (eines derselben ist $32 \mathrm{Mm}$. hoch und - die Stacheln sind theilweise abgebrochen - etwa $30 \mathrm{Mm}$. breit), die Gehäuse aus dem Badener Tegel und jene von den übrigen Fundorten bleiben zumeist merklich hinter den Dimensionen des von M. Ho e r n e s - Taf. XXVI, Fig. 9 - zur Abbildung gebrachten Gehäuses zurück.

\section{Typhis fistulosus Brocc.}

Typhis fistulosus Brocc. M. Hoernes: Foss. Moll. d. Tert.-Beck. v. Wien, I., pag. 261, Taf. XXVI, Fig. 11. Typhis fistulosus Brocc. C. d'Ancona: Malacologia pliocenica italiana, pag. 52, Tav. VI, Fig. 10.

Typhis fistulosus Brocc. L. Bellardi: I Moll. d. terr terz. d Piem. e d. Ligur., I., pag. 40.

Der Schilderung, welche diese Form und ihr Auftreten im österreichisch-ungarischen Miocän durch M. Hoernes erfahren hat, haben wir nichts Wesentliches beizufügen. 
M. Hoernes nennt als Fundorte von Typhis fistulosus im Wiener Becken: Baden, Möllersdorf, Vöslau und Forchtenau mit dem Beisatze „häufig". Wir haben als weitere Fundorte, welche gegenwärtig in der Sammlung des k. k. Hof-Mineralien-Cabinetes vertreten sind, Steinabrunn, Niederleis, Oedenburg und Lapugy namhaft zu machen. Am letzterwähnten Punkte ist Typhis fistulosus nicht weniger häufig als an den Fundpunkten des Badener Tegels - an anderen Orten erscheint die Form vergleichsweise selten.

\section{Typhis tetrapterus Bronn.}

Taf. XXIX, Fig. 13 von Bujtur, Fig. 14 bis 16 von Steinabrunn.

Typhis tetrapterus Brom. M.'H o ernes: Foss. Moll. d. Tert.-Beck. v. Wien, I., pag. 263, Taf. XXVI, Fig. 10. Typhis tetrapterus Bronn. C. d'Ancona: Malac. plioc. ital., pag. 53, Tav. VI, Fig. 8.

Typhis tetrapterus Bronn. L. Bellardi: I Moll. d. terr. terz. d. Piem. e d. Ligur., I., pag. 41.

Leider hat M. Hoernes am angegebenen Orte ein aberrantes Gehäuse (von Vöslau) zur Abbildung gebracht, was Zweifel an der Richtigkeit seiner Bestimmung verursachte. So bemerkt Bellar di (bei Discussion von Typhis fistulosus): "La forma figurata da Hoernes col nome di Murex. (Typhis) tetrapterus Bronn. mi sembra differire della forma tipica della specie cui è riferita, perchè le varici vi sono brevissime, non dilatate in ala e perchè la sua spira e più lunga: è dessa una forma intermedia fra il Typhis fistulosus Brocc. ed il vero Typhis tetrapterus Bronn." Wir können dem letzten Theil dieser Bemerkung nicht beipflichten, wenn wir auch zugeben müssen, dass das erwähnte von M. Hoernes abgebildete Gehäuse wesentlich von den typischen Exemplaren des Typhis tetrapterus abweicht. Es gehört einer Varietät an, von welcher sich in der Sammlung des k. k. Hof-Mineralien-Cabinetes noch etliche Gehäuse vorfinden, welche von den Fundorten Lapugy, Bujtur und Kostej stammen. Es liegen uns aber auch Exemplare in grösserer Zahl (und zwar von den Fundorten Gainfahrn, Steinabrunn, Enzesfeld und Forchtenau) vor, welche vollkommen mit typischen Exemplaren des Typhis tetrapterus aus italienischen Ablagerungen übereinstimmen. Wir bringen drei Gehäuse von Steinabrunn, sowie eines von Bujtur zur Abbildung, um das Auftreten des echten Typhis tetrapterus in den österreichisch-ungarischen Tertiärbildungen nachzuweisen, sowie zu zeigen, dass diese typische Form durch Uebergänge mit jener Varietät verknüpft ist, von welcher M. Hoernes ein Exemplar vom Fundorte Vöslau abbilden liess.

Wir bemerken schliesslich, dass auch der Gesammtumriss jener Formen, welche sich unmittelbar an die italienische Type anschliessen, stark variirt - das bauchige Extrem der abgebildeten Steinabrunner Gehäuse ist $27 \mathrm{Mm}$. lang, $16 \mathrm{Mm}$. breit, während ein gleichfalls zur Abbildung gebrachtes schlankes Exemplar $25 \mathrm{Mm}$. lang, $13 \mathrm{Mm}$. breit ist. Aehnliche Verhältnisse haben wir bei den verschiedensten Gasteropodenformen zu beobachten - sie lehren, dass die schlankere oder gedrungenere Gestalt der Schale nur mit Vorsicht als Unterscheidungsmerkmal nahe verwandter Formen benützt werden darf. Bei Vorhandensein genügenden Iateriales kann man wohl bei den meisten Gasteropoden schlankere und bauchigere Gehäuse nachweisen.

\section{Typhis Wenzelidesi M. Hoern.}

M. Ho ernes: Foss. Moll. d. Tert.-Beck. v. Wien, I., pag. 269, Taf. XXVI, Fig. 12.

Der Schilderung dieser Form haben wir nichts Neues beizufügen - sie ist eine der seltensten Conchylien des österreichisch-ungarischen Miocäns. M. Ho ern es führt nur ein einziges Gehäuse von dem Fundorte Steinabrunn an; - heute liegen von diesem Fundorte drei vollkommen übereinstimmende Exemplare in der Sammlung des k. k. Hof-Mineralien-Cabinetes, sowie ein (fragmentäres) von Forchtenau, welches gleichfalls mit Sicherheit auf Typhis Wenzelidesi bezogen werden darf.

\section{Genus: Jania Bell.}

Bellardi hat diese Gattung 1871 aufgestellt. Er charakterisirt sie (I Moll. d. terr. terz. d. Piem. e d. Ligur., I., pag. 147) mit folgenden Worten :

"T'esta subfusiformis; spira elongata. - Os postice vix canaliculatum, subintegrum, labrum sinistrum exterius marginatum, interius nodosum vel plicatum; dexterum postice uniplicatum: columella antice uniplicata: cauda brevis, recurva." 
Wir bringen diese Gattung hier, im Anschlusse an die Murices, zur Sprache, weil die zu Jania gehörigen Formen meistens der Gattung Murex zugerechnet wurden; so führt auch M. INoernes die im österreichisch-ungarischen Tertiär auftretenden Formen als Murex angulosus und Murex labrosus (Foss. Moll. d. Tert.-Beck. v. Wien, I., pag. 237 und pag. 242) an. Beide sind übrigens verschieden von denjenigen italienischen Typen, welchen sie M. Hoernes zurechnete; - die erstere entspricht dem Murex (Jania) maxillosus Bon., neben welchem allerdings auch der echte Murex (Jania) angulosus Brocc., jedoch als grosse Seltenheit vorkommt; - die zweitgenannte Form ist von Murex (Jania) labrosus Michti. verschieden, wie neuerdings von Bellardi mit Recht hervorgehoben wurde, sie muss daher den ihr zuerst von M. Hoernes beigelegten Namen Murex Reussii erhalten; die Zugehörigkeit desselben zur Gattung Jania ist übrigens nicht unzweifelhaft, wie unten dargelegt werden soll.

Um die gleichzeitige Benützung des vorliegenden Werkes und der "Fossilen Mollusken des TertiärBeckens von Wien" möglichst zu erleichtern, besprechen wir die Gattung Jania, deren Formen von M. Ho e rn es noch unter Murex angeführt wurden, im unmittelbaren Anschlusse an Murex und Typhis - und werden ebenso hierauf die Discussion der Gattung Pollia Gray folgen lassen, obwohl beide eher an Fusus zu reihen wären. Jania wird z. B. von Tryon geradezu als Untergattung zu Fusus gestellt (George W. Tryon: Structural and systematic Concholog, Vol. II, pag. 128). - Pollia findet (und zwar im Zusammenhang mit Tritonidea Swainson) bald bei den Fusinae (so bei Chenu: Manuel de Conchyliologie, I., pag. 142), bald bei den Pisaniinae (so bei Tryon: Struct. and syst. Conch., Vol. II, pag. 143) Stellung. Wie unten bei Discussion der Gattung Pollia zn erörtern sein wird, fassen wir dieselbe in jenem weiten Umfange auf, welchen Bellardi der Gray'schen Gattung verliehen hat, und welcher auch von Tryon, allerdings unter der Bezeichnung Cantharus Baltcn, unter Einbeziehung der Gattungen Pollia Gray und Tritonidea Swains. angewendet wurde. Während der Umfang dieser Gattung, für welche wir den Namen Pollia, den Gray 1839 gab, dem 1798 von Bolten vorgeschlagenen vorziehen, ein so grosser ist, dass wir mit Vortheil die von Bellardi aufgestellten Sectionen zur Eintheilung der einzelnen Formen verwenden werden, ist die Zahl der zu Jania gehörigen Arten eine sehr geringe.

Wie bereits bemerkt, kommen im österreichisch-ungarischen Miocän nur drei Formen vor, welche der Gattung Jania zuzurechnen sind, und von diesen dürfen wir eine (Murex Reussii $M$. Hoern.), welche früher fälschlich mit Murex (Jania) labrosus Michti. identificirt worden war, nur mit Vorbehalt und unter Hervorhebung eines wesentlichen unterscheidenden Merkmales zu Jania stellen. Diese Form gleicht allerdings in vielen Stücken dem Murex labrosus Michti., doch macht schon M. Hoe rnes auf die kräftigere Berippung aufmerksam. Worin sich aber Murex Reussii ganz wesentlich von seinen grösseren Verwandten: Murex angulosus Brocc. und Murex maxillosus Bon., die als typische Repräsentanten der Gattung Jania gelten können, unterscheidet, das ist die Gestaltung der Mündung - insbesondere der Mangel der kräftigen Spindelfalte, welche für Jania angulosa und maxillosa so charakteristisch ist.

M. Hoernes hat in einer längeren Auseinandersetzung (vergl. Foss. Moll. d. Tert.-Beck. von Wien, I., pag. 238) versucht, den Nachweis zu führen, dass Bonelli Unrecht gethan, seinen Murex maxillosus aufzustellen, und dass dieser nur eine Varietät des Brocchi'schen Murex angulosus darstelle. „Formen, wolche das kaiserliche Cabinet von Enzesfeld besitzt", sagt M. Hoernes, „stellen so vollkommene Uebergänge von einer Species zur anderen dar, dass beide zusammengefasst werden müssen." Es geht indess aus den von M. Hoernes als Fundorte des Murex angulosus angeführten Punkten hervor, dass ihm jene drei Gehäuse von Grund, welche wir nunmehr (wie wir glauben mit Recht) dem Murex angulosus zurechnen, noch gar nicht bekannt waren. Er würde andernfalls doch Bedenken getragen haben, so entschieden die Aufstellung der Bonelli'schen Art für unberechtigt zu erklären. Weniger die geringe Grösse, die schlankere Gestalt und die zahlreicheren Längsrippen, welche die Jania maxillosa gegenüber der Jania angulosa auszeichnen, als vielmehr die Charaktere der Mündung: die kräftigeren, aber weniger zahlreichen (5) Zähne des rechten Mundrandes der Jania maxillosa, gegenüber den schwächeren, erhabenen Streifen gleichenden, zahlreicheren (bis 10!) Zähnen bei Jania angulosa, möchten wir als sichere Unterscheidungsmerkmale hervorheben.

Wir haben demnach folgende drei Formen als Vertreter der Gattung Jania im österreichisch-ungarischen Miocän zu discutiren:

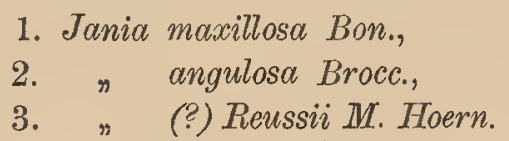

Wenn M. Hoernes auch diese Formen theilweise verkannt hat, so. war er doch über die eigenthümliche Gestalt derselben und die Nothwendigkeit, für sie eine eigene Gattung zu schaffen, im Klaren. Er sagt (1. c. pag. 238) bei Discussion des Murex angulosus: 
„Ueber die Frage, welchem Geschlechte man diese Form zutheilen soll, herrschen noch verschiedene Ansichten, man schwankt $\mathrm{z}$ wischen $\mathbb{M}$ urex und Fusus; nach meiner Ansicht ist der Bau der Schale dieser Art so verschieden von allen übrigen Murex - und Fusus-Arten, die starken Zähne und die einzige Spindelfalte so bezeichnend, dass es in Zukunft, wenn sich mehrere derlei Formen finden sollten, gerathen erscheinen dürfte, daraus ein eigenes Geschlecht zu machen, welches in die Nähe der Turbinellen zu stellen wäre."

\section{Jania maxillosa Bon.}

Taf. XXVII, Fig. 11, 12 von Lapugy.

Murex maxillosus. Bonelli: Mus. Zool. di Torino, Nr. 2537.

Murex maxillosus Bon. Bellardi et Michelotti: Sagg. orittogr. d. Piem., T. III, pag. 110, Tav. I, Fig. 14.

Murex maxillosus Bon. Michelotti: Descript. des Foss. mioc. d. l'Italie septent, pag. 285, Taf. X, Fig. 9, 13.

Murex maxillosus Bon, E. Sismond a: Synopsis method. anim. inert. Ped. foss., pag. 38.

Murex angulosus. M. Hoernes: Foss. Moll. d. Tert.-Beck. v. Wien, I., pag. 237, Taf. XXV, Fig. 1 (non Brocc.)

Jania maxillosa Bon. L. Bella rdi: I Moll. d. terr. terz. d. Piem. e d. Ligur., I., pag. 149, Tav. XI, Fig. 6.

Der Schilderung, welche M. Ho ernes am angeführten Orte von dieser Form, respective ihrer Vertretung im österreichisch-ungarischen Miocän gegeben hat, haben wir verhältnissmässig wenig beizufügen; hingegen müssen wir, wie bereits oben bemerkt, der durch M. Hoernes versuchten Zusammenziehung der Jania angulosa Brocc. und Jania maxillosa Bon. entgegentreten. Der letzteren Form sind die durch M. Ho er n es geschilderten Gehäuse zuzuweisen.

M. Hoernes selbst betont die grosse Aehnlichkeit der Formen des Wiener Beckens und jener Gehäuse, für welche Bonelli seinen Murex maxillosus gegründet hat, will aber die Abtrennung des letzteren nicht für gerechtfertigt halten: „Die Wiener Exemplare sind bei weitem kleiner als jene von Tortona und Castell' arquato, sie nähern sich vielmehr in der Grösse jenen Formen, welche Bonelli als eine selbstständige Art unter dem Namen Murex maxillosus im Turiner Museum aufstellte; allein alle übrigen Eigenschaften stimmen so vollkommen mit der Species von Brocchi überein, dass eine Trennung dieser Formen unstatthaft ist." Wir werden unten zu zeigen versuchen, dass diese Trennung nicht nur möglich, sondern durch die constanten Mündungscharaktere beider Formen auch sehr leicht durchführbar ist, haben jedoch vorerst noch der Erklärung zu gedenken, welche M. Hoernes für das Auftreten einer localen Varietät (als welche er Murex maxillosus hinstellt) anführt: „Sonderbarerweise sind fast alle Arten, welche sich im Tegel von Castell' arquato und Baden finden, an ersterem Fundorte stets grösser, vollkommener entwickelt und mehr ausgebildet, während unsere Exemplare stets ein verkümmertes Ansehen haben; sie gleichen in dieser Beziehung vielmehr jenen Formen, welche man im Serpentinsand der Superga bei Turil findet; es scheinen an diesen beiden Fundorten die localen Verhältnisse für die Entwicklung der Schalen nicht so günstig gewesen zu sein als an den übrigen Orten Italiens, wie z. B. Tortona, Asti, Castell' arquato u.s. w., und man würde sich nach meiner Ansicht gewaltig täuschen, wenn man eine geringe Abweichung der Schalenstructur, die wahrscheinlich durch locale Verhältnisse bedingt ist, für den Charakter einer eigenen Species halten wollte. In diesen Fehler scheint Bonelli gefallen zu sein, indem er den Murex maxillosus aufstellte." Ohne uns hier darauf einzulassen, dass altersverschiedene Bildungen mit einander verglichen worden sind, müssen wir zunächst der Ansicht entgegentreten, als ob Murex maxillosus eine vicarirende - und, wie M. Ho ernes andeutet, theilweise verkümmerte oder doch beträchtlich geringere Dimensionen aufweisende Varietät des Murex angulosus sei. Das stattlichste der Gehäuse, welche M. Hoernes zur Untersuchung vorlagen und welches er in Fig. 1 der Taf. XXV seines Werkes abbilden liess, besass allerdings nur $37 \mathrm{Mm}$. Höhe und $18 \mathrm{Mm}$. Breite. Derzeit liegen uns jedoch beträchtlich grössere Gehäuse vor, von welchen wir zwei vom Fundorte Lapugy zum Gegenstand von Abbi_. dungen gemacht haben, um die nicht unbeträchtliche Variabilität der Jania maxillosa zu zeigen und ihre Vergleichung mit Jania angulosa zu erleichtern. Das auf unserer Taf. XXVII in Fig. 11 dargestellte Gehäuse ist $50 \mathrm{Mm}$. lang, $20 \mathrm{Mm}$. breit - jenes in Fig. 12 zur Abbildung gebrachte ist $46 \mathrm{Mm}$. lang, $18 \mathrm{Mm}$. breit es erreichen diese Gehäuse sonach und übertreffen theilweise jene an Grösse, welche wir auf derselben Tafel in Fig. 13 und 14 als Repräsentanten der Jania angulosa zur Ansicht bringen. Beide Formen zeigen, worauf wir bei Discussion der Jania angulosa noch ausführlicher zurückkommen werden, nicht unbedeutende Variationen in der Gesammtgestalt und in der Entwicklung der Längsrippen. Wenn man auch im Allgemeinen sagen kann, dass Jania maxillosa sich durch schlankere Gestalt, höhere und spitzere Spira, zahlreichere (10 bis 12) Varices auszeichnet (wie z. B. die Vergleichung der Fig. 12 und 14 ergibt), so kann doch andererseits nicht geleugnet werden, dass es Gehäuse der Jania maxillosa von bauchigerer Form gibt (vergl. z. B. Fig. 11), sowie dass bei 
Jania angulosa schlankere Formen mit zahlreichen Varices vorkommen (vergl. z. B. Fig. 13), so dass die Grenzformen beider Typen in den allgemeinen Umrissen und in der Berippung nicht sehr weit von einander entfernt sind - ja dass man hier geradezu in Verlegenheit wäre, ein sicheres Unterscheidungsmerkmal namhaft zu machen. Viel leichter gelingt es, Jania maxillosa und angulosa durch Merkmale der Mündung zu unterscheiden. Bei der erstgenannten Form sind die Zähne und Falten viel kräftiger entwickelt als bei der letzteren, - dafür sind die streifenförmigen Zähne des rechten Mundrandes bei Jania angulosa viel zahlreicher (8 bis 10), während die Zahl der kräftigen, stark vorragenden Zähne der Jania maxillosa nur fünf erreicht. Es ist also M. Ho ernes einestheils im Recht, wenn er das Vorhandensein von Uebergängen zwischen Jania angulosa Broce. und Jania maxillosa Bon. behauptet; solche Uebergänge liegen allerdings, was die Gesammtgestalt und die äussere Verzierung anlangt, thatsächlich vor. Andererseits muss aber hervorgehoben werden, dass die Gestaltung der Mündung bei beiden Formen starke Verschiedenheit aufweist und dass in dieser Hinsicht keinerlei Uebergänge - wenigstens in dem spärlichen Materiale, welches uns aus den österreichisch-ungarischen Miocänbildungen vorliegt, - bis nun nachgewiesen werden konnten.

M. Hoernes nennt als Fundorte der in Rede stehenden Form Baden, Enzesfeld und Forchtenau mit der Bezeichnung "selten". Uns liegen ausserdem heute noch je ein Gehäuse von Möllersdorf, Vöslau und Ruditz, sowie acht Exemplare von Lapugy vor. Jania maxillosa gehört sonach zu den selteneren Conchylien und findet sich nur in den so überaus reichen Schichten von Lapugy etwas häufiger.

\title{
2. Jania angulosa Brocc.
}

Taf. XXVIII, Fig. 13, 14 von Grund.

\author{
Murex angulosus. Brocchi: Conchiologia fossile subap., Tom. II, pag. 411, Tav. VII, Fig. 16. \\ Murex angulosus Broccin. Bronn: Italiens Tertiärgebilde, pag. 36, Nr. 160. \\ Cancellaria angulata. Ja n: Cat. nerum nat. in Museo Cristofori et Jan. extant., pag. 10. \\ Murex angulosus Brocc. Michelotti: Monografia del genere Murex, pag. 22. \\ Fusus angulosus Brocc. Michelotti: Descript. des Foss. mioc. de l'Italie sept., pag. 286. \\ Fusus angulosus Brocc. E. Sismonda: Synopsis meth. anim invert. Ped. foss., pag. 37. \\ Fusus angulosus Brocc. d'Orbigny: Prodrôme de Paléontologie stratigraph., Tom. III, pag. 173, Nr. 169. \\ Jania angulosa Brocc. L. B ell a rd i: I Moll. foss. d. terr. terz. d. Piem. e d. Ligur., I., pag. 148, Tav. XI, Fig. 5.
}

M. Hoernes hatte offenbar bei Abfassung der Schilderungen jener Gehäuse, welche wir nunmehr der Jania maxillosa Bon. zurechnen, wirkliche Vertreter der Jania angulosa gar nicht vor Augen. Erst in seinem Verzeichniss der im Wiener Becken vorkommenden Gasteropoden und Pteropoden nennt er unter Nr. 144 (auf pag. 694 der Foss. Moll. etc.) auch Grund unter den Fundorten des Murex angulosus.

Es befinden sich heute in der Sammlung des k. k. Hof-Mineralien-Cabinetes drei Gehäuse von diesem Fundorte, welche wir dem echten Murex angulosus Brocc. zurechnen zu dürfen glauben. Nur eines davon, welches wir in Fig. 14 der Taf. XXVII zur Anschauung bringen, stimmt genau mit der Schilderung und der Abbildung der Jania angulosa des italienischen Tertiärs - es ist bauchig, mit entfernt stehenden Längsrippen (neun auf dem leizten Umgange) geziert und misst $47 \mathrm{Mm}$. in der Höhe, $21 \mathrm{Mm}$. in der Breite. Das zweite Exemplar, welches wir nicht zur Abbildung gebracht haben, vermittelt in jeder Hinsicht den Uebergang von dem eben erörterten zu dem dritten Gehäuse, welches in Fig. 13 dargestellt ist. Dieses letztere Exemplar, dessen Höhe $45 \mathrm{Mm}$., dessen Breite $19 \mathrm{Mm}$. beträgt, ist weit schlanker als das in Fig. 14 dargestellte. Seine Umgänge sind stärker abgesetzt, die Nähte tiefer, die Längsrippen zahlreicher (auf dem letzten Umgange stehen eilf Längsrippen); kurz in allen, den Gesammtumriss und die äussere Sculptur anlangenden Merkmalen stellt dieses Gehäuse gewissermassen ein Uebergangsglied zu Jania maxillosa her, wie bereits bei Schilderung dieser Form erwähnt wurde. Die Charaktere der Mündung sind es, welche uns veranlassen, auch dieses Gehäuse der Jania angulosa zuzurechnen. Es zeichnet sich diese durch zahlreiche ( 8 bis 10) streifenförmige, wenig vortretende Zähne im Innern des rechten Mundrandes aus, während bei Jania maxillosa weniger (5), dafür aber um so kräftigere Zähne auf der Innenseite des rechten Mundrandes auftreten.

Vielleicht würde reichlicheres Material (es liegen uns eben nur die drei Gehäuse von Grund vor) das Vorhandensein von Uebergängen zwischen Jania maxillosa und Janic angulosa auch hinsichtlich des Baues der Gehäusemündung constatiren lassen. Derzeit ist dies unmöglich, und müssen wir demnach, wenigstens vorläufig, die Brocchi'sche und Bonelli'sche Art von einander sondern. - Insbesondere die acht oben besprochenen Gehäuse der Jania maxillosa von Lapugy lassen die Trennung, welche Bonelli durchgeführt hat, sowie die Ausführungen Bellardi's über diesen Gegenstand als gerechtfertigt erscheinen. 


\section{Jania (?) Reussii M. Hoern.}

Murex Reussii. M. Hoernes: Verz. in Cžjžek's Erläut. z. geogn. Karte v. Wien, pag. 18, Nr. 199. Murex labrosus. M. Ho ernes: Foss. Moll. d. Tert.-Beck. v. Wien, I., pag. 242, Taf. XXV, Fig. 3 (non.Michti.).

Der Schilderung, welche diese Form durch M. Hoernes erfahren hat, haben wir nichts Wesentliches beizufügen. M. Hoernes hat bereits, und zwar mit hinlänglicher Entschiedenheit, die Unterschiede hervorgehoben, welche diese Form von Murex labrosus Michti. trennen. Doch glaubte er, nach Vergleichung mit den Original-Exemplaren Michelotti's, die österreichischen Gehäuse der italienischen Art, obschon als einen abweichenden Typus, als eine Varietät anreihen zu sollen. Bei der heute üblichen, schärferen Abgrenzung der Formen geht dies nicht wohl an, und gerne folgen wir dem Beispiele Bell a rd i's, welcher Murex labrosus M. Hoern. non Michti. für eine besondere, nicht zur Jania labrosa Michti. gehörige Form erklärt. Eis ist selbstverständlich, dass dieselbe sodann den ihr zuerst von M. Hoernes zugedachten Namen Murex (Jania?) Reussii erhalten muss. Weniger sicher ist es, ob wir es in diesem Falle wirklich mit einer der Gattung Jania Bell. angehörigen Form zu thun haben.

Wir wollen nicht leugnen, dass Murex Reussii mit demselben Recht, mit welchem wir ihn zu Jania bringen, auch bei Pollia eingereiht werden könnte. Von den typischen Jania-Formen unterscheidet ihn der Mangel einer Spindelfalte und die schwache Entwicklung der erhabenen Streifen auf der Innenseite des rechten Mundrandes. Indessen sind die letzteren auch bei Jania maxillosa und angulosa sehr verschieden stark entwickelt und auch die Spindelfalte zeigt grosse Verschiedenheiten in ihrer Ausbildung bei den einzelnen Angehörigen der Gattung Jania. Der Gesammtumriss des Gehäuses und die Sculptur erinnern allerdings sehr an die echte italienische Jania labrosa Michti., und deshalb mag, wenn auch nur vorläufig und unter Vorbehalt, Murex Reussii M. Hoern. bei der Gattung Jania eingereiht werden.

Murex (Jania?) Reussii gehört zu den wenigst verbreiteten Conchylien des österreichischen Miocäns. Die interessante Form kommt nur in den Schichten von Steinabrunn, hier aber geradezu häufig vor. 

TAFEL XXIII.

Ranella (Apollon) gigantea Lamk pag. 188.

Fig. 1-4 von Lapugy (Fig. $1 c, 2 c, 4 c$ Anfangswindungen vergrössert).

Fig. 5 von Ruditz.
Ranella (Lampas) papillosa Pusch pag. 188 Fig. 6-9 von Lapugy.

Ranella (Lampas) austriaca nov. form. pag. 186. Fig. 10-12 von Soos.

Sämmtliche Originalexemplare werden im $\mathrm{k} . \mathrm{k}$. Hof-Mineralien-Cabinete aufbewahrt. 
RIIoemes u.M.Auinger. Gasteropoden der Lull.mocänen Mediterranstufe.

Tul:XXIII .
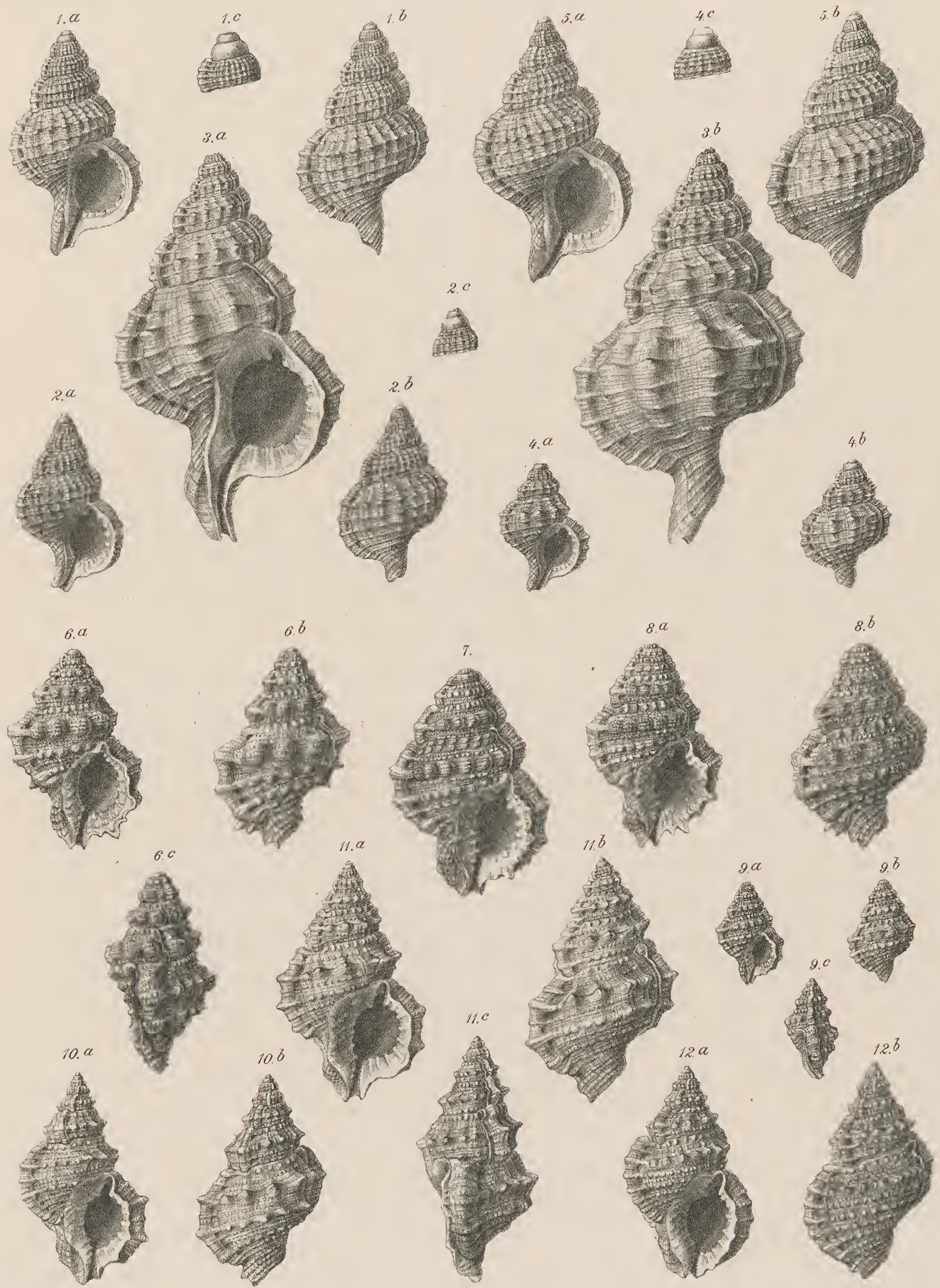

Rud. Schörn n.d. Nat. . ez. u. itth
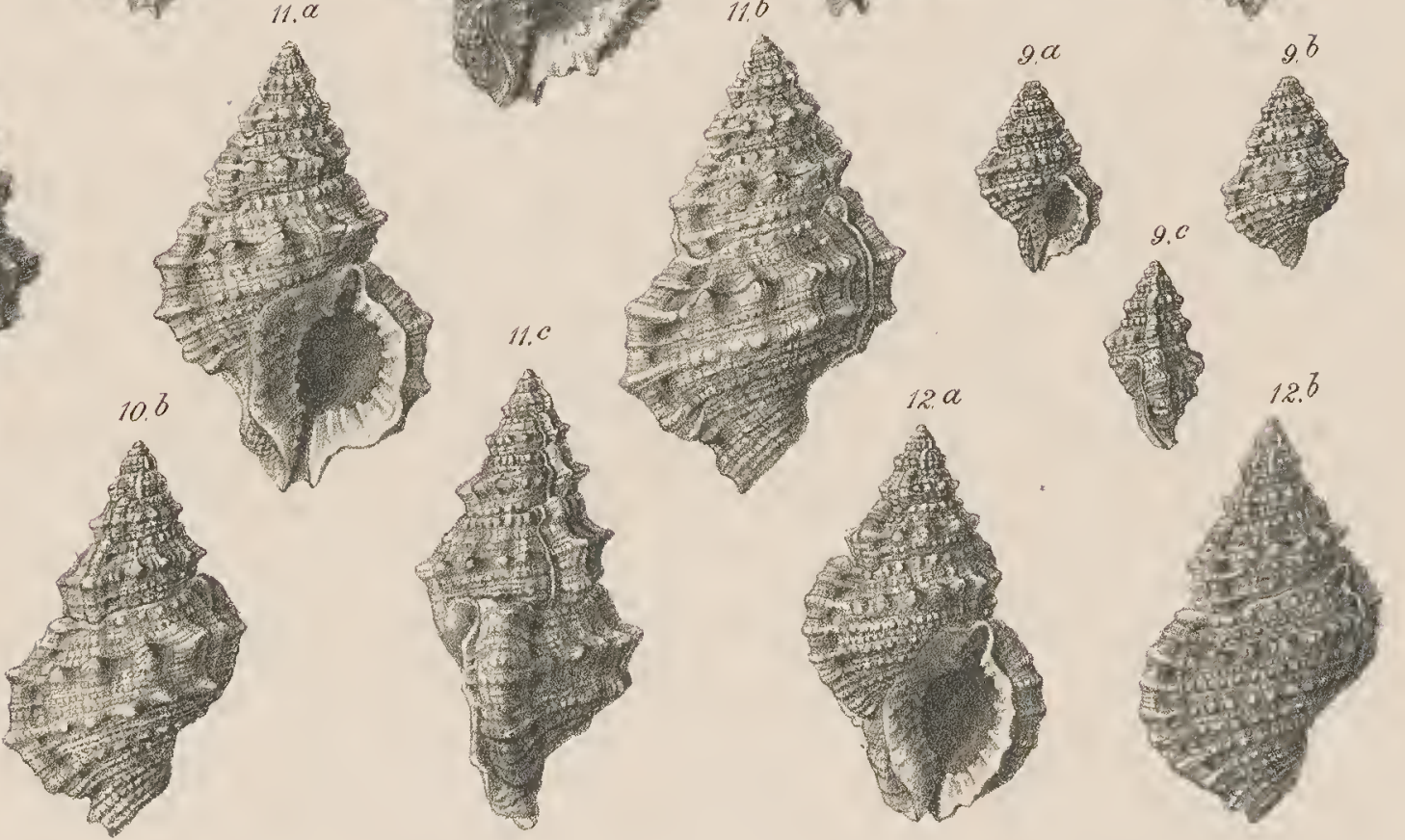

Verlag v. Aifred Hölder, k.k. Hof-u. Universitäts-Buchhändler in Wien. 
TAFEL XXIV.

Ranella (Aspa) marginata Martini sp. pag. 190. Fig. 1, 2 von Lapugy.

Ranella (Apollon) anceps Lamk. pag. 190.

Fig. 3 von Steinabrunn (Fig. $b, c$ doppelt vergrössert).

Ranella (?) hungarica nov. form. pag. 191.

Fig. 4 von Kostej (Fig. $b$, $c$ dreimal vergrössert).

Murex (Muricidea) heptagonatus Bronn pag. 205.

Fig. 5 von Vöslau.

Fig. 6 von Steinabrann.

Fig. 7,8 von Lapugy.

Murex Delbosianus Grat. pag. 199.

Fig. 9 von Kostej.

Fig. 10, 11 von Korytnice.
Murex (Muricidea) transylvanicus nov. form. pag. 207. Fig. 12 von Lapugy (Fig. $b, c$ doppelt vergrössert)

Murex (Chicoreus) perlongus Bell. pag. 207.

Fig. 13 von Lapugy.

Murex (Muricidea) moravicus nov. form. pag. 206.

Fig. 14, 15, 16 von Jaromierčic (Fig. 146 Varix der Schlusswindung, dreimal vergrössert).

Murex (Trophon) ruditzensis nov. form. pag. 214. Fig. 17 von Ruditz.

Sämmtliche Originalexemplare werden im k. k. Hof-Mineralien-Cabinete aufbewahrt. 
R.Hoernes u. M. Auinger. Gasteropoden der LuII.miocänen Mediterranstufe.

Tat. XXIV.
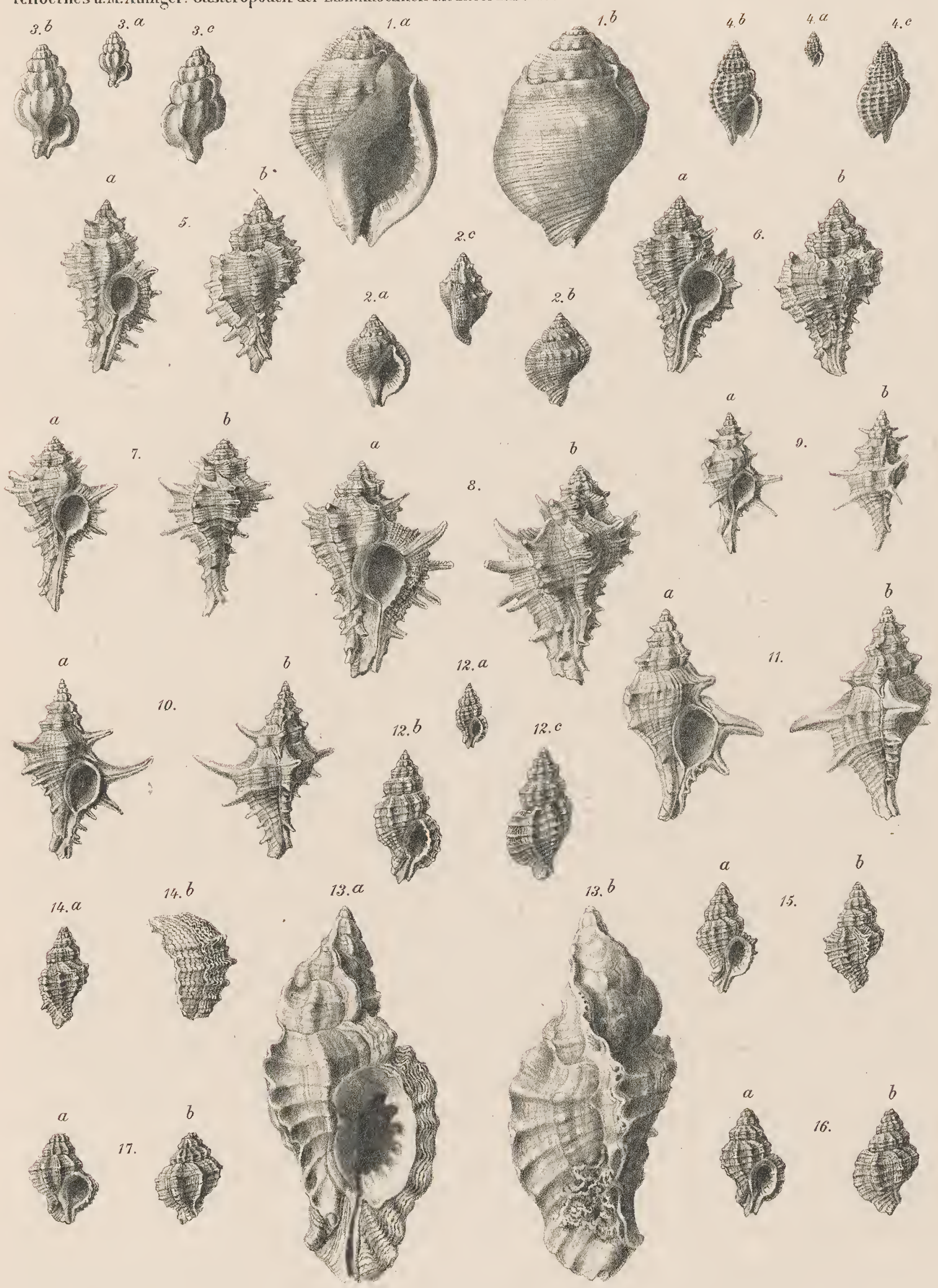

Rud. Schönn nd Nat gez. u. hith.

Verlag v. Alfred Hölder, k. k. Hof-u.Universitats-Buchhändler in Wien. 
TAFEL XXV.

Murex (Trophon) vaginatus Jan. pag. 216. Fig. 1 von Steinabrunn.

Murex (Phyllonotus) vindobonensis M. Hoern. pag. 213. Fig. 2 von Lapugy.

Murex (Chicoreus) Aquitanicus Grat. pag. 207. Fig. 3 von Gainfahrn.
Murex (Vitularia) lingua-bovis Bast. pag. 213.

Fig. 4 von Porstendorf.

Fig. 5 von Grund.

Fig. 6, 7 von Gainfahrn.

Sämmtliche Originalexemplare werden im k. k. Hof-Mineralien-Cabinete aufbewahrt. 
R.Hoernes u.ML.Auinger, Gasteropoden der L..IL.miocänen Mediterranstufe.

Tal: XXV.

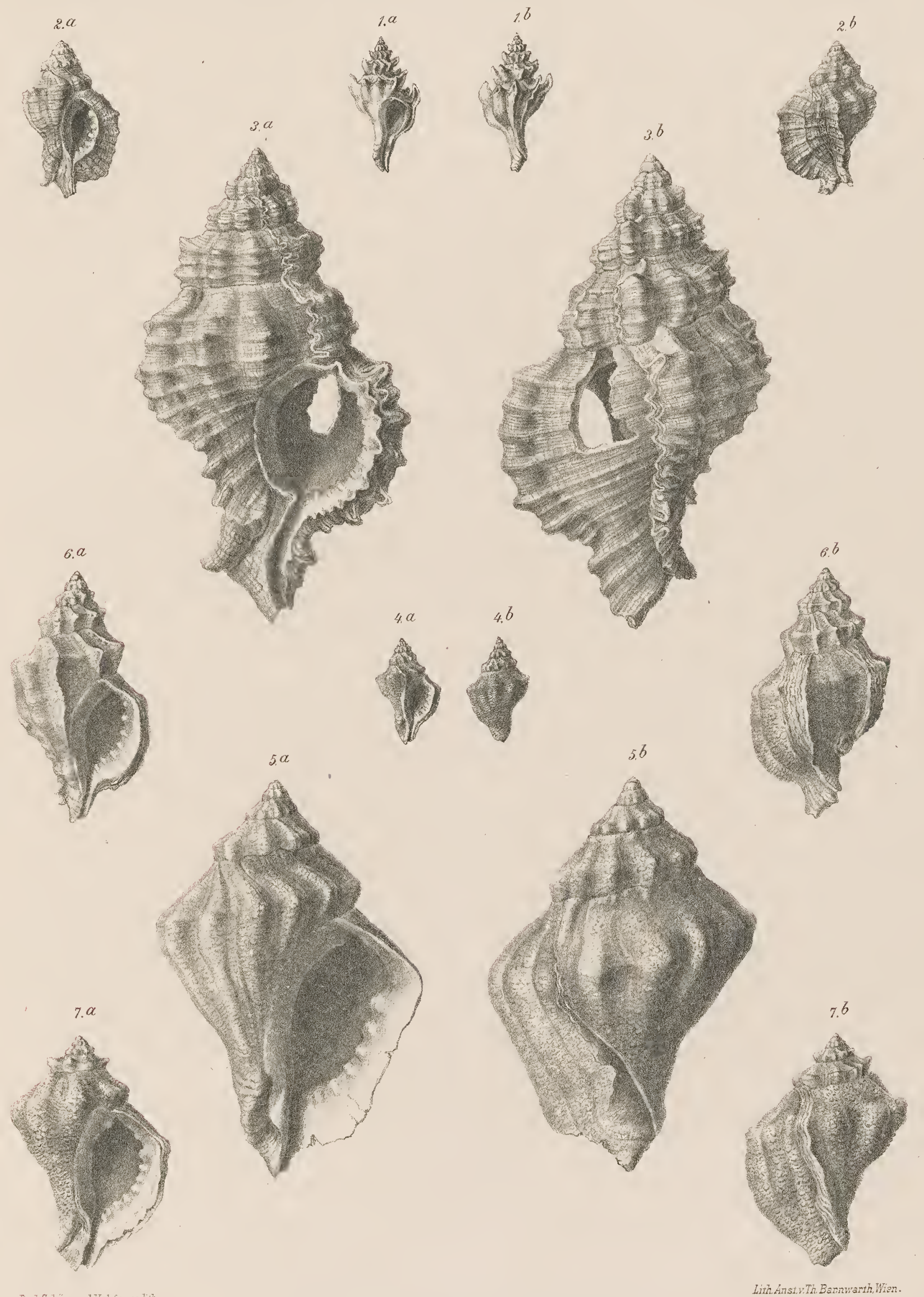

Verlag v. Alfred Holder, k.k. Hof-u.Universitats-Buchhändler in Wien. 
TAFEL XXVI.

Murex (Phyllonotus) cristatus Broce. pag. 210. Fig. 1, 2, 3 von lapugy.

Murex (Occenebra) sublavatus Bast. pag. 216. Fig. 4, 5 von Grund.

Murex (Occenebra) sublavatus Bast. var. grundensis Fig. 6 von Grund.

Murex (Occenebra) caelatus Grat. pag. 217. Fig. 7-12 von Enzesfeld, Gainfahrn und Steinabrunn.

NB. Die Figuren 9, 11 und 12 stellen Uebergangsformen dar, welche zu Murex sublavatus var. grundensis füren.
Murex (Occenebra) caelatus Grat. var. badensis. Fig. 13, 14 von Soos.

Murex (Occenebra) Dertonensis May. pag. 218.

Fig. 15 von Lapugy.

Murex (Occenebra) Credneri nov, form. pag. 218. Fig. 16, 17 von Lapugy.

Murex (Oecenebra) crassilabiatus Hilb. pag. 219 Fig. 18 von Gamlitz

Fig. 19 von Niederkreuzstetten.

Fig. 20 von Drei-Eichen bei Molt.

Sämmtliche Originalexemplare (mit Ausnahme des in Fig. 18 dargestellten, welches in der geologischen Sammlung der k. k. Universität Graz aufbewabrt wird) befinden sich im k. k. Hof-Mineralien-Cabinete 
R.Hoernes u.Ll. Auinger. Gasteropoden der Luillmiocänen Mediterranstufe .
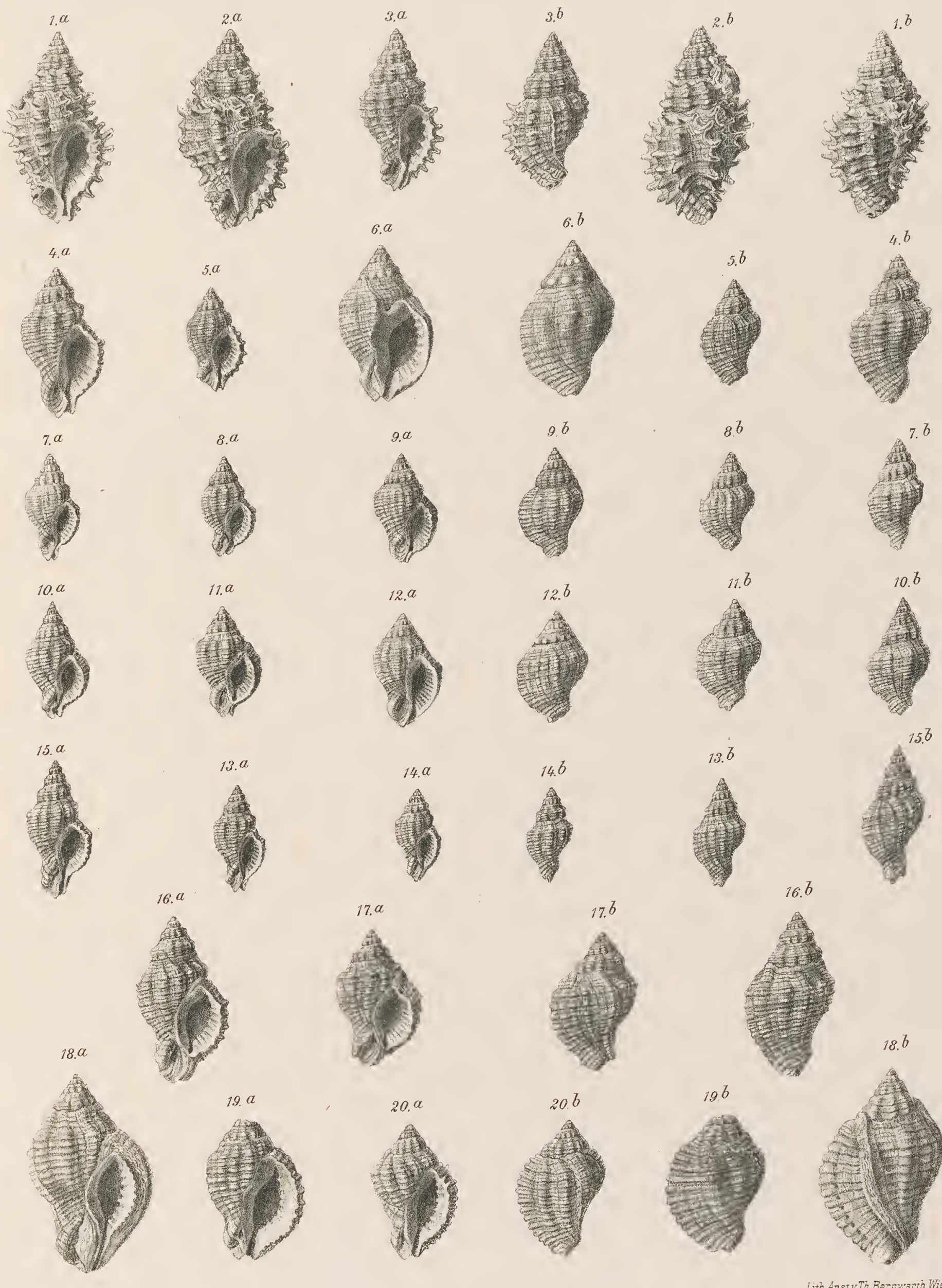


\section{TAFEL XXVII}

Murex (Occenebra) craticulatus Linné pag. 220.

Fig. 1 von Enzesfeld.

Fig. 2 von Grinzing.

Murex (Occenebra) Boeckhi nov. form. (Var.) pag. 221.

Fig. 3 von Niederleis.

Murex (Occenebra) imbricatus Brocc. pag. 223.

Fig. 4 von Lapugy.

Murex (Occenebra) Renieri Michtti. pag. 225.

Fig. 5 von Forchtenau.

Murex (Occenebra) alternatus Bell. pag. 224.

Fig. $6,7,8$ von Lapugy.
Murex (Occenebra) Hochstetteri nov. form, pag. 225. Fig. 9, 10 von Isapugy.

Jania maxillosa Bonn. pag. 230.

Fig. 11, 12 von Lapugy.

Jania angulosa Broce. pag. 231.

F'ig. 13, 14 von Grund.

Pollic Bellardii nov. form.

Fig. 15 von Lapugy (Fig. $b$, dreimal vergrössert)

Pollia Mariae nov. form.

Fig. 16 von Lapugy.

Pollia (Engina) Weinsteigensis nov. form.

Fig. 17 von Weinsteig. 
R.Hoernes u.M.Auinger. Gasteropoden der I.ull.miocänen Mediterranstufe .

Taf:XXVI
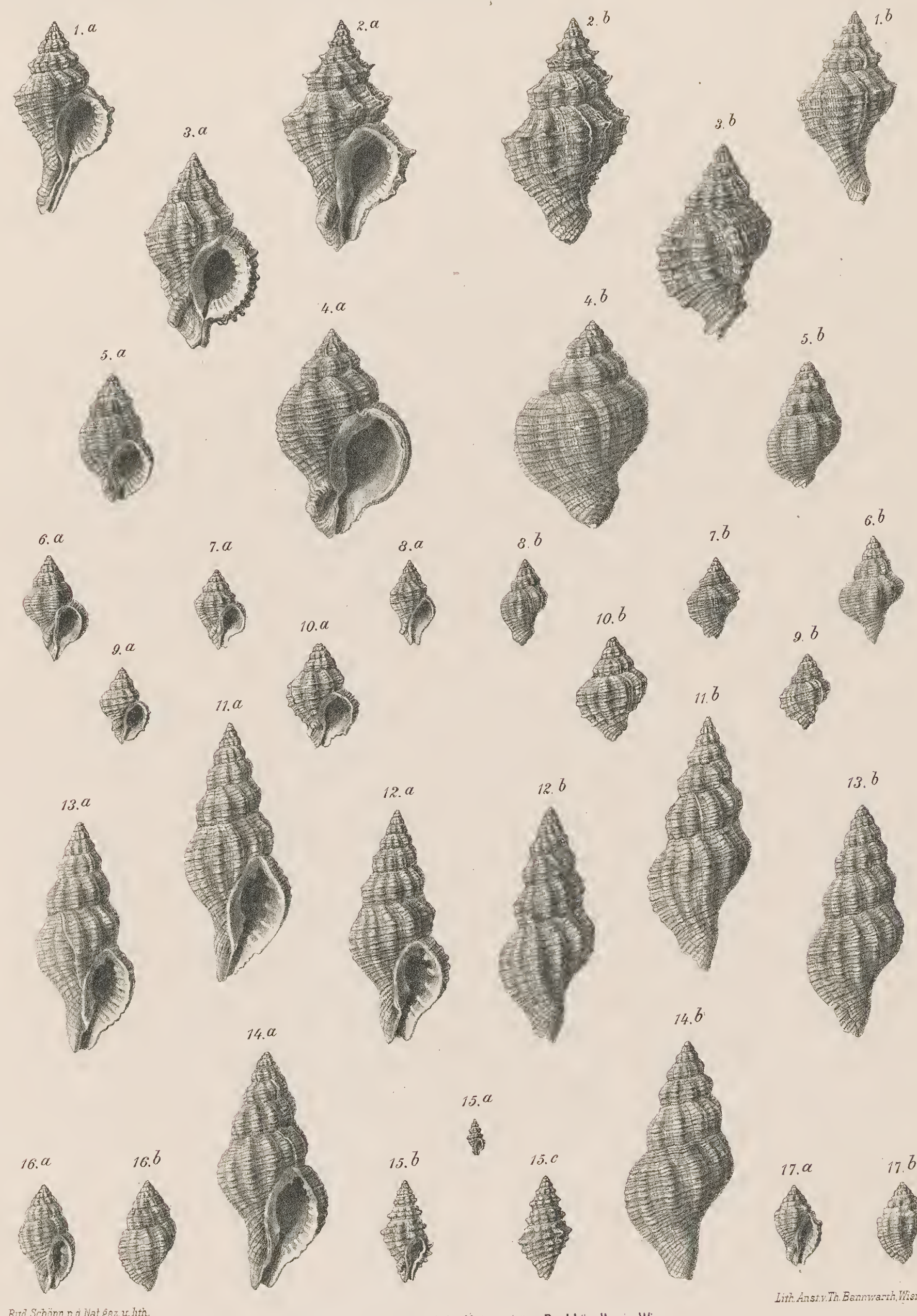

\footnotetext{
Verlag v. Alfred Hölder, k.k. Hof-u.Universitats-Buchhändler in Wien.
}
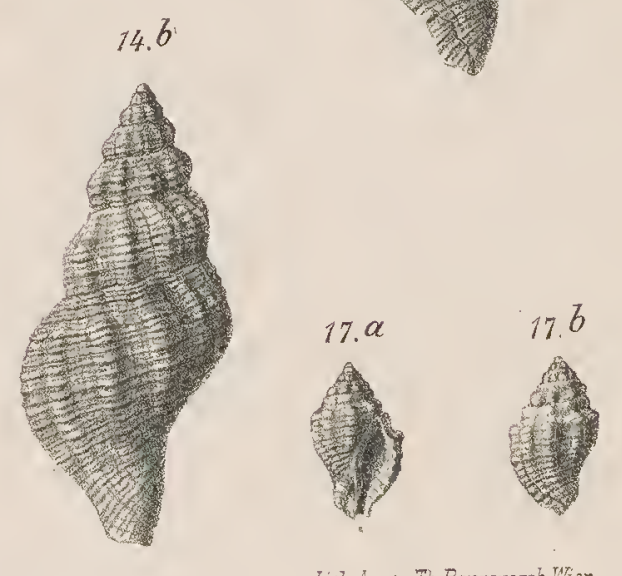


\section{TAFEL XXVIII.}

Pollia multicostata nov. form

Fig. 1, 2, 3 von Lapugy.

Pollia moravica nov. form.

Fig. 4 von Ruditz.

Pollia lapugyensis nov. form.

Fig. 5 von Kostej.

Fig. $6,7,8$ von lapugy.

Pollia d'Orbignyi Payn.

Fig. 9 von Lapugy.

Pollia ranellaeformis nov. form. Fig. 10 von Kostej.
Pollia Phitippii Michtti.

Fig. 11 von Gainfahrn.

Pollia subpusitla nov. form.

Fig. 12 von Forchtenau.

Fig. 13 von Niederleis (Fig. 12b, $c$ und Fig $13 b, c$ doppelt vergrössert).

Pyrula cornuta Ag.

Fig. 14 von Niederkreuzstetten.

Fig. 15 von. Gamlitz.

Fig. 16 von Vosslau.

Sämmtliche Originalexemplare werden im k. k. Hof-Mineralien Cabinete aufbewahrt.

Anmerkung. Dem Hefte Nr. 6, welches die Discussion der Gattungen Pollia und Pyrula enthalten wird, soll ein die Seitenzahlen des Textes anführender Abdruck dieser Tafelerklärung beigegeben werden. 
R.Hoernes u.M. Luinger. Gasteropoden der I.u.ll.miocänen Medilerranstufe.

Taf. XXVIIT.
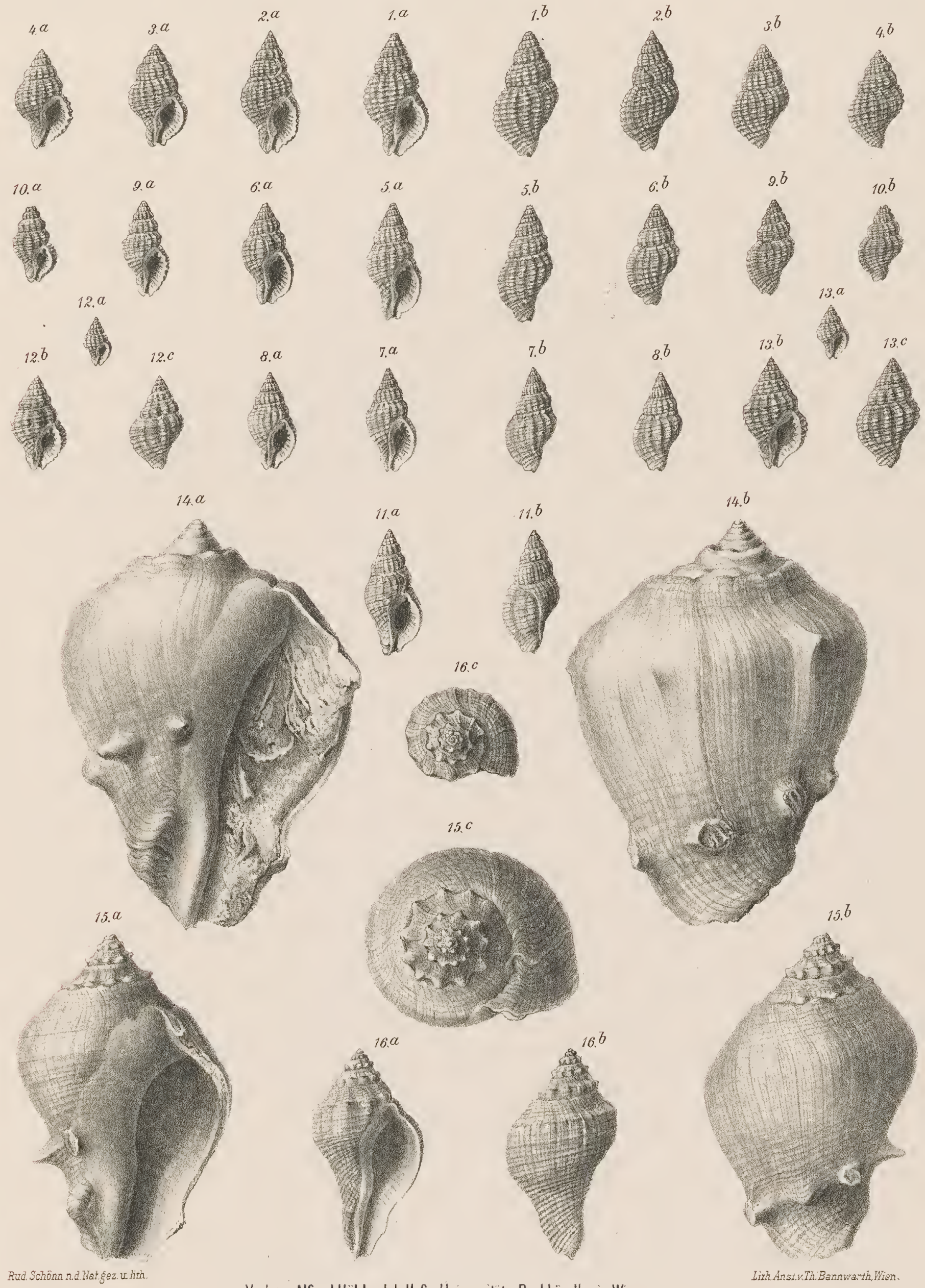

Verlag v. Alfred Hölder, k.k. Hof-u.Universitäts-Buchhändler in Wien. 


\section{DIE CEPHALOPODEN MEDITERRANEN ${ }_{\text {Von }}^{\text {dee }}$ TRIASPROVINZ.}

Dr. Edm. Mojsisovics von Mojsvár,

k. k. Oberbergrath und Chefgeologe der k, k. geologischen Reichsaustalt. Mit 94 lithographirten Tafeln in gr. $4 .-$ Preis $700 . \mathrm{W}$. f. $=140 \cdot \mathrm{M}$.

B耳IT民咅G耳

PALÄONTOLOGIE ÖSTERREICH-UNGARNS UND DES ORIENTS

herausgegeben von

Oberbergrath E. v. MOJSISOVICS und Prof. Dr. M. NEUMAYR.

Jährl. 4 Hefte, zusammen circa 30 Bogen Text und 30 lithogr. Tafeln. - Preis $20 \mathrm{fl} .=40 \mathrm{M}$.

\section{GRUNDLINIEN DER GEOLOGIE \\ BOSIJIHIJ - F工 F \\ Dr. Edm. v. Mojsisourcs, Dr. E. Tietze unlt Dr. A. Bittuer.}

Mit :) lithogr. Tafeln und der geologischen Vebersichtskarte von Bosnien-Hercegovina. (Kunstdruck in 21 Farben. Massstab $1: 576.100$.

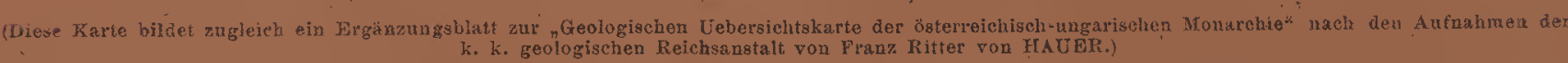

Hieraus apart:

Preis 12 fl. $=24 \mathrm{M}$.

\section{GEOLOGISCHE ÜBERSICH'TSKARTE VON BOSNIEN-HERCEGOVINA.}

Von

Dr. Edm. \%. Mojsisovics, Dr. E. Tietse und Dr. A. Bittner.

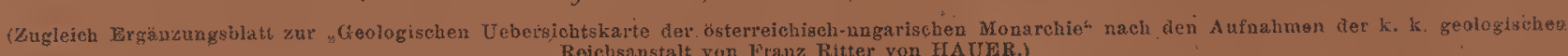

Cartonnirt Preis $6 \mathrm{ff} .=12 \mathrm{Mr}$; auf Leinwand gespannt, gebunden $7 \mathrm{fl} .50 \mathrm{kr} .=15 \mathrm{M}$.

\section{DIE GEOLOGIE}

und ihre Anwendung auf die Kenntniss der Bodenbeschaffenheit der österr.-ungar. Monarchie

$$
\begin{gathered}
\text { Franz Ritter von EI a u ex, } \\
\text { Director der k. keolog. Reichsanstalt. }
\end{gathered}
$$

Zweite, vermohrie, Auflage, mit 691 Original-Holzschnitten. -- 48 Druokbogen Lex. Octav in gediagenster Ausstaltung.

Preis complet broschirt $10 \mathrm{fl}=20 \mathrm{M}$., elegant in Leinwand geb. $11 \mathrm{fl} .=22 \mathrm{Mr}$, in Halbfranzhand $11 \mathrm{fl} .50 \mathrm{kr} .=23 \mathrm{M}$

Von demselben' Verfasser:

GEOLOGISCHE KARTE VON OESTERREICH-UNGARN MIT BOSNIEN-HERCEGOWINA UND MONTENEGRO.

Auf Grundlage der Aufnahmen der k. k. geologischen Reichsanstalt

$$
\begin{gathered}
\text { FRANZ RITTER VON HAUER, } \\
\text { Director her k. keolog. Reichsanstalt. } \\
\text { Viexte, verbessexte A ufla ge- }
\end{gathered}
$$

Preis. flacli oder cart. \&; fl. $=12, M_{\text {. }}$ anf Leinwand gespannt und in Ieeinwand geb. $7 \mathrm{H}$. $=14 \mathrm{M}$.

Verlag von Alfred Hölder; k. k. Hof- und Universitäts-Buchhändler in Wien, Rothenthurmstrasse 18 . 
Verlag von Alfred Hölder, k. k. Hof- lind Universitats-Buchhändle in Wien, Rothenthumstrasse $1 \mathrm{~B}$

\section{Die IDolomitriffe in Südtirol und Venetien.}

Beitrïge zur Bildungsgeschichte der Alper

Eamund Mojsisovics von Mojsvár.

Mit 30 Lichtdruckbildern, ilo Holzschnitten

Geolog. Vebersichtskarte des tirolisch-venetianischen Hochlandes zwischen Etsch u. Piave in 6 Blättern (dreè Blätter in der Bildgrösse $38 / 68 \mathrm{Ctm}$. und drei in der Bildgrósse $38 / 54$ Ctm.) Kunstdruck in 42 Farben.

Preis fl. $19=$ M. 38 , eleg. geb. $22 \mathrm{fl} 50 \mathrm{kr}$. $=$ M. 45.

\section{GEOLOGISCHE UBERSICHT VON MONTENEGRO.}

Dr. E. TIETZE.

Mit einer geologischen Karte von Montenegro in Farbendruck.

Preis 2 .fl. $40 \mathrm{kr} .=4$ M. $80 \mathrm{Pf}$.

Von demselben Veriasser

DIE GEOGNOSTISCHEN VERHÄLTNISSE

der

\section{GEGEND VON LEMBERG.}

Mit einer geologischen Karte der Umgebung von Lemberg.

Preis 2 tl. $80 \mathrm{kr} .=5$ M. 60 Pf. Die Karte apart $2 \mathrm{fl} .=4 \mathrm{Y}$.

Der Boden der Fauptstädte Europas.

$$
\begin{gathered}
\text { Geologisobe Studie } \\
\text { FiLLIX KARRER. }
\end{gathered}
$$

Mit 22 in den Text eingedruckten geologischen Profilen und einem Titelbilde. Preis $1 \mathrm{H}=2 \mathrm{X}$.

LEHRBUCH DER MINERALOGIE

$$
\text { Dr. GUSTAV ISCHERMLK, }
$$

k. k. Hofrath, o. o. Profeessor der Mineralogie und Petrographie an der Wiener Universitat.

Zweite, verbesserte Auflage. - Mit 756 Abbildungen und zwei Farbentafeln.

Preis broschirt $9 \mathrm{fl} .60 \mathrm{kr}$. $=18$ M., in Falbfranz gebunden $10 \mathrm{fl}$. $50 \mathrm{kr}$. $=19 \mathrm{M}$. $40 \mathrm{Pf}$.

\section{Arbeiten aus dem Zoologischen Institute}

der Universität Wien und der Zoologischen Station in Triest.

Heransgegeben von

Dr. C. CIa us

Professor der Univerisitat und Vorstand des zoolog,-vergl.-anatom. Institutes in Wien,

Director Rer zoolog. Station in Triest.

I. Band, 3 Hefte mit 33 Tafeln. Preis $22 \mathrm{fl} .=44 \mathrm{M}$.

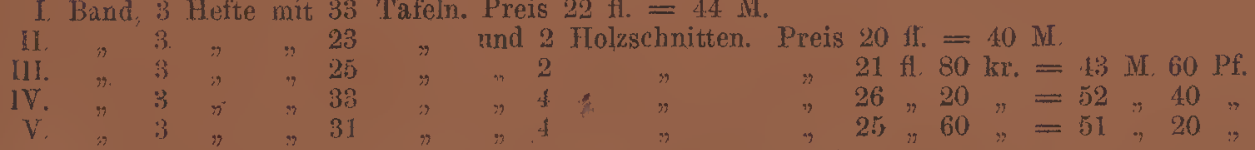

Verlag von Alfred Hölder, k. k. Hof- und Universitäts-Buchhändler in Wien, Rothen thurnstrasse 19 